MARCIA MOREIRA MARTINS PEREIRA

\title{
A MATURIDADE EM GERENCIAMENTO DE PROJETOS E SUA CONTRIBUIÇÃO PARA A SELECÃO DE PROJETOS DE ACORDO COM A ESTRATÉGIA ORGANIZACIONAL
}

\author{
Dissertação apresentada à Escola \\ Politécnica da Universidade de São Paulo \\ para obtenção do título de Mestre em \\ Engenharia \\ Área de Concentração: \\ Engenharia Naval e Oceânica \\ Orientador: \\ Prof. Dr. Marcelo Ramos Martins
}

São Paulo 
Aos meus pais, exemplos de persistência e superação. 


\section{AGRADECIMENTOS}

A Deus, princípio e fim de todas as coisas, por me permitir levantar e percorrer este longo caminho.

Aos meus amores: meus pais, Guilhermino e Maria de Lurdes, eternos incentivadores; minhas irmãs, Luciana e Fabiana, amigas inseparáveis; meu noivo Marcelo, antigo e futuro companheiro. Obrigada pelo apoio, pela torcida e pela paciência durante esta jornada.

Ao professor Marcelo, pela disponibilidade, pela confiança e pela dedicação ao longo do processo de orientação.

Aos professores Nilton e Roque, pelas considerações feitas durante o Exame de Qualificação.

Aos professores das disciplinas cursadas durante o Mestrado, em especial aos envolvidos no programa oferecido pelo Departamento de Engenharia Naval e Oceânica, pelas enriquecedoras experiências trocadas.

A todos os colegas que fizeram parte da minha vida acadêmica, universitária e escolar, pela contribuição para a formação do meu caráter. De modo especial, agradeço aos colegas Vergilio e Andréia pelos trabalhos desenvolvidos em coautoria.

Aos profissionais da área de gerenciamento de projetos, pela contribuição para o meu crescimento profissional. Também agradeço pela participação na pesquisa de campo.

A toda a minha família, pelo carinho e pela preocupação de sempre.

Aos meus amigos e afilhados, pelas orações e pela compreensão das minhas ausências. 
Mais vale o fim de uma coisa que o seu começo. Mais vale um espírito paciente que um espírito pretensioso.

(Ecl 7, 8) 


\section{RESUMO}

A crescente busca pela utilização do gerenciamento de projetos enquanto diferencial estratégico no mercado atual e, mais recentemente, a procura pelo gerenciamento de projetos formal e estruturado, como parte da estratégia competitiva da organização, associadas à popularização do termo maturidade, justificam o conceito de maturidade em gerenciamento de projetos e a existência dos modelos de maturidade em gerenciamento de projetos. Existem atualmente diversos modelos de maturidade no mercado. A maioria deles está alinhada a um guia de conhecimento, que é utilizado como medida comparativa na avaliação do nível de maturidade da organização, e classifica o estágio de maturidade da organização em cinco níveis. Difere dos demais o modelo Organizational Project Management Maturity Model (OPM3®), proposto pelo Project Management Institute (2003). Ao invés de ser concebido como um modelo de níveis de maturidade, tem como enfoque três elementos (conhecimento, avaliação e melhoria), através dos quais o modelo se auto-atribui a capacidade de vincular projetos à estratégia organizacional. O presente estudo procurou avaliar a contribuição da maturidade em gerenciamento de projetos para a seleção de projetos de acordo com a estratégia organizacional. Quanto ao método de pesquisa, foi utilizado o survey, tendo como fonte de evidência um questionário auto-administrado web-based. A população de interesse do pesquisador foi composta pelas organizações estabelecidas no Brasil que se utilizam do gerenciamento de projetos; a amostra da pesquisa foi constituída de profissionais da área de gerenciamento de projetos da rede de contatos do pesquisador. As 78 respostas válidas obtidas com o survey foram submetidas às análises descritiva $\mathrm{e}$ inferencial. Em relação aos resultados obtidos, foi possível comprovar que a utilização do modelo OPM3® para avaliação do nível de maturidade da organização influencia a prática da seleção de projetos relacionados à estratégia organizacional. Não foi possível provar que a prática da seleção de projetos relacionados à estratégia organizacional seja influenciada pela existência de processo de formulação da estratégia ou pelo estágio de maturidade predominante na organização para cada domínio (projeto, programa e portfólio). Em se tratando das limitações do estudo, citam-se a pequena quantidade de empresas brasileiras onde 
o questionário de Auto-Avaliação proposto pelo OPM $3 \circledR$ foi utilizado e a obtenção da visão da organização através da percepção do respondente (em alguns casos as questões exigiam uma resposta subjetiva). Por sua vez, a principal contribuição obtida com a pesquisa refere-se à identificação de elementos facilitadores da seleção de projetos relacionados à estratégia organizacional. Como contribuição secundária, pode ser citada a ampliação da quantidade de pesquisas acadêmicas realizadas com apoio de tecnologia para o recebimento dos dados, neste caso, email e hospedagem na Internet. Outras contribuições referem-se à proposição do modelo teórico para a pesquisa e à realização da pesquisa de campo em si, esta última permitindo a obtenção de dados sobre empresas nacionais no que tange ao gerenciamento de projetos e à utilização do modelo OPM3® para avaliação do nível de maturidade.

Palavras-chave: Maturidade em gerenciamento de projetos. Modelo de Maturidade Organizacional em Gerenciamento de Projetos (OPM3®). Estratégia organizacional. 


\section{ABSTRACT}

The increasing use of project management as strategic differential in our market and, most recently, the search of formal and structured project management, as part of organizational competitive strategy, in association with the maturity concept popularization, justify the concept of project management maturity and the existence of project management maturity models. There are many maturity models at the market. Most of them are aligned with a project management body of knowledge, used as reference to the organizational maturity level evaluation, and classify the organizational maturity stage into five linear levels. The Organizational Project Management Maturity Model (OPM3®), developed under the stewardship of the Project Management Institute (2003), is different. Instead of being designed as a system of levels of maturity, it focuses on three basic elements (knowledge, assessment and improvement), through which the model assigns itself the capability of join organizational strategy and projects. This study aimed to evaluate the contribution of project management maturity into bridging strategy and individual projects. The research method used was the survey, and the measurement instrument was a web-based self-assessment questionnaire. The population frame was composed by Brazilian organizations that use project management; the research sample was composed by researcher networking professionals used to work at project management area. The 78 valid responses obtained through survey were analyzed by descriptive and statistical inference. Regarding the results, it was possible to prove that $\mathrm{OPM} \Omega\left({ }^{\circledR}\right.$ model application in order to assess organizational maturity level acts on the project selection according to organizational strategy. It was not possible to prove that project selection according to organizational strategy depends on the formulation process of the strategy or the organizational maturity stage for each domain (project, program and portfolio). Among the study limitations, there was the small quantity of Brazilian companies that had used Self-Assessment tool provided in $O P M 3 \AA$ and the collection of organizational view through the respondent perceptions (in some cases the questions requested a subjective answer). On the other hand, the main research contribution was the identification of helpful agents of project selection according to organizational strategy. As a 
secondary contribution, the growing in academical research using technological support to data collection, in this case, e-mail and web-based, might be mentioned. Other contributions refer to the theoretical model proposed to the study and the field research itself, this one allowing data collection about project management and the use of OPM $3 \circledR$ model to maturity level assessment in Brazilian companies.

Keywords: Project management maturity. Project Management Maturity Model (OPM3®). Organizational strategy. 


\section{LISTA DE ILUSTRAÇÕES}

Figura 1 - Quantidade de profissionais associados ao PMI $\quad$ e certificados $\mathrm{PMP} \circledast$ 17

Figura 2 - $\quad$ Níveis de atuação e tipos de planejamento .....................................41

Figura 3 - Modelo teórico da pesquisa...........................................................

Figura 4 - Questões e hipóteses da pesquisa inseridas no modelo teórico da

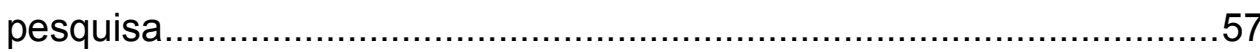

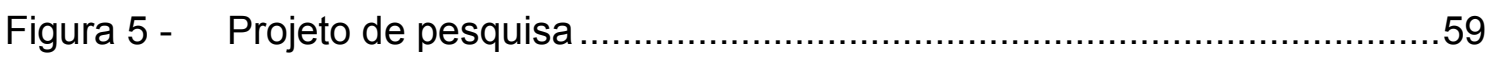

Figura 6 - Índice de questões principais respondidas .....................................66

Figura 7 - Caracterização do respondente quanto ao cargo ocupado na organização .................................................................................... 67

Figura 8 - Caracterização do respondente quanto ao grau de relação de suas atividades profissionais com a área de gerenciamento de projetos ......68

Figura 9 - Caracterização da organização quanto ao tipo ...................................68

Figura 10 - Caracterização da organização quanto à origem do capital .................69

Figura 11 - Caracterização da organização quanto ao setor de atuação ................69

Figura 12 - Caracterização da organização quanto ao número de funcionários......70

Figura 13 - Caracterização da organização quanto à estrutura organizacional predominante .70

Figura 14 - Caracterização da organização quanto ao grau de importância dado às técnicas modernas de gerenciamento de projetos. 71

Figura 15 - Caracterização da organização quanto ao desenvolvimento e utilização de metodologia de gerenciamento de projetos 71

Figura 16 - Caracterização da organização quanto à aderência da metodologia de gerenciamento de projetos ao PMBoK .72

Figura 17 - Caracterização da organização quanto à utilização do questionário de Auto-Avaliação proposto pelo OPM3® para verificação do nível de maturidade. .72

Figura 18 - Caracterização da organização quanto ao tempo decorrido da última avaliação do nível de maturidade da organização pelo OPM3 ${ }^{\circledR}$ .73 
Figura 19 - Caracterização da organização quanto à elaboração do Plano de Melhorias como parte da avaliação da empresa pelo modelo de

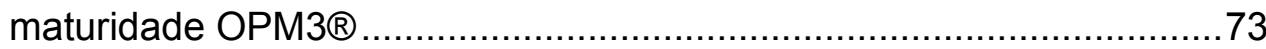

Figura 20 - Caracterização da organização quanto à existência de ação relacionada à identificação e seleção de projetos através do seu relacionamento com a estratégia empresarial ............................................................74

Figura 21 - Caracterização da organização quanto ao aumento na quantidade de projetos selecionados de acordo com a estratégia após a aplicação do OPM3 3 .75

Figura 22 - Freqüência observada para Critério de seleção de projetos x Estágio de maturidade predominante na organização para o domínio projeto .......93

Figura 23 - Freqüência observada para Critério de seleção de projetos x Estágio de maturidade predominante na organização para o domínio programa ...94

Figura 24 - Freqüência observada para Critério de seleção de projetos x Estágio de maturidade predominante na organização para o domínio portfólio......94

Figura 25 - Coeficiente de critério de seleção por estágio de maturidade e domínio. 


\section{LISTA DE TABELAS}

Tabela 1 - Decisões acerca da aceitação ou rejeição da hipótese nula $(H)$...........52

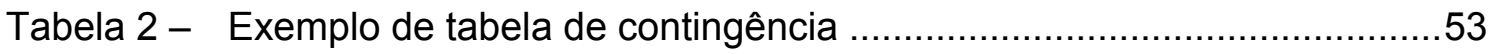

Tabela 3 - Variáveis da pesquisa e associação com as Questões de Pesquisa ....58

Tabela 4 - Estrutura do questionário de pesquisa .................................................64

Tabela 5 - Tabela de contingência para Critério de seleção de projetos x Estágio de maturidade predominante na organização para o domínio projeto ..78

Tabela 6 - Teste qui-quadrado para o Critério de seleção de projetos x Estágio de maturidade predominante na organização para o domínio projeto ........78

Tabela 7 - Tabela de contingência para Critério de seleção de projetos $x$ Estágio de maturidade predominante na organização para o domínio projeto (agrupamento A) .79

Tabela 8 - Teste qui-quadrado para o Critério de seleção de projetos x Estágio de maturidade predominante na organização para o domínio projeto (agrupamento A).

Tabela 9 - Tabela de contingência para Critério de seleção de projetos $x$ Estágio de maturidade predominante na organização para o domínio programa 80

Tabela 10 - Teste qui-quadrado para o Critério de seleção de projetos x Estágio de maturidade predominante na organização para o domínio programa ...80

Tabela 11 - Tabela de contingência para Critério de seleção de projetos x Estágio de maturidade predominante na organização para o domínio programa (agrupamento A).

Tabela 12 - Teste qui-quadrado para o Critério de seleção de projetos x Estágio de maturidade predominante na organização para o domínio programa (agrupamento A)

Tabela 13 - Tabela de contingência para Critério de seleção de projetos $\times$ Estágio de maturidade predominante na organização para o domínio portfólio. 82

Tabela 14 - Teste qui-quadrado para o Critério de seleção de projetos x Estágio de maturidade predominante na organização para o domínio portfólio.......82 
Tabela 15 - Tabela de contingência para Critério de seleção de projetos x Estágio de maturidade predominante na organização para o domínio portfólio (agrupamento A)

Tabela 16 - Teste qui-quadrado para o Critério de seleção de projetos x Estágio de maturidade predominante na organização para o domínio portfólio (agrupamento A)

Tabela 17 - Tabela de contingência para Critério de seleção de projetos x Avaliação da maturidade pelo OPM $3 \AA$ .85

Tabela 18 - Teste qui-quadrado para o Critério de seleção de projetos x Avaliação da maturidade pelo OPM $3 \circledR$ .85

Tabela 19 - Tabela de contingência para Critério de seleção de projetos $\times$ Avaliação da maturidade pelo OPM $3 \circledast$ (agrupamento A) .86

Tabela 20 - Teste qui-quadrado para o Critério de seleção de projetos x Avaliação da maturidade pelo OPM $3 \circledR$ (agrupamento $A$ ).

Tabela 21 - Tabela de contingência para Critério de seleção de projetos x Existência de processo sistemático de formulação da estratégia empresarial ........88

Tabela 22 - Teste qui-quadrado para Critério de seleção de projetos x Existência de processo sistemático de formulação da estratégia empresarial .88

Tabela 23 - Tabela de contingência para Critério de seleção de projetos x Existência de decomposição da estratégia empresarial para os níveis tático e operacional .90

Tabela 24 - Teste qui-quadrado para Critério de seleção de projetos x Existência de decomposição da estratégia empresarial para os níveis tático e operacional .90 


\section{SUMÁRIO}

1 INTRODUÇÃO

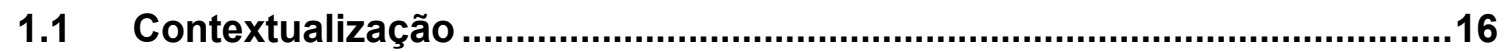

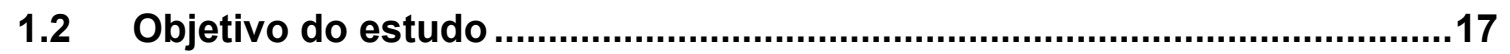

1.2.1 Questões e hipóteses da pesquisa .........................................................18

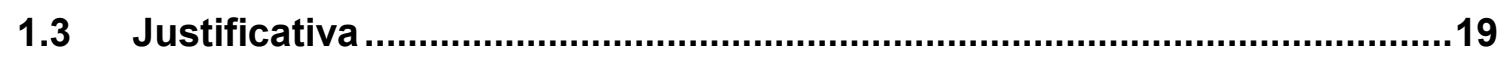

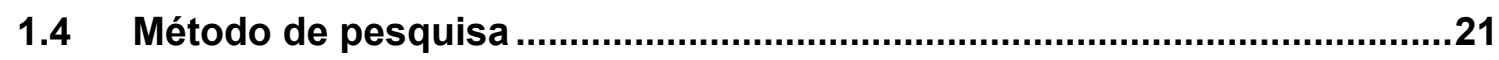

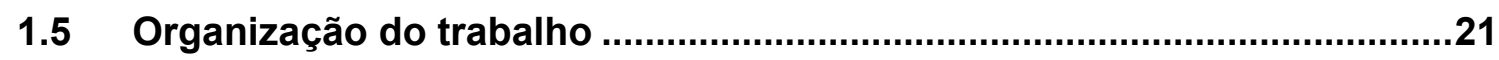

2 REVISÃO DA LITERATURA

2.1 Implementação da metodologia de gerenciamento de projetos .................23

2.1.1 Histórico do Escritório de Gerenciamento de Projetos .................................24

2.1.2 Implementação do Escritório de Gerenciamento de Projetos...........................25

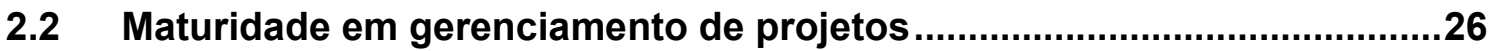

2.2.1 Conceito de maturidade em gerenciamento de projetos ................................26

2.2.2 Modelos de maturidade em gerenciamento de projetos.............................. 28

2.30 modelo de maturidade em gerenciamento de projetos OPM3 $₫$..............29

2.3.1 Histórico do Modelo OPM3® ...................................................................... 30

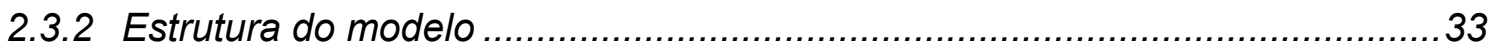

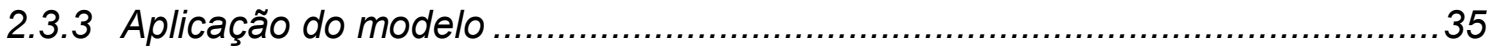

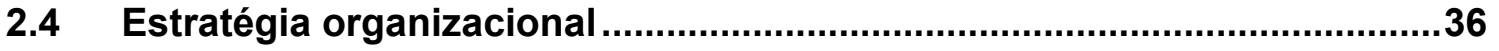

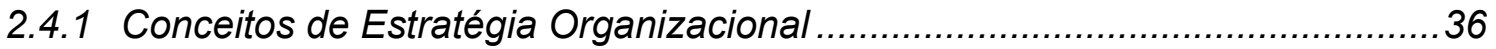

2.4.2 Formulação e implementação da estratégia organizacional............................38

2.4.3 Planejamento tático e operacional ............................................................. 40

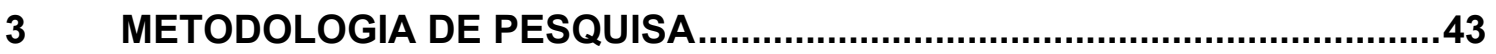

3.1 Revisão da literatura sobre Metodologia de Pesquisa...............................43

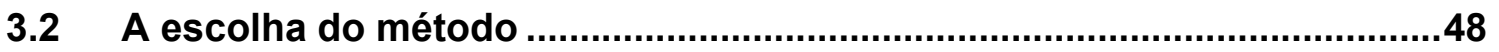

3.3 Breve resumo sobre Análise de dados ...................................................50

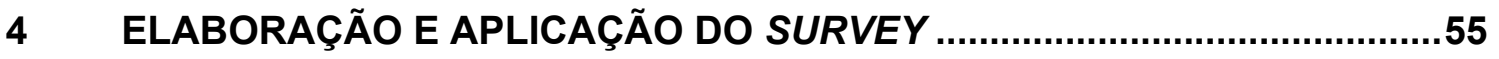

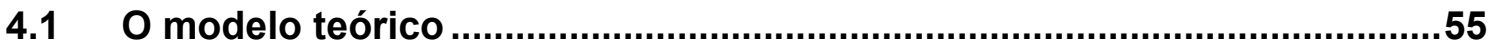

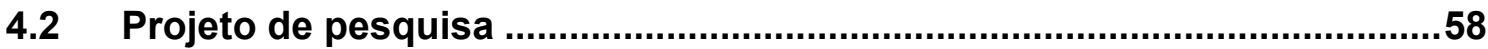

4.2.1 Elaboração do questionário de pesquisa ......................................................60 
4.2.2 Teste Piloto

4.2.3 Revisão do questionário de pesquisa ...................................................... 63

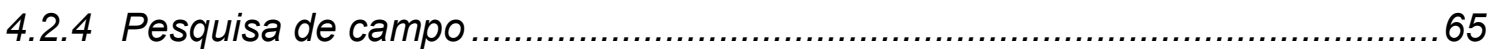

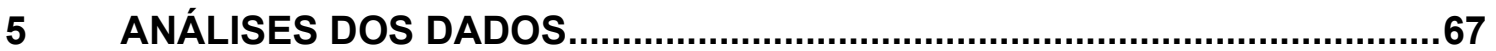

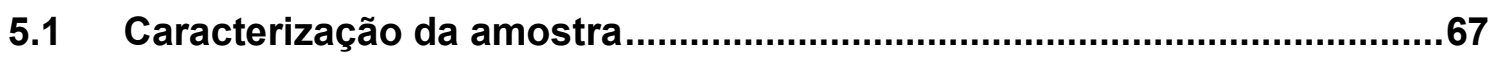

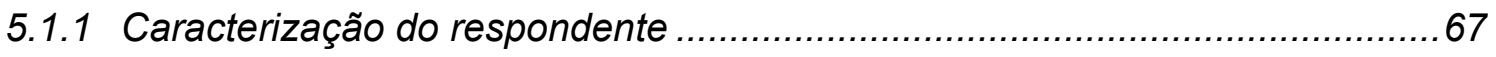

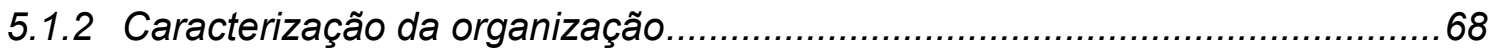

5.1.3 Caracterização da organização quanto ao gerenciamento de projetos ..........70

5.1.4 Caracterização da organização quanto à utilização do modelo OPM ${ }^{\circledR}$ para

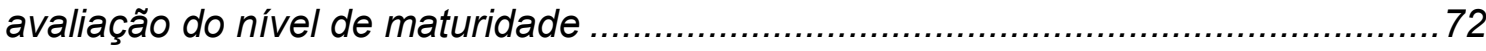

5.2 Testes estatísticos das Hipóteses.........................................................76

5.2.1 Relação entre o estágio de maturidade predominante na organização para os domínios projeto, programa e portfólio e a prática da seleção de projetos de acordo

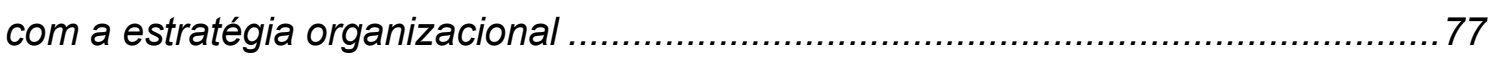

5.2.2 Relação entre utilização do modelo OPM3® para avaliação do nível de maturidade da organização e a prática da seleção de projetos de acordo com a estratégia organizacional .....

5.2.3 Relação entre a existência de processo de formulação da estratégia e a prática da seleção de projetos de acordo com a estratégia organizacional.

5.2.4 Relação entre a existência de processo de decomposição da estratégia nos níveis tático e operacional e a prática da seleção de projetos de acordo com a estratégia organizacional 89

6 INTERPRETAÇÃO DOS RESULTADOS .92

6.1 O nível de maturidade e a prática da seleção de projetos de acordo com a estratégia organizacional

6.2 O processo de formulação da estratégia e a prática da seleção de projetos de acordo com a estratégia organizacional ............................................96

7 CONCLUSÕES E RECOMENDAÇÕES ...................................................97

7.1 Contribuições e limitações do estudo ...................................................97

7.2 Recomendações para pesquisas futuras ............................................99

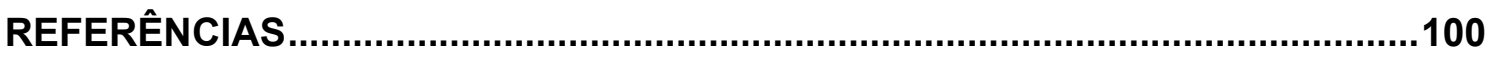

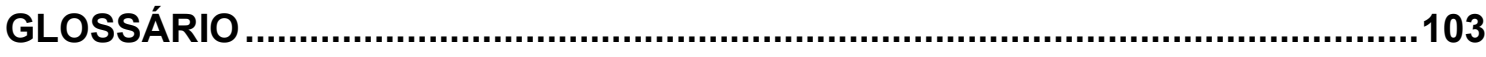

APÊNDICE A - TESTE DE INDEPENDÊNCIA QUI-QUADRADO .........................104

APÊNDICE B - INSTRUMENTO DE PESQUISA PARA O TESTE PILOTO .........107 
APÊNDICE C - E-MAIL PARA AVALIADORES DO TESTE PILOTO ...................116

APÊNDICE D - INSTRUMENTO DE PESQUISA ...............................................117

APÊNDICE E - E-MAIL PARA RESPONDENTES.............................................126 


\section{INTRODUÇÃO}

Neste capítulo introdutório é apresentado o contexto do trabalho de pesquisa, bem como é delimitado o problema da pesquisa. Também neste capítulo são apresentados os fatores que justificaram a escolha do tema pelo pesquisador.

\subsection{Contextualização}

O acirramento da concorrência e a conseqüente necessidade do estabelecimento de diferenciais competitivos percebidos nas últimas décadas podem ser citados dentre os principais fatores motivadores da utilização da disciplina de gerenciamento de projetos nas organizações.

Como evidência desta utilização, observa-se o crescimento de instituições que visam disseminar a disciplina de gerenciamento de projetos, dentre elas o PMIß - Project Management Institute, associação americana não-lucrativa de profissionais de gerenciamento de projetos. Segundo Schlichter, Friedrich, Haeck (2003), em 1998 o $P M I \circledast$ tinha menos de 50.000 associados; em abril de 2007 eram 238.565 associados em 164 países (PROJECT MANAGEMENT INSTITUTE, 2007). No período compreendido entre abril de 2004 e abril de 2007, o número de associados apresentou taxa de crescimento de $81 \%$. Também é significativo o aumento do número de profissionais da área que buscam o reconhecimento de seu grau de proficiência em gerenciamento de projetos através do programa de certificação do PMI® - Project Management Professional (PMP®). Em 1998, eram menos de 10.000 profissionais com a certificação PMP® (SCHLICHTER; FRIEDRICH; HAECK, 2003); em abril de 2007 eram 228.277 profissionais (PROJECT MANAGEMENT INSTITUTE, 2007). Em relação ao mesmo mês de 2005, os dados de 2007 representam crescimento de $106 \%$.

A Figura 1 apresenta a quantidade de profissionais associados ao PMI® e certificados PMP® entre os meses de abril de 2005 e abril de 2007. 


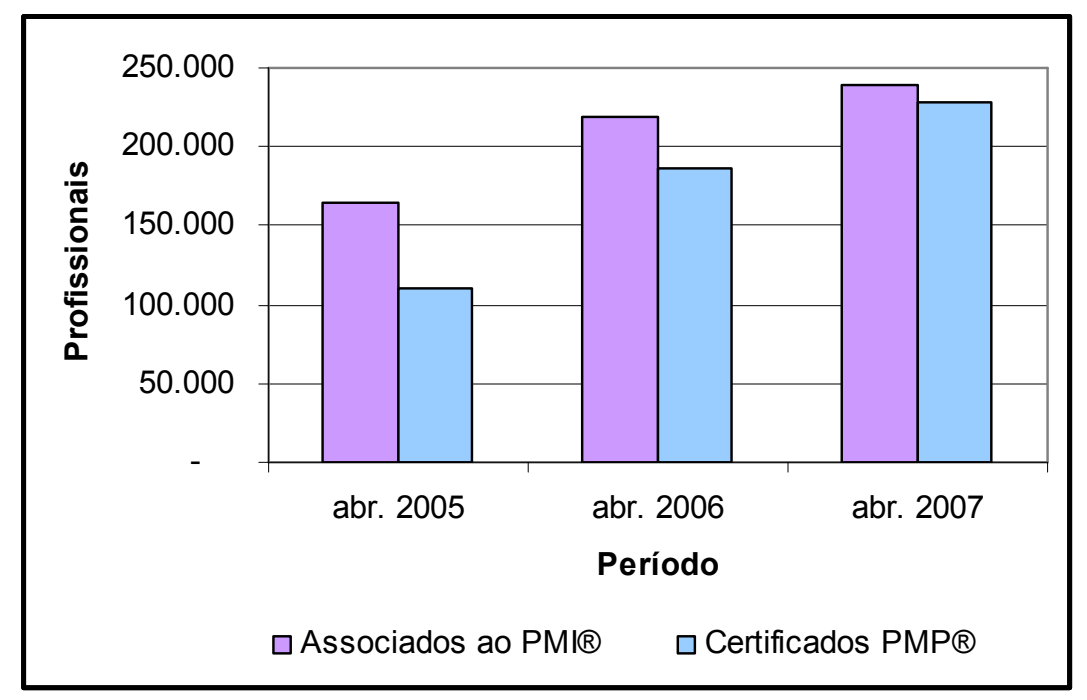

Figura 1 - Quantidade de profissionais associados ao PMI $\circledast$ e certificados $\mathrm{PMP} \circledast$ Fonte: adaptado de Project Management Institute (2007)

Visando mensurar o quão sistemática e institucionalizada é a prática de gerenciamento de projetos na organização, surgem os modelos de maturidade organizacional em gerenciamento de projetos. Dentre os modelos atualmente existentes, encontra-se o OPM3® - Organizational Project Management Maturity Model, lançado oficialmente pelo PMI® em 2003.

Dentre os benefícios que o modelo de maturidade OPM3® se auto-atribui, destacase a supressão da lacuna existente entre a estratégia organizacional e os projetos individuais. De modo resumido, a estratégia, no campo organizacional, está relacionada ao plano que integra as ações utilizadas pela organização para alcançar os objetivos ou resultados almejados. Assim, o modelo OPM3® visa prover meios para avançar rumo aos objetivos e resultados da organização através da aplicação dos princípios de gerenciamento de projetos, programas e portfólio.

\subsection{Objetivo do estudo}

O objetivo principal do presente estudo é avaliar se a maturidade em gerenciamento de projetos contribui para a seleção de projetos de acordo com a estratégia organizacional. Como objetivo secundário, o estudo almeja avaliar também se a 
existência de processo de formulação da estratégia contribui para esta mesma prática.

Para tanto, pretende-se comparar o critério de seleção de projetos em organizações com características diversas quanto aos estágios de maturidade em gerenciamento de projetos, programas e portfólio, quanto à utilização do modelo OPM $3 \circledR$ para avaliação do nível de maturidade e quanto aos processos de formulação e decomposição da estratégia organizacional.

\subsubsection{Questões e hipóteses da pesquisa}

Visando alcançar os objetivos da pesquisa, elaboraram-se as questões de pesquisa (QP) descritas abaixo. As hipóteses $(H)$ assumidas para o tratamento de cada questão e cujas validades serão verificadas com o estudo também estão apresentadas a seguir:

QP1: O nível de maturidade da organização contribui para a prática da seleção de projetos relacionados à estratégia organizacional?

H1.a: O critério de seleção de projetos é influenciado pelo estágio de maturidade predominante na organização para cada domínio definido pelo OPM3® (projeto, programa e portfólio).

H1.b: O critério de seleção de projetos é influenciado pela utilização do questionário de Auto-Avaliação proposto pelo OPM3® para verificação do nível de maturidade.

QP2: A existência, na organização, de processo de formulação da estratégia contribui para a prática da seleção de projetos relacionados à estratégia organizacional?

H2.a: O critério de seleção de projetos é influenciado pela existência de processo sistemático de formulação da estratégia empresarial.

H2.b: O critério de seleção de projetos é influenciado pela decomposição da estratégia empresarial nos níveis tático e operacional.

Ao responder às questões acima, pretende-se obter como contribuição a identificação de elementos facilitadores da seleção de projetos relacionados à estratégia organizacional. 


\subsection{Justificativa}

Segundo Kerzner (2001), projetos são críticos para o sucesso de qualquer organização, uma vez que correspondem às atividades que resultam em produtos, serviços e processos novos ou modificados. Além disso, atualmente acredita-se que as atividades rotineiras não mais adicionam valor aos produtos e serviços da organização, mas sim aquelas caracterizadas pela inovação e inteligência, ou seja, atividades de projetos (FLEURY; FLEURY, 2000 apud RABECHINI JR., 2003). Tais fatores justificam a crescente busca pela utilização do gerenciamento de projetos enquanto diferencial estratégico no mercado atual, caracterizado pela alta competitividade. Kerzner (2001) cita os centros de excelência em gestão de projetos, conhecidos como Escritórios de Gerenciamento de Projetos (ou Project Management Offices - PMOs), os programas de treinamento e os programas de mudança organizacional para melhoria das práticas de gerenciamento de projetos como indícios do aumento do foco em gestão de projetos.

O que se observa nos últimos anos, porém, é a procura pela visão holística do gerenciamento de projetos, ou seja, busca-se o gerenciamento de projetos formal e estruturado, como parte da estratégia competitiva da organização (DINSMORE, 1999; HILLSON, 2003; JUGDEV; THOMAS, 2002; KERZNER, 2001; PITAGORSKY, 2001). Tal fato deve-se tanto à percepção da importância do enfoque orientado a projetos e dos benefícios do gerenciamento de projetos (HILLSON, 2003; KERZNER, 2001) quanto à existência de projetos tidos como falhos (STANDISH GROUP, 2001 apud JUGDEV; THOMAS, 2002).

Associado a este fenômeno e à popularização do termo maturidade com a divulgação do Capability Maturity Model $^{1}$ para software, surgiram o conceito de maturidade em gerenciamento de projetos e os modelos de maturidade.

A maturidade em gerenciamento de projetos é definida por Kerzner (2002) como sendo o desenvolvimento de sistemas e processos repetitivos visando aumentar a probabilidade de obtenção de sucesso nos projetos. Por sua vez, os modelos de

1 O modelo Capability Maturity Model (CMM) para software foi desenvolvido pelo Instituto de Engenharia de Software (Software Engineering Institute - SEI) da Universidade Carnegie Mellon, entre 1986 e 1993. 
maturidade em gerenciamento de projetos são caracterizados como meios tangíveis de avaliar o estágio de desenvolvimento em gerenciamento de projetos da organização, considerando o diagnóstico de pontos fortes e de carências da organização e a identificação de oportunidades de melhoria através de análises comparativas com outras organizações (benchmarking) (HILLSON, 2003; JUGDEV; THOMAS, 2002).

Existem atualmente diversos modelos de maturidade no mercado. A maioria deles está alinhada a um guia de conhecimento, que é utilizado como medida comparativa na avaliação do nível de maturidade da organização, e classifica o estágio de maturidade da organização em cinco níveis. A nomenclatura dos níveis difere de acordo com o modelo, porém os níveis apresentam significado comum à medida que refletem a variação entre o estabelecimento de conhecimento comum a respeito do gerenciamento de projetos, no nível inferior, até a instituição de melhoria contínua nos processos de gerenciamento de projetos, no nível superior (HILLSON, 2003; JUGDEV; THOMAS, 2002; PITAGORSKY, 2001).

Segundo o Project Management Institute (2003), este é o diferencial do modelo Organizational Project Management Maturity Model (OPM3®): o modelo não foi concebido para ser um modelo de níveis de maturidade. Ao invés disso, tem como enfoque três elementos: conhecimento, avaliação e melhoria. Através deles, o modelo se auto-atribui a capacidade de vincular a estratégia organizacional aos projetos, provendo o conhecimento das melhores práticas (best practices), permitindo a avaliação das práticas atualmente implementadas na organização e apontando as potenciais ações de melhoria a serem implementadas pela organização (PROJECT MANAGEMENT INSTITUTE, 2003; ROSE, 2004).

A presente pesquisa originou-se da inquietação do pesquisador diante desta autoatribuição do modelo $\mathrm{OPM} 3 \circledR$. Assim, a condução deste projeto de pesquisa teve como justificativa principal o anseio de se verificar, na prática, a relação entre a maturidade em gerenciamento de projetos e a capacidade de vinculação da estratégia organizacional aos projetos.

Neste capítulo introdutório foram abordados o contexto do trabalho, a delimitação do problema da pesquisa e a justificativa do pesquisador para a escolha do seu tema, respectivamente nos itens Contextualização, Objetivo do Estudo e Justificativa. Ao longo deste capítulo, foram inseridas de maneira sucinta algumas definições relacionadas ao tema do trabalho. Estas definições serão retomadas com maior 
profundidade no capítulo seguinte, onde serão analisadas em função da literatura existente sobre as mesmas.

\subsection{Método de pesquisa}

Para alcançar o objetivo da pesquisa, a abordagem utilizada será a quantitativa, através do método survey.

A população de interesse do pesquisador são as organizações estabelecidas no Brasil que se utilizam do gerenciamento de projetos. A amostra da pesquisa corresponde a uma parcela desta população e foi constituída através de seus sujeitos, profissionais da área de gerenciamento de projetos da rede de contatos do pesquisador.

Quanto à fonte de evidência, a pesquisa utiliza o questionário auto-administrado web-based e os respondentes foram convidados a participar por e-mail. Os dados coletados foram submetidos às análises descritiva e inferencial.

Cabe ressaltar que, visando ampliar o tamanho da amostra a ser atingida, o instrumento de pesquisa atendeu aos objetivos de uma pesquisa mais ampla. Por este motivo, algumas questões elaboradas não possuem relação direta com o objeto deste trabalho, não sendo aqui apresentadas.

\subsection{Organização do trabalho}

O presente trabalho está organizado conforme os capítulos abaixo e seus respectivos conteúdos:

Capítulo 1: Introdução

Apresentação do contexto do trabalho, do problema da pesquisa e da justificativa para a condução da mesma.

Capítulo 2: Revisão da Literatura

Discussão de aspectos da literatura sobre o tema deste trabalho e os principais assuntos relacionados ao mesmo. O capítulo encontra-se dividido em quatro itens, 
onde cada assunto é tratado: a implementação da metodologia de gerenciamento de projetos, o conceito de maturidade em gerenciamento de projetos, o modelo de maturidade em gerenciamento de projetos OPM3 $®$ e o conceito de estratégia organizacional.

\section{Capítulo 3: Metodologia de Pesquisa}

Breve revisão da literatura sobre metodologia de pesquisa e sobre análise de dados. O capítulo apresenta também os fatores considerados pelo pesquisador para a escolha do método utilizado para esta pesquisa.

Capítulo 4: Elaboração e aplicação do survey

Apresentação do modelo teórico da pesquisa e das etapas consideradas para a condução do projeto. São detalhadas as etapas de elaboração do questionário de pesquisa, teste piloto, revisão do questionário de pesquisa e pesquisa de campo.

Capítulo 5: Análises dos dados

Análise estatística (descritiva e inferencial) dos dados obtidos com a pesquisa de campo. O capítulo é composto de dois itens: caracterização da amostra e testes estatísticos das hipóteses da pesquisa.

Capítulo 6: Interpretação dos resultados

Interpretação dos resultados obtidos com a pesquisa.

Capítulo 7: Conclusões e recomendações

Apresentação das conclusões e contribuições do trabalho de pesquisa, bem como as recomendações para trabalhos futuros. 


\section{REVISÃO DA LITERATURA}

O capítulo anterior procurou apresentar o tema da pesquisa acadêmica, bem como justificar sua escolha e evidenciar sua atualidade.

Por sua vez, o presente capítulo pretende discutir os aspectos relevantes apresentados na literatura sobre o modelo de maturidade OPM3 $尺$ e assuntos que auxiliam o entendimento da base teórica sobre o mesmo. Assim, inicialmente o capítulo trata da implementação da metodologia de gerenciamento de projetos e do surgimento do conceito de maturidade em gerenciamento de projetos e dos modelos de maturidade em gerenciamento de projetos. Depois, é apresentado com maior detalhamento o modelo OPM $3 \circledast$ para avaliação da maturidade em gerenciamento de projetos. Finalmente, o conceito de estratégia organizacional é discutido, uma vez que 0 OPM $3 \circledR$ se auto-atribui a capacidade de vincular projetos à estratégia organizacional.

\subsection{Implementação da metodologia de gerenciamento de projetos}

Embora o gerenciamento de projetos enquanto disciplina tenha sua origem na década de 50, foi apenas ao longo das últimas décadas que obteve ampla divulgação, principalmente em função do acirramento da concorrência e da necessidade do estabelecimento de diferenciais competitivos. Como conseqüência da profissionalização da área, surgiram também instituições que agrupam os profissionais e buscam disseminar a disciplina de gerenciamento de projetos, dentre elas o PMI ${ }^{\circ}$ - Project Management Institute, associação americana de profissionais de gerenciamento de projetos estabelecida em 1969.

Em 1987, o PMI® lançou a primeira versão de seu padrão para gerenciamento de projetos, chamado PMBOK® Standards (PROJECT MANAGEMENT INSTITUTE, 2003). A versão posterior, lançada em 1996, teve ampla difusão, sendo que já em

seu título procurava ser menos prescritivo ao incorporar a palavra "guia": $P M B O K \circledR$ Guide - A Guide to the Project Management Body of Knowledge (PROJECT 
MANAGEMENT INSTITUTE, 2003). Deste então, o guia apresentou novas edições, mais conhecidas como Edição 2000 e Terceira Edição, esta última de 2004, refletindo o compromisso do PMI $\circledast$ em mantê-lo atualizado.

Cabe aqui ressaltar que, no contexto do presente trabalho, os termos projeto, programa e portfólio serão utilizados de acordo com a definição do Project Management Institute (2004).

"Um projeto é um esforço temporário empreendido para criar um produto, serviço ou resultado único."

"Um programa é um grupo de projetos relacionados gerenciados de modo coordenado para a obtenção de benefícios que não estariam disponíveis se eles fossem gerenciados individualmente."

"Um portfólio é o conjunto de projetos e/ou programas e outros trabalhos agrupados para facilitar o gerenciamento efetivo deste esforço para alcançar os objetivos estratégicos."

Também é válido ressaltar que o termo organização será utilizado indistintamente ao longo deste trabalho para se referir a empresas, associações, sociedades, unidades de negócios, grupos funcionais e departamentos.

Apesar da ampla propagação da disciplina de gerenciamento de projetos nos últimos anos, a implementação desta metodologia nas organizações ainda é um desafio. Kerzner (2002) afirma que a implementação da gerência de projetos deve ter por base a cultura da organização. De modo a facilitar esta implementação, a institucionalização da cultura de gerenciamento de projetos pode ser feita concomitantemente à implantação do Escritório de Gerenciamento de Projetos (EGP). Os itens a seguir tratam do histórico e das etapas sugeridas para a implementação de um EGP.

\subsubsection{Histórico do Escritório de Gerenciamento de Projetos}

Em sua origem, o gerenciamento de projetos individuais evoluiu naturalmente para um centro de gerenciamento de projetos (CRAWFORD, 2002). Segundo Kerzner (2003), entre 1950 e 1990 o EGP funcionava como uma organização dentro da organização, porém dedicada a servir a um cliente específico. No período de 1990 a 
2000, em função da divulgação dos benefícios do gerenciamento de projetos e do reconhecimento do gerenciamento de projetos como uma profissão, o EGP passou a abrigar sob sua supervisão todas as atividades críticas relacionadas ao gerenciamento de projetos.

Diversas são as definições atuais sobre o EGP, porém a maioria delas está associada ao fato de ser um centro de excelência em gerenciamento de projetos, responsável por implementar e manter a abordagem de projetos na organização, bem como por suprir as necessidades da organização no que se refere ao gerenciamento de projetos (CRAWFORD, 2002; ENGLUND; GRAHAM; DINSMORE, 2003; KERZNER, 2003).

\subsubsection{Implementação do Escritório de Gerenciamento de Projetos}

A literatura propõe que a implementação do EGP seja conduzida como um processo de mudança. A seguir serão apresentadas as sugestões da literatura para que esta mudança ocorra de forma bem sucedida. Englund; Graham e Dinsmore (2003) sugerem que a implementação do EGP seja feita em três etapas. Na primeira etapa, devem ser criadas as condições para a mudança, havendo um descongelamento da situação atual. Na etapa seguinte ocorre a mudança em si, ou seja, os agentes da mudança implementam-na. Na terceira e última etapa estabelece-se a motivação para que a situação pós-mudança seja a nova realidade, como um recongelamento da nova situação.

A primeira etapa pode ser entendida como uma etapa de planejamento e é crítica para o sucesso do projeto. Englund; Graham e Dinsmore (2003) propõem que os agentes da mudança percorram, nesta primeira etapa, os seguintes passos:

1) Descobrir os processos necessários à mudança organizacional.

2) Estabelecer, junto aos membros da organização, a importância da mudança e a razão pela qual ela deve ocorrer nesse momento. Isso pode acontecer através da apresentação das taxas de insucesso em projetos ou através de análises comparativas com outras organizações (benchmarking). Outra maneira de justificar esta mudança está em mostrar o valor adicionado à organização com a implementação. 
3) Desenvolver coalisões com membros da organização, bem como um patrocinador (sponsor) poderoso.

4) Estabelecer a visão do futuro da organização e a estratégia do EGP para atingir essa visão. Muitos EGPs iniciam desenvolvendo práticas de gerenciamento de projetos para a organização.

5) Elaborar o plano de implantação e comunicá-lo à organização.

\subsection{Maturidade em gerenciamento de projetos}

No item anterior, a implantação do Escritório de Gerenciamento de Projetos foi apresentada como facilitadora da implementação da metodologia de gerenciamento de projetos nas organizações.

Já o presente capítulo pretende discutir o conceito de maturidade em gerenciamento de projetos, que se origina das falhas na utilização do gerenciamento de projetos como iniciativa isolada e da conseqüente busca pelo gerenciamento de projetos formal e estruturado, como parte da estratégia competitiva das organizações (DINSMORE, 1999; HILLSON, 2003; JUGDEV; THOMAS, 2002; KERZNER, 2001; PITAGORSKY, 2001).

\subsubsection{Conceito de maturidade em gerenciamento de projetos}

A partir da necessidade da visão holística em gerenciamento de projetos e com a popularização do conceito de maturidade a partir da divulgação do Capability Maturity Model - CMM para software surgiu o conceito de maturidade em gerenciamento de projetos. A seguir, destacam-se as definições do Project Management Institute (2003): "A maturidade organizacional em gerenciamento de projetos pode ser definida como o grau através do qual a organização pratica o gerenciamento organizacional de projetos", sendo este "[...] a aplicação de conhecimentos, habilidades, ferramentas e técnicas às atividades da organização e dos projetos para atingir os objetivos da organização através dos projetos." 
Por sua vez, Kerzner (2002) define a maturidade em gerenciamento de projetos como o desenvolvimento de sistemas e processos que são por natureza repetitivos de modo a garantir a alta probabilidade de sucesso dos projetos, ou seja, que o mesmo seja executado no prazo, dentro do orçamento, no nível desejado de qualidade e com a aceitação do cliente.

Embora não haja consenso aparente entre os conceitos de maturidade acima apresentados, entende-se que os mesmos convergem, à medida que refletem a busca dos objetivos da organização através de projetos e da melhoria contínua do gerenciamento de projetos, utilizando-se de conhecimentos, habilidades, ferramentas, técnicas, sistemas e processos.

De modo geral, os fatores que motivam as organizações na busca da maturidade são os mesmos que as levam a utilizar a disciplina de gerenciamento de projetos. Pode-se citar como principais fatores: projetos estratégicos, expectativas dos clientes, competitividade, entendimento e comprometimento dos gerentes executivos, desenvolvimentos de novos produtos, eficiência e eficácia, sobrevivência, crescimento rápido por meio de aquisições e o processo de certificação ISO 9000 (KERZNER, 2002).

Por se tratar de um processo evolutivo, Kerzner (2002) divide o ciclo de vida para a maturidade em gerenciamento de projetos nas seguintes fases e respectivas características:

- Fase embrionária: na qual os gerentes intermediários e seniores reconhecem a necessidade, os benefícios e as aplicações do gerenciamento de projetos.

- Fase de aceitação pela gerência executiva: onde os executivos prestam abertamente o seu apoio ao gerenciamento de projetos.

- Fase de aceitação pelos gerentes de área: na qual os gerentes de área entendem os princípios do gerenciamento de projetos, prestam apoio e se comprometem com ele.

- Fase de crescimento: durante a qual os sistemas de gerenciamento de projetos são desenvolvidos, podendo ocorrer concomitantemente às três fases anteriormente citadas.

- Fase de maturidade: na qual é integrado o controle de custos e prazos e é desenvolvido um programa de treinamento para manutenção da condição de maturidade. 
Destaca-se aqui a fundamental importância do apoio dos níveis organizacionais superiores à gestão de projetos. Do mesmo modo que o comprometimento dos gerentes executivos é uma das forças que encaminham a organização para a maturidade em gerenciamento de projetos, a ausência de apoio concreto dos executivos é o maior obstáculo para alcançá-la (KERZNER, 2002).

\subsubsection{Modelos de maturidade em gerenciamento de projetos}

Juntamente com o conceito de maturidade em gerenciamento de projetos, surgiram os modelos de maturidade em gerenciamento de projetos, baseados no Capability Maturity Model - CMM - para software (Carnegie Mellon Software Engineering Institute 2002; Dymond, 1995 apud JUGDEV; THOMAS, 2002). O CMM foi desenvolvido pelo Instituto de Engenharia de Software (Software Engineering Institute - SEI) da Universidade Carnegie Mellon, entre 1986 e 1993, e classifica o estágio de maturidade através de cinco níveis (SCHLICHTER; FRIEDRICH; HAECK, 2003).

Em sua essência, os modelos de maturidade em gerenciamento de projetos são ferramentas que avaliam as práticas em gerenciamento de projetos e as comparam com um padrão, como, por exemplo, o PMBOK® Guide - A Guide to the Project Management Body of Knowledge (ROSE, 2004). Assim, as principais funções dos modelos são, segundo Jugdev; Thomas (2002):

- identificar pontos fortes e fraquezas organizacionais;

- comparar competências explícitas nos níveis de projeto e programa ao padrão;

- fornecer informações sobre outras organizações, permitindo assim estabelecer análises comparativas (benchmarking).

Uma vez que tiveram origem no CMM, diversas variações de modelos de maturidade em gerenciamento de projetos também envolvem cinco estágios lineares de maturidade (DINSMORE, 1998 apud JUGDEV; THOMAS, 2002; KERZNER, 2001):

- Nível 1: onde é estabelecida a linguagem comum sobre gerenciamento de projetos e por isso é considerado inicial; 
- Nível 2: caracterizado pela repetição, uma vez que os processos já estão estabelecidos;

- Nível 3: no qual a metodologia está desenvolvida, atribuindo ao nível o caráter organizado;

- Nível 4: onde é realizada a identificação de oportunidades de melhoria através de análises comparativas com outras organizações (benchmarking);

- Nível 5: considerado o nível otimizado ou de melhoria contínua.

A seguir encontram-se algumas críticas práticas aos modelos de maturidade existentes até 2002. Estas críticas referem-se aos trabalhos de Cabanis (1998); Dinsmore (2001); Kujala \& Artto (2000); Compass Fact Based Consulting (2001); LSM-International (2001), que não se encontram nas Referências do presente trabalho por terem sido consultadas através de Jugdev; Thomas (2002).

- Os cinco níveis de maturidade não oferecem estágios suficientes para a avaliação do progresso ao longo do tempo.

- Os modelos são úteis na identificação de problemas, porém não auxiliam na solução dos mesmos, devendo as organizações desenvolver planos, implementá-los, controlá-los e ajustá-los.

- Os modelos não contemplam outros fatores relacionados à sua implementação, como o gerenciamento de mudanças, princípios de melhoria de qualidade, velocidade de introdução de novas tecnologias e conseqüentes alterações de processos, bem como aspectos organizacionais e de recursos humanos.

\subsection{O modelo de maturidade em gerenciamento de projetos OPM3®}

O Organizational Project Management Maturity Model (OPM3®), modelo de maturidade publicado em 2003 pelo PMI $囚$, tem uma proposta diferenciada dos demais modelos e por esta razão foi escolhido como tema do presente trabalho.

Como passaremos a tratar nos itens a seguir, $O$ OPM $3 \AA$ não foi concebido para ser um modelo de níveis de maturidade. Ao invés disso, o modelo se auto-atribui a capacidade de vincular projetos à estratégia organizacional provendo o conhecimento das melhores práticas (best practices), permitindo a avaliação das 
práticas atualmente implementadas na organização e apontando as potenciais ações de melhoria a serem implementadas pela organização (ROSE, 2004).

\subsubsection{Histórico do Modelo OPM3®}

Com o desenvolvimento do CMM para software, a partir de 1993 o conceito de maturidade se popularizou e atingiu a área de gerenciamento de projetos, despertando o interesse dos membros do PMI no desenvolvimento de um padrão para o modelo de maturidade em gerenciamento de projetos. Assim, em 1998 os membros do Comitê de Padrões (Standards Committee) do PMI mapearam a necessidade de desenvolvimento de um padrão internacional para a indústria e governo que, segundo Schlichter; Friedrich e Haeck (2003):

- auxiliasse as organizações a avaliar e melhorar suas capacidades relacionadas ao gerenciamento de projetos e à obtenção da estratégia organizacional através dos projetos;

- definisse as melhores práticas em gerenciamento de projetos, programas e portfólio, bem como explicasse as capacidades necessárias a estas melhores práticas.

De modo a obter ampla participação de profissionais de diversos setores e localidades, definiu-se que a iniciativa seria conduzida por um time de voluntários não-remunerados, o que a diferenciava das demais iniciativas de desenvolvimento dos modelos de maturidade conduzidas até o momento. Originalmente, Marge Combe e Paul Dinsmore foram intitulados os gerentes do projeto (SCHLICHTER; FRIEDRICH; HAECK, 2003).

Em 1999, com algumas alterações na organização do PMI, John Schlichter passou a ser o Diretor do Programa OPM3®. Foram então recrutados voluntários, independentemente de sua origem, e definido um time central, chamado Time Guia. A missão do programa era desenvolver um modelo de maturidade que provesse métodos para avaliar e desenvolver capacidades associadas à entrega de projetos com sucesso, conforme planejado e consistentes com a obtenção da estratégia e melhoria da eficácia organizacionais. 
A visão da liderança era criar um modelo de maturidade amplamente aprovado e que fosse reconhecido ao redor do mundo como o padrão para desenvolvimento e avaliação de capacidades em gerenciamento de projetos em qualquer organização.

Algumas estratégias foram adotadas para diferenciar o OPM3® (SCHLICHTER; FRIEDRICH; HAECK, 2003):

- o padrão deveria relacionar o gerenciamento de projetos à execução da estratégia organizacional;

- o padrão deveria não apenas descrever mas explicar como as capacidades originavam saídas mensuráveis;

- ao invés de ser derivado de modelos comerciais, o padrão deveria ser uma inovação que avançaria o gerenciamento de projetos pela indústria;

- em função da diversidade de organizações, estruturas organizacionais e ambientes, o padrão deveria identificar variáveis de contingência em diferentes tipos de organização e como elas diferem na busca da maturidade.

Ainda no início do programa, a quantidade de voluntários aumentou rapidamente, ocasionando a necessidade de implementação de políticas que garantissem os direitos à propriedade intelectual ao $\mathrm{PMI}$. Alguns voluntários discordaram destas políticas e deixaram o programa, gerando a necessidade de recrutamento de novos voluntários e atrasando o programa em aproximadamente um ano (SCHLICHTER; FRIEDRICH; HAECK, 2003).

Em 1999, a pesquisa foi o foco principal do programa. O time entendia que o modelo deveria ser baseado em sólidas pesquisas, envolvendo profissionais de diversas indústrias pelo mundo. Assim, deveriam analisar diversos modelos e consultar mais de 30000 profissionais. O foco inicial da pesquisa era a análise dos modelos de maturidade existentes. Foram identificados 27 modelos, dos quais 17 foram revisados procurando-se identificar itens como: escopo, objetivos, capacidades, definição de maturidade, processo de avaliação e possibilidade de auto-avaliação, estrutura básica do modelo (existência de estágios ou não) e existência de plano de implementação para aumento da maturidade. O principal resultado desta pesquisa foi identificar que algumas questões sobre a maturidade em gerenciamento de projetos não estavam respondidas pelos modelos disponíveis (SCHLICHTER; FRIEDRICH; HAECK, 2003).

Como parte do trabalho de pesquisa, foi utilizada a técnica Delphi para identificar elementos que contribuíam para a maturidade organizacional em gerenciamento de 
projetos, depois chamados melhores práticas, tendo sido divididos nas seguintes categorias (SCHLICHTER, 2001 apud RABECHINI JR., 2003; SCHLICHTER; FRIEDRICH; HAECK, 2003):

1) Padronização e integração de métodos e processos

2) Desempenho e métricas de performance

3) Comprometimento com os processos de gerenciamento de projetos

4) Priorização de projetos e alinhamento estratégico

5) Melhoria Contínua

6) Estabelecimento de critérios de sucesso

7) Pessoas e suas competências

8) Alocação de recursos em projetos

9) Aspectos organizacionais

10)Trabalho em equipes

Assim, foram organizados 10 times menores, também chamados "células de projeto", cada qual com seu líder e responsável pelo desenvolvimento dos trabalhos acerca de uma categoria de "melhor prática" resultante da análise Delphi. Estes times também foram responsáveis pela divisão de cada "melhor prática" em passos incrementais, que foram chamados capacidades, e pela definição da dependência entre as capacidades referentes a mais de um time (SCHLICHTER; FRIEDRICH; HAECK, 2003).

Enquanto este trabalho utilizando a análise Delphi era conduzido, outro time de trabalho realizava pesquisas de campo visando identificar os desejos dos clientes e validar os requisitos necessários ao modelo. Entre as exigências identificadas durante as pesquisas, destacam-se a necessidade de ser um meio efetivo para avaliação de maturidade, além de requisitos como praticidade, facilidade de uso, consistência, flexibilidade, foco em melhorias e demonstração clara de relacionamento causa-efeito (SCHLICHTER; FRIEDRICH; HAECK, 2003).

Dentre os desafios encontrados ao longo do programa, Schlichter; Friedrich e Haeck (2003) citam:

- o desenvolvimento de processos de gerenciamento de projetos organizacional e a tradução destes processos em Melhores Práticas, Capacidades e Produtos;

- o refinamento da análise Delphi para garantia da consistência interna do modelo; 
- a consistência com o guia A Guide to the Project Management Body of Knowledge (PMBOK Guide);

- cumprimento do prazo para lançamento do modelo, exigindo inclusive a decisão estratégica pela redução de alguns componentes do escopo original;

- tamanho e complexidade do modelo em si, ocasionando a decisão pela sua apresentação em formato multimídia.

Ao longo do projeto, algumas alterações na equipe também se fizeram necessárias, como a remobilização da equipe de voluntários e a alteração da liderança do programa para Ralf Friedrich em novembro de 2002 (SCHLICHTER; FRIEDRICH; HAECK, 2003).

O trabalho foi conduzido ao longo dos anos seguintes, tendo duração aproximada de 6 anos. Durante este período, contou com mais de 800 voluntários, dispersos em 35 países, tendo a equipe do projeto trabalhado como um time virtual. Após uma série de três rodadas de testes e revisões, em 2003 o modelo foi submetido ao PMI publicação (SCHLICHTER; FRIEDRICH; HAECK, 2003).

\subsubsection{Estrutura do modelo}

Como resultado do programa descrito no item anterior, o PMI® lançou em 2003 o seu modelo de maturidade organizacional em gerenciamento de projetos - OPM3 $\AA$, tendo como idéia central fornecer subsídios para que a organização possa reexaminar como obter seus objetivos estratégicos através das melhores práticas em gerenciamento organizacional de projetos.

Segundo o Project Management Institute (2003), muito mais do que apresentar caráter prescritivo, o modelo de maturidade é oferecido como base de estudo e autoavaliação, habilitando as organizações a tomar suas próprias decisões relacionadas às mudanças.

O modelo OPM3® é composto de três elementos-chave: Conhecimento, Avaliação e Melhoria.

O Conhecimento apresenta o conteúdo do modelo; é apresentado sob a forma de um livro texto (Knowledge Foundation) que contém os conceitos fundamentais do 
OPM3 $®$, incluindo o diretório de aproximadamente 600 melhores práticas em gerenciamento organizacional de projetos e suas respectivas capacidades.

Por sua vez, o elemento Avaliação apresenta o método para Auto-Avaliação da maturidade, determinando forças e fraquezas da organização a partir da comparação com as melhores práticas. Geralmente a avaliação é feita através de uma ferramenta, como, por exemplo, a OPM3® Self-Assesment, que acompanha o modelo em um CD-ROM.

Já o elemento Melhoria subsidia o processo de incremento da maturidade, à medida que auxilia na ordenação das capacidades ainda não desenvolvidas, fornecendo assim a base para o plano de melhorias. Segundo o Project Management Institute (2003), o elemento Melhoria é um diferencial do OPM $3 \circledR$ comparativamente aos outros modelos de maturidade.

Outro ponto de diferenciação do modelo OPM3® é a continuidade do aumento da maturidade, ou seja, o modelo foi propositadamente desenvolvido sem um sistema de níveis de maturidade. Por outro lado, no modelo OPM3® o aumento da maturidade organizacional é considerado em diversas dimensões, conforme abaixo:

- de acordo com os estágios de melhoria de processos: padronização, medição, controle e melhoria contínua (Standardize, Measure, Control, Improve - SMCl);

- domínio de gerenciamento: projetos, programas e portfólio (Project, Program, Portfolio - PPP);

- grupos de processos de gerenciamento de projetos: iniciação, planejamento, execução, controle e encerramento (Initiating, Planning, Executing, Controling, Closing - IPECC).

Dentre os benefícios para a organização que o modelo se auto-atribui (PROJECT MANAGEMENT INSTITUTE, 2003), destacam-se:

- fornecimento de subsídios para a organização avaliar sua maturidade comparativamente a uma ampla base de conhecimento: o diretório de melhores práticas em gerenciamento organizacional de projetos. Neste diretório estão identificadas as melhores práticas, as capacidades que as compõem e as dependências entre melhores práticas e capacidades, tanto no contexto de gerenciamento de projetos como de programas e portfólio;

- auxílio à organização que deseja aumentar sua maturidade organizacional em gerenciamento de projetos a planejar as melhorias; 
- consistência com o PMBOK®;

- aplicação global, ou seja, para organizações de quaisquer tamanhos, tipos, segmentos da indústria e situadas em qualquer país;

- abertura de diálogo a respeito do gerenciamento de programas e portfólio.

Dentre as limitações do modelo, o próprio Project Management Institute (2003) destaca que, enquanto primeira interação pública, esta edição testaria o modelo e forneceria base para ajustes e refinamentos no desenvolvimento de futuras edições. Ressalta-se ainda que não é escopo do modelo, e tal fato pode ser entendido como uma restrição, o processo de implementação das melhorias recomendadas pelo mesmo, em função principalmente de sua complexidade e do envolvimento de outras disciplinas, como, por exemplo, o desenvolvimento organizacional. De modo similar, embora exista relação entre o modelo e a implementação da estratégia organizacional, o planejamento estratégico também não é escopo do modelo.

\subsubsection{Aplicação do modelo}

A aplicação do modelo prevê a execução de um ou mais passos para cada elemento-chave que o constitui, quais sejam, Conhecimento, Avaliação e Melhoria. A seguir, segue um breve resumo das etapas sugeridas para a aplicação do modelo: 1) Preparar-se para o processo de avaliação do nível de maturidade organizacional em gerenciamento de projetos a partir do conhecimento profundo do modelo.

2) Realizar a avaliação, devendo a organização comparar as características do seu estágio de maturidade com as descritas pelo modelo. Esta etapa pode ser dividida em duas fases: visão de alto nível e avaliação detalhada. $\mathrm{Na}$ primeira fase ocorre a identificação da posição geral da organização no contínuo de maturidade, através da constatação de quais melhores práticas do modelo são demonstradas pela organização. Já na avaliação detalhada, são determinadas quais capacidades são apresentadas pela organização.

3) Planejar melhorias, a partir da base obtida como resultado da avaliação. As saídas e capacidades que a organização ainda não possui devem ser 
organizadas de acordo com a prioridade para a organização, estabelecendose um plano de melhorias.

4) Implementar melhorias, ou seja, implementar as ações de desenvolvimento organizacional necessárias à obtenção das capacidades priorizadas no plano de melhorias.

5) Repetir o processo após a implementação de ações de melhoria.

Destaca-se ainda que o processo é cíclico, ou seja, após a implementação das melhorias, a organização pode retornar ao passo da avaliação para medir o efeito das melhorias ou ainda iniciar ações em outras áreas, ainda a partir da avaliação anteriormente conduzida.

É difícil quantificar a duração do processo de aplicação do OPM3®, uma vez que está relacionado a diversas variáveis como tamanho, complexidade e maturidade da organização. Segundo o Project Management Institute (2003), a condução do processo de avaliação (assesment) provavelmente dure entre semanas e meses.

\subsection{Estratégia organizacional}

O termo estratégia deriva da palavra grega strategus, sendo usada, inicialmente, no setor militar (CHIAVENATO, 2004; MINTZBERG, 2006; OLIVEIRA, 2005). A partir do século XIX, com a Segunda Revolução Industrial, a terminologia estratégica começou a ser adaptada para as organizações (CHIAVENATO, 2004), sendo este o contexto do presente trabalho.

Nos itens a seguir discute-se os principais conceitos de estratégia organizacional e as etapas da sua formulação.

\subsubsection{Conceitos de Estratégia Organizacional}

Existem diversas definições de estratégia na literatura sobre o assunto. Segundo Mintzberg (2006), o reconhecimento dessas múltiplas definições pode ajudar as pessoas a moverem-se neste campo. 
Os itens a seguir destacam, dentre as diversas definições, aspectos comuns e fundamentais da estratégia:

- apresenta caráter holístico, ou seja, está relacionada ao comportamento global da organização (CHIAVENATO, 2004);

- busca posicionar a organização no ambiente em que está inserida (CHIAVENATO, 2004; OLIVEIRA, 2005);

- possui orientação para o longo prazo, definindo, de maneira consciente e proposital, os resultados e objetivos a serem alcançados, bem como a maneira através da qual a organização pretende alcançá-los (CHIAVENATO, 2004; MINTZBERG, 2006; OLIVEIRA, 2005). Assim, formata as principais ações da organização (OLIVEIRA, 2005) e requer a atuação ativa e proativa da cúpula da organização (CHIAVENATO, 2004).

Outro enfoque para a análise da estratégia é apresentado em Mintzberg (2006), também conhecido como Cinco P's:

- plano (plan): a estratégia envolve a adoção de um curso intencional de ação e a alocação de recursos para alcançar os objetivos de longo prazo da organização(CHIAVENATO, 2004; MINTZBERG, 2006);

- pretexto ou estratagema (ploy): manobra específica para superar um concorrente (MINTZBERG, 2006);

- padrão (pattern): refere-se à consistência no comportamento organizacional, podendo ela ser pretendida ou não (CHIAVENATO, 2004; MINTZBERG, 2006);

- posição (position): refere-se à interligação da organização com o seu ambiente, sendo este caracterizado pela mudança, incerteza, concorrência e competitividade, donde o ambiente não é controlável (CHIAVENATO, 2004; MINTZBERG, 2006; OLIVEIRA, 2005);

- perspectiva (perspective): representa a maneira da organização visualizar o mundo. Nesta definição fica evidente o caráter conceitual da estratégia: uma vez que a estratégia é uma abstração, é fundamental que seja uma perspectiva compartilhada pelos membros da organização. (CHIAVENATO, 2004; MINTZBERG, 2006; OLIVEIRA, 2005).

Cabe ainda ressaltar que, no contexto do presente trabalho, os termos estratégia empresarial e estratégia organizacional serão utilizados indistintamente, não 
denotando o tipo de organização (empresas, associações, sociedades, unidades de negócios, grupos funcionais ou departamentos).

\subsubsection{Formulação e implementação da estratégia organizacional}

A partir dos conceitos de estratégia organizacional acima apresentados, percebe-se que a estratégia está intimamente relacionada à existência da organização, dado o seu caráter holístico e sua relação com o posicionamento da organização no ambiente externo, e também às suas pretensões futuras, em função da sua orientação para o longo prazo.

A etapa de formulação da estratégia organizacional é comumente chamada de Planejamento Estratégico e consiste no processo administrativo que permite estabelecer os rumos a serem seguidos pelas organizações de modo a otimizar a interação organização-ambiente. Este processo é, normalmente, de responsabilidade do nível mais alto da organização (OLIVEIRA, 2005).

Chiavenato (2004) divide o processo de Planejamento Estratégico em 5 fases:

- Fase 1: Definição da missão, visão e objetivos organizacionais

- Fase 2: Análise ambiental das oportunidades e ameaças externas

- Fase 3: Análise organizacional das forças e fraquezas internas

- Fase 4: Análise competitiva das alternativas estratégicas

- Fase 5: Escolha da estratégia

A seguir apresentam-se as definições de Chiavenato (2004) para os conceitos envolvidos na primeira fase. A missão organizacional refere-se à razão da existência ou a filosofia da organização; define o negócio da organização. Por sua vez, a visão organizacional consiste na imagem que a organização possui de si mesma e de seu futuro. Finalmente, os objetivos organizacionais são os resultados concretos e específicos que se pretende alcançar dentro de um período de tempo; indicam a orientação a ser seguida pela organização e estabelecem os padrões para avaliar o resultado da organização.

Pode-se dizer que existe um desdobramento da visão e da missão da organização até a estratégia, passando pelos seus objetivos. Ou seja, a estratégia é formulada a partir de uma base de sustentação que leva em conta os seguintes aspectos 
(CHIAVENATO, 2004; OLIVEIRA, 2005): a missão organizacional; a visão organizacional, o diagnóstico estratégico e os objetivos organizacionais. Os conceitos de missão, visão e objetivos organizacionais foram apresentados no parágrafo anterior; a seguir é apresentado o detalhamento de como proceder ao diagnóstico estratégico, que corresponde às Fases 2 e 3 citadas anteriormente.

Segundo Chiavenato (2004), o diagnóstico estratégico pode ser desmembrado na análise do ambiente externo e na análise interna da organização. A primeira análise identifica as oportunidades e ameaças externas à organização, tanto aquelas existentes no momento quanto as projetadas para o futuro. Uma vez que o ambiente é caracterizado pela mudança acelerada e profunda, a análise do ambiente em que a organização está inserida deve ser continuamente revisada. Já a análise interna avalia os recursos organizacionais, através do mapeamento de pontos fortes e fracos da organização. Estas análises podem ser representadas através da matriz SWOT: forças organizacionais (strengths), fraquezas organizacionais (weaknesses), oportunidades ambientais (opportunities) e ameaças ambientais (threats).

Cabe observar que, uma vez que os fatores e condições ambientais se modificam constantemente, alterando o diagnóstico estratégico, o processo de formulação da estratégia é complexo.

A Fase 4 corresponde à formulação e análise competitiva das alternativas estratégicas. Assim, a partir dos aspectos da organização e do ambiente obtidos nas fases anteriores, associados à imaginação e criatividade, é elaborada uma lista de alternativas estratégicas, de modo a englobar as configurações da organização em diversos cenários. Para que uma estratégia seja considerada viável, deve ser: ajustável às alterações no ambiente, aderente aos objetivos da organização e consistente com os recursos disponíveis (CHIAVENATO, 2004; OLIVEIRA, 2005). Oliveira (2005) sugere duas formas para reduzir a lista a uma quantidade aceitável de opções: o processo de múltiplos estágios do estreitamento do campo de alternativas ou ainda a priorização dos objetivos aos quais as estratégias estão relacionadas.

Na última fase são feitas análises dos diversos aspectos de cada alternativa visando escolher, dentre as alternativas, a que representa a melhor interação entre a organização e o ambiente, contribuindo para a vantagem competitiva da organização. Oliveira (2005) cita a técnica de análise decisória GUT (Gravidade / Urgência / Tendência), desenvolvida por Kapner e Tregoe, como forma estruturada 
de escolha da estratégia organizacional. De modo resumido, a Gravidade é avaliada pelo nível de dano da situação, a Urgência mede o tempo que se dispõe para atacar a situação e a Tendência procura prever o estado futuro caso não haja alteração de recursos na situação.

Terminado o processo de formulação da estratégia, inicia-se a sua implementação, Chiavenato (2004) e Oliveira (2005) citam a divisão do processo de implementação da estratégia em duas fases:

- Fase 1: implementação propriamente dita;

- Fase 2: controle, avaliação e acompanhamento.

$\mathrm{Na}$ fase de implementação, a estratégia é colocada em prática, através de profissionais alocados para transformá-la em ações. Chiavenato (2004) apresenta como técnicas para a implementação estratégica: programas, criando uma série de atividades organizacionais conjuntas; orçamentos, visando alocar recursos; e procedimentos, referindo-se aos detalhes operacionais dos programas. Uma vez que a implementação da estratégia pode ocasionar alterações internas na organização, Oliveira (2005) sugere o desenvolvimento organizacional como instrumento administrativo que proporciona métodos para minimizar eventuais resistências à estratégia.

Por sua vez, na Fase 2 é avaliado se a estratégia está alcançando os objetivos organizacionais aos quais estava relacionada. Geralmente os critérios para avaliação de resultados são definidos na formulação da estratégia e refletem os critérios de viabilidade da mesma: capacidade de ajuste às alterações no ambiente, aderência aos objetivos da organização e consistência com os recursos disponíveis (CHIAVENATO, 2004; OLIVEIRA, 2005).

\subsubsection{Planejamento tático e operacional}

O item anterior apresentou o processo de formulação da estratégia. Cabe, porém, ressaltar que este processo não tem fim em si mesmo. Oliveira (2005) sugere que o processo de planejamento estratégico deva continuar, interligando-se com o planejamento tático e o planejamento operacional. Estes conceitos, bem como os níveis administrativos da organização, serão discutidos a seguir. 
A organização é administrada por três níveis de atuação, também chamados níveis hierárquicos (CHIAVENATO, 2004):

- Nível institucional ou estratégico: é o nível mais alto da organização, que mantém a interface com o ambiente externo. Constituído pelos dirigentes, diretores proprietários ou acionistas da organização.

- Nível intermediário, tático ou gerencial: é o nível mediador, que faz a articulação interna entre os níveis estratégico e operacional. É composto pela média administração da organização.

- Nível operacional ou técnico: é o nível localizado nas áreas inferiores da organização, onde as tarefas são executadas e as operações são realizadas.

Assim, cada tipo de planejamento pode ser relacionado ao nível de decisão, conforme apresenta a Figura 2.

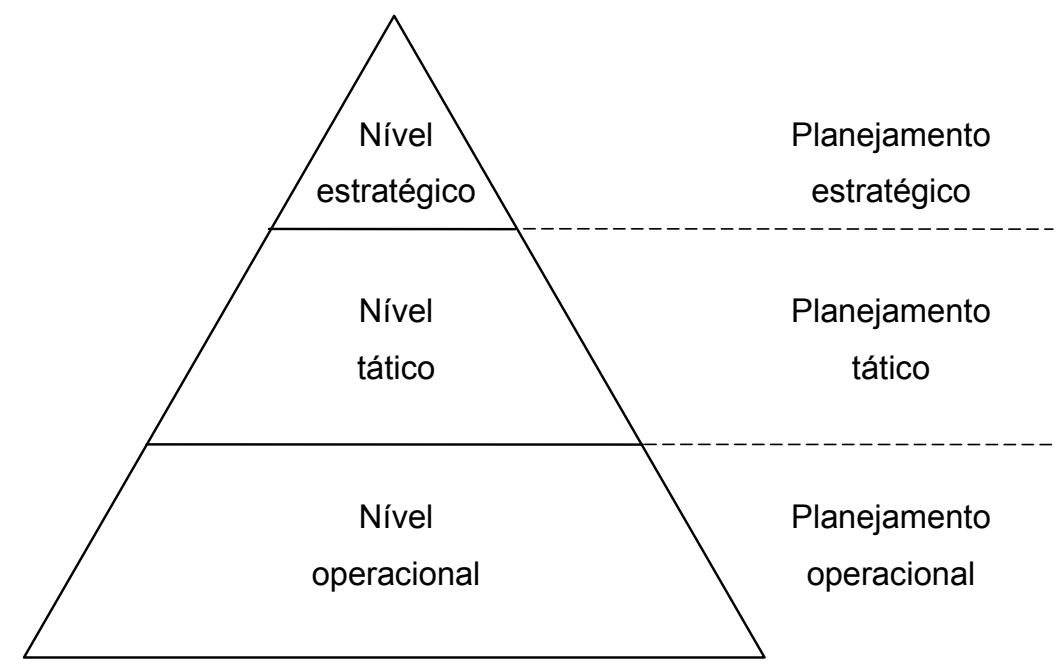

Figura 2 - Níveis de atuação e tipos de planejamento Fontes: Chiavenato (2004) e Oliveira (2005)

Conforme apresentado anteriormente, o planejamento estratégico está relacionado aos objetivos organizacionais de longo prazo e à estratégia organizacional para alcançá-los, envolvendo, assim, toda a organização. Já o planejamento tático trabalha com os objetivos estabelecidos no planejamento estratégico, porém busca otimizar determinada área de resultado, relacionando-se a objetivos de prazo mais curto (OLIVEIRA, 2005).

Por sua vez, o planejamento operacional consiste na decomposição do planejamento tático a partir da formulação de planos de ação ou planos 
operacionais. Cada plano operacional deve conter os procedimentos básicos a serem adotados, os produtos ou resultados finais esperados, os prazos estabelecidos, os recursos necessários para a sua implantação e os responsáveis pela execução (OLIVEIRA, 2005).

Cabe ainda uma consideração acerca da interligação entre a estratégia e os planos de ação da organização: segundo Oliveira (2005), esta interligação se dá através dos projetos. Assim, cada estratégia tem que proporcionar, no mínimo, um projeto. Por sua vez, os projetos, decompostos em suas diversas atividades que sejam comuns, geram os planos de ação (OLIVEIRA, 2005). 


\section{METODOLOGIA DE PESQUISA}

O presente capítulo, inicialmente, apresenta uma revisão teórica sobre metodologia de pesquisa. Em seguida, descreve as ponderações feitas pelo pesquisador para proceder à escolha do método. Finalmente, apresenta de maneira resumida algumas considerações que serão utilizadas no presente trabalho para a análise dos dados.

\subsection{Revisão da literatura sobre Metodologia de Pesquisa}

A busca do pesquisador pelas respostas aos seus questionamentos é o principal fator responsável pela geração de conhecimento. Parra Filho e Santos (1998) citam que o conhecimento é comumente definido como a apreensão de um objeto pelo sujeito, porém este processo não ocorre de maneira passiva, sendo que o sujeito busca captar as propriedades do objeto através da construção de imagem. Assim, a veracidade do conhecimento está associada à inexistência de contradição entre a imagem formada e o objeto em si.

Parra Filho e Santos (1998) classificam o conhecimento em quatro tipos:

- Intuitivo ou sensitivo: possui origem nas experiências e nas sensações transmitidas pelos sentidos;

- Racional: apresenta a razão como fonte de conhecimento;

- Intelectual: admite a razão e a experiência como fontes de conhecimento;

- Científico: conhecimento formal anteriormente existente que recebe o conteúdo da experiência. O conhecimento científico estabelece previamente um método que lhe permita descobrir e demonstrar as causas ou razões dos fatos.

Assim, dentre as formas de se obter o esclarecimento da problemática identificada pelo pesquisador tem-se os estudos científicos. Eco (1977) apresenta quatro requisitos para que um estudo seja classificado como científico:

- tratar sobre um objeto definido que seja reconhecível pelos outros, estabelecendo, se necessário, as regras de reconhecimento; 
- ser original, à medida que deve apresentar algo não publicado ou analisado sobre outra ótica a respeito do objeto;

- apresentar utilidade a outras pessoas, ou seja, deve ser uma contribuição científica;

- fornecer elementos para validação.

Para a construção de estudos relacionados aos problemas sociais e humanos, duas abordagens são encontradas: qualitativa e quantitativa.

A abordagem qualitativa está baseada no paradigma qualitativo, que apresenta dentre os seus pressupostos a subjetividade da realidade, vista a partir dos participantes do estudo, e a interação entre o pesquisador e o objeto da pesquisa. Neste paradigma, o processo de pesquisa tem como base uma visão holística e é indutivo, ou seja, parte de um caso particular para a generalização. (CRESWELL, 1994).

De modo semelhante, a abordagem quantitativa fundamenta-se no paradigma quantitativo, que tem como pressupostos a objetividade da realidade e a independência entre o pesquisador e o objeto da pesquisa. Ao contrário do paradigma qualitativo, no paradigma quantitativo o processo de pesquisa é dedutivo, partindo-se do caso geral para explicar o particular, testando teorias existentes através de variáveis, números e análises estatísticas (CRESWELL, 1994).

Em função dos pressupostos dos paradigmas qualitativos e quantitativos, alguns critérios sugeridos por Creswell (1994) para a seleção do tipo de estudo a ser realizado são:

- Treinamento e experiência do pesquisador: na abordagem quantitativa, o pesquisador deve possuir habilidades de redação técnica e de estatística, enquanto na abordagem qualitativa necessita de habilidades de redação literária;

- Natureza do problema: enquanto na abordagem quantitativa o problema foi estudado previamente por outros pesquisadores e as variáveis de pesquisa são conhecidas, na abordagem qualitativa as variáveis são desconhecidas e pode haver falta de base teórica para o estudo.

Os métodos de pesquisa quantitativa consistem basicamente em dois tipos:

- Experimento: objetiva testar relações de causa e efeito. (CRESWELL, 1994);

- Survey: caracterizado pela coleta de dados, informações e opiniões de um conjunto de interesse para a pesquisa chamado população. Geralmente 
utiliza-se de um sub-conjunto da população, também chamado unidade de análise ou amostra, a partir do qual se generalizam os resultados, consistindo no processo de inferência. A unidade de análise pode ser composta, por exemplo, de indivíduos, grupos, empresas, projetos ou sistemas (BOTTER et al., 1996; CRESWELL, 1994; FILIPPINI, 1997).

Por sua vez, dentre os métodos de pesquisa de abordagem qualitativa, destacamse:

- Pesquisa-ação: método onde o pesquisador age sobre a organização pesquisada, possuindo relacionamento com os seus profissionais (RABECHINI JR, 2003);

- Estudo de Caso: Segundo Yin (1994), o estudo de caso em geral é adotado como estratégia quando as questões de pesquisa a serem respondidas são do tipo "como" ou "por que", quando o pesquisador tem pouco controle sobre os eventos a serem investigados e quando o foco está em um fenômeno contemporâneo inserido em um contexto na vida real. Uma das vantagens do estudo de caso é permitir o estudo de um fenômeno no ambiente em que ele ocorre.

Em se tratando do método survey, Freitas et al. (2000) consideram sua utilização apropriada quando:

- há interesse no fenômeno ("o que está acontecendo"), na sua descrição ("como está acontecendo") e na sua causa ("por que está acontecendo");

- não é possível controlar as variáveis dependentes e independentes;

- o estudo do fenômeno deve ocorrer em seu ambiente natural;

- o fenômeno ocorre no presente ou ocorreu no passado recente.

Assim, de acordo com o seu propósito, a pesquisa do tipo survey pode ser classificada em (FILIPPINI, 1997; FORZA, 2002; FREITAS et al., 2000):

- Exploratória: visa definir quais conceitos estão relacionados com o fenômeno e como mensurá-los, geralmente ocorre nos estados iniciais da pesquisa de um fenômeno e constitui base para um estudo mais aprofundado;

- Explanatória ou confirmatória: objetiva testar a teoria e as relações causais entre as variáveis;

- Descritiva: busca descrever fenômenos e a sua distribuição na população.

Segundo Creswell (1994) e Filippini (1997), a coleta de dados na pesquisa do tipo survey pode ocorrer em um só momento (corte-transversal) ou ao longo do tempo, 
em períodos ou pontos especificados (longitudinal). Além disso, a coleta de dados deve utilizar um instrumento de pesquisa estruturado e pré-definido (FILIPPINI, 1997), classificado, segundo Fink (1995a), em:

- Questionário auto-administrado: consiste de questões que o indivíduo completa sozinho. Pode ser enviado por correio, aplicado no local (por exemplo, em sala de aula), ou ainda computadorizado, onde o pesquisado fornece as respostas diretamente no computador.

- Entrevista: este instrumento requer pelo menos duas pessoas: o entrevistador, que faz as perguntas, e o entrevistado, que as responde. As entrevistas geralmente são feitas por telefone ou pessoalmente.

- Relatório estruturado: é uma pesquisa que se utiliza de um formulário especialmente criado para guiar a coleta de dados de relatórios (por exemplo, financeiros).

- Observação estruturada: consiste na coleta de dados feita visualmente, designada para guiar o pesquisador com foco em ações e características específicas.

Em se tratando do uso do questionário auto-administrado, tem se mostrado atrativa para os pesquisadores a aplicação da tecnologia também para o recebimento dos dados, através de e-mail (correspondência eletrônica) e pesquisas web-based (hospedadas na Internet). De acordo com llieva; Baron e Healey (2002), as principais vantagens obtidas com o uso de pesquisas por e-mail e web-based são:

- Redução de custos quando comparado aos questionários enviados por correio, como, por exemplo, custos de postagem e fotocópias;

- Diminuição do tempo de resposta, uma vez que as mensagens são entregues instantaneamente, qualquer que seja a distância geográfica entre o pesquisador e o respondente;

- Redução do prazo e dos custos associados ao processo de carga, uma vez que os dados são coletados diretamente em softwares de análise de dados.

Ilieva; Baron e Healey (2002) apresentam também os resultados de trabalhos empíricos que comparam pesquisas por e-mail e web-based. Geralmente as pesquisas por e-mail apresentam maior taxa de respostas e proporcionam maior controle, evitando mais de uma entrada de dados pelo mesmo respondente. Por outro lado, nas pesquisas web-based o questionário é melhor visualizado, mais interativo e mais fácil de preencher. Assim, o contato com o pesquisado através de 
e-mail enviando o questionário em formato HTML (ou enviando URL do mesmo) combinaria as vantagens das pesquisas por e-mail e web-based (ILIEVA; BARON; HEALEY, 2002).

Ainda em relação ao uso da tecnologia no processo de coleta de dados da pesquisa, algumas limitações referem-se à representatividade da amostra, ou seja, casos onde os usuários de Internet não refletem totalmente a população estudada e à possibilidade de problemas técnicos, como, por exemplo, a incompatibilidade entre o software de pesquisa com o browser do pesquisado (ILIEVA; BARON; HEALEY, 2002).

Ainda em relação ao uso do questionário auto-administrado como instrumento de pesquisa, Fink (1995b) apresenta as seguintes recomendações para a sua elaboração:

- Número de questões adequado ao tempo disponibilizado pelos respondentes para o preenchimento do questionário;

- Padronização das questões e do formato das respostas,

- Uso de questões precisas, não ambíguas, relacionadas aos objetivos da pesquisa e escritas utilizando linguagem adequada ao público-alvo;

- Uso de questões fechadas, permitindo a extração de dados padronizados que possam ser analisados estatisticamente.

Após a elaboração do questionário, recomenda-se, nas pesquisas do tipo survey, a realização do teste piloto com uma amostra reduzida da população (FINK, 1995a; FORZA, 2002), visando validar o instrumento de pesquisa elaborado no que tange à viabilidade de aplicação do mesmo e às propriedades dos dados coletados. Forza (2002) sugere que o teste piloto seja submetido a três grupos de pessoas: colegas (pesquisadores), especialistas e respondentes, cada qual com diferentes funções. Assim, o primeiro grupo deve avaliar se o questionário atinge os objetivos da pesquisa; o grupo dos especialistas procura prevenir a inclusão de questões óbvias e o último grupo objetiva avaliar o preenchimento do questionário sob o ponto de vista do público-alvo da pesquisa. 


\subsection{A escolha do método}

A primeira etapa para a escolha do método de pesquisa a ser utilizado no presente trabalho envolveu a decisão entre as abordagens quantitativa e qualitativa.

Inicialmente imaginou-se que o objetivo da pesquisa seria atingido ao se verificar a existência de alterações na quantidade de projetos selecionados de acordo com a estratégia organizacional quando da evolução do nível de maturidade, avaliado através do modelo $\mathrm{OPM} 3 \AA$, de uma organização. Assim, o processo de pesquisa seria indutivo, partindo de um caso particular de aplicação do modelo OPM3® para a generalização. Para tanto, algumas organizações foram contatadas na ânsia de realização de um estudo de caso. Porém, não se obteve sucesso, principalmente em função do pouco tempo de existência do modelo OPM3® como é conhecido hoje e do prazo para a conclusão deste projeto de pesquisa.

Assim, passou a ser considerada a abordagem quantitativa da pesquisa, onde o processo de pesquisa seria dedutivo e seriam utilizadas análises estatísticas para validação das hipóteses de pesquisa. Para esta abordagem, deveria ser respeitada a necessidade de independência entre o pesquisador e o objeto da pesquisa.

Decidida a abordagem que seria utilizada na pesquisa, a etapa posterior consistiu na decisão entre os métodos de pesquisa quantitativa apresentados no item anterior: experimento ou survey.

Conforme apresentado no Capítulo 1, as questões e hipóteses desta pesquisa não apresentam testes da relação de causa e efeito entre as características observadas, donde a utilização do método do experimento foi considerada inapropriada para o estudo em questão.

Em contrapartida, a utilização do survey foi considerada válida, uma vez que o problema de pesquisa descrito no Capítulo 1 é contemporâneo à pesquisa e poderia ser estudado em seu ambiente natural, ou seja, nas organizações.

À medida que o estudo visa avaliar se o conceito de maturidade em gerenciamento de projetos e a existência de processo de formulação da estratégia estão relacionados à seleção de projetos de acordo com a estratégia organizacional, a pesquisa em questão constitui um estudo exploratório, conforme as classificações possíveis para o survey apresentadas no item anterior. 
Ressalta-se ainda que, uma vez que as questões de pesquisa não apresentam caráter temporal, a coleta de dados poderia ocorrer em um só momento (cortetransversal).

Quanto ao instrumento de pesquisa utilizado, para o problema de pesquisa não existia a possibilidade de coleta de dados de relatórios existentes ou coleta de dados visual, inviabilizando o relatório estruturado e a observação estruturada. Considerando-se o prazo para a conclusão deste projeto de pesquisa, optou-se pelo questionário auto-administrado em detrimento à entrevista, já que a última exigiria maior intervenção pessoal do pesquisador.

Cabem ainda algumas considerações a respeito dos meios utilizados para a aplicação do questionário. As ferramentas de e-mail e hospedagem de páginas na Internet já eram facilmente acessíveis ao pesquisador. A utilização das mesmas para a pesquisa traria as vantagens de redução de custos, prazo associado ao processo de carga e diminuição do tempo de resposta descritas em detalhes no item anterior. Além disso, o acesso à Internet não comprometeria a representatividade da amostra, uma vez que, conforme será melhor detalhado no próximo capítulo, a unidade de observação da pesquisa é o profissional da área de gerenciamento de projetos, para o qual essa ferramenta de trabalho já é uma realidade. Assim, para a pesquisa em questão, o uso do questionário web-based para coleta de dados foi considerado viável.

Cabe ainda ressaltar que o questionário foi desenvolvido em HTML para diminuir a incidência de casos de incompatibilidade com o browser do pesquisado e, assim, minimizar a ocorrência de problemas técnicos no preenchimento da pesquisa.

Em resumo, pode-se caracterizar a pesquisa em questão conforme abaixo:

- Quanto à abordagem: Quantitativa

- Método de pesquisa: Survey

- Quanto ao propósito: Exploratório

- Quanto ao número de momentos: Corte-transversal

- Quanto à fonte de evidência: Questionário auto-administrado web-based 


\subsection{Breve resumo sobre Análise de dados}

Segundo Fink (1995d), a escolha do método de análise dos dados do survey deve ser antecedida pelas etapas de definição do objetivo da pesquisa, do número de variáveis associadas à pesquisa e do tipo de dado obtido com a mesma. A seguir discorre-se sobre o conceito de variáveis e tipos de dados de pesquisa e apresentam-se suas classificações.

As características da pesquisa que podem ser medidas são chamadas variáveis, sendo identificadas a partir da análise do objetivo e do público-alvo da pesquisa. São classificadas como (FINK, 1995d):

- Variável dependente: resposta, saída ou resultado da pesquisa.

- Variável independente: usada para explicar ou prever a variável dependente.

Para a medição de uma variável ou característica a ser pesquisada, três escalas podem ser utilizadas (FINK, 1995d):

- Escala de medida nominal: permite a categorização dos dados obtidos com a pesquisa (por exemplo, sexo: feminino ou masculino);

- Escala de medida ordinal: os dados obtidos com a pesquisa são categorizados e existe uma ordem entre as categorias, como, por exemplo, as taxas de qualidade (excelente, muito bom, bom, regular, ruim, péssimo);

- Escala de medida numérica: as diferenças entre os números possuem significado em uma escala numérica (por exemplo, idade).

O tipo de dado gerado com a pesquisa varia de acordo com a escala utilizada e recebe a mesma nomenclatura: dado nominal, dado ordinal e dado numérico.

As pesquisas do tipo survey geralmente utilizam a análise estatística para organizar e interpretar as informações numéricas coletadas (Fink, 1995d). A análise estatística pode ser composta pelas análises descritiva e inferencial (BOTTER et al., 1996). A estatística descritiva, ou exploração dos dados, objetiva fornecer informações sobre a qualidade dos dados e indicar algumas tendências. Em geral, esta análise não tem um fim em si própria, porém é recomendada por Botter et al. (1996) por proporcionar ao pesquisador a intimidade necessária com os dados coletados para a posterior análise inferencial. Para os dados nominais, Fink (1995d) sugere que os dados sejam analisados utilizando os seguintes conceitos da estatística descritiva: 
- Proporção: número de observações ou respostas de uma dada característica dividido pela quantidade total de observações.

- Porcentagem: é a proporção multiplicada por $100 \%$.

- Razão: número de observações ou respostas de uma dada característica dividido pelo número de observações sem esta mesma característica.

- Taxa: é similar à proporção, exceto porque apresenta caráter temporal, existindo um fator para multiplicação.

Já a análise por inferência consiste no conjunto de métodos que permitem inferir o comportamento de uma população a partir do conhecimento da amostra (BOTTER et al., 1996).

Uma vez que as pesquisas do tipo survey geralmente estão interessadas no relacionamento entre duas variáveis nominais utilizam como técnica de análise por inferência o teste de hipóteses, sendo que este visa, a partir dos dados da amostra, validar ou não as hipóteses formuladas. Antes, porém, de proceder ao teste de hipótese propriamente dito, o pesquisador deve percorrer algumas etapas, descritas a seguir.

Inicialmente, faz-se necessário estabelecer a hipótese nula. A hipótese nula $(H)$ é a afirmação de que não existe diferenciação entre os grupos de uma variável que está sendo analisada (FINK, 1995d). Esta hipótese deve ser formulada pelo pesquisador levando-se em conta que, sendo esta afirmação verdadeira, a sua rejeição implicará no erro mais importante para o problema. Assim, estão associados à hipótese nula dois tipos de erros: tipo I, que consiste na rejeição de $\mathrm{H}$ quando $\mathrm{H}$ é verdadeira, e tipo II, que consiste na aceitação de $\mathrm{H}$ quando $\mathrm{H}$ é falsa (BOTTER et al., 1996).

A segunda etapa consiste em estabelecer o nível de significância desejado para o teste estatístico. O nível de significância estatística $(\alpha)$ reflete a probabilidade de se rejeitar a hipótese nula quando ela é verdadeira, ou seja, a probabilidade do erro de tipo I. Por sua vez, a probabilidade do erro de tipo II é geralmente denotada por $\beta$ (BOTTER et al., 1996).

A Tabela 1 resume as possíveis decisões que podem ser tomadas e suas respectivas probabilidades: 


\begin{tabular}{lll}
\hline \multicolumn{1}{c}{ Decisão } & \multicolumn{1}{c}{ H é verdadeira } & \multicolumn{1}{c}{ H é falsa } \\
\hline \multirow{2}{*}{ Aceitar H } & Decisão correta & Erro de tipo II \\
& Probabilidade $=1-\alpha$ & Probabilidade $=\beta$ \\
\hline \multirow{2}{*}{ Rejeitar H } & Erro de tipo I & Decisão correta \\
& Probabilidade $=\alpha$ & Probabilidade $=1-\beta$ \\
\hline
\end{tabular}

Tabela 1 - Decisões acerca da aceitação ou rejeição da hipótese nula $(\mathrm{H})$

Fonte: Botter et al. (1996)

Cabe aqui ressalvar que toda tentativa de diminuição de $\alpha$ implica no aumento da região de aceitação, aumentando $\beta$. De modo análogo, toda tentativa de diminuição de $\beta$ ocasiona o aumento de $\alpha$. Por isso, é usual fixar um valor para $\alpha$,controlandose o erro de tipo I. Geralmente são utilizados os valores de $5 \%, 1 \%$ e $0,1 \%$. (BOTTER et al., 1996).

Outro conceito importante relacionado ao teste de hipótese é o nível de significância obtido ( $p$-value), também chamado nível descritivo ou nível probabilístico. Corresponde ao dado calculado após o teste estatístico e determina o valor para o nível de significância a partir do qual a hipótese $\mathrm{H}$ deve ser rejeitada. Assim, para $p$ value $\leq \alpha$, a hipótese nula $(\mathrm{H})$ é rejeitada (BOTTER et al., 1996).

Para proceder à escolha do método estatístico a ser utilizado é necessário atentar para o tipo de dado a ser tratado. Para pesquisas cujo objetivo apresenta uma variável independente e uma variável dependente, ambas nominais, Fink (1995d) aponta para o teste qui-quadrado (chi-square). Segundo Botter et al. (1996), este teste pode servir para testar aderência, homogeneidade e independência. Para o presente trabalho, o teste qui-quadrado será utilizado como teste de independência.

Para a aplicação do teste, geralmente se considera a seleção aleatória de $n$ indivíduos de uma população. Cada um dos $n$ indivíduos é classificado segundo duas variáveis, A e B, que possuem, respectivamente, l e c categorias (BOTTER et al., 1996).

Estes dados podem ser agrupados em uma tabela de contingência, que possui $I$ linhas e $c$ colunas, também denominada $I \times c$. Esta tabela exibe a distribuição conjunta das duas variáveis A e B. Visando verificar a existência de associação entre A e $B$, o teste de hipótese consiste na comparação das freqüências observadas nas I 
x c células com as freqüências esperadas, sendo que as últimas são calculadas considerando-se as distribuições de probabilidades de A e B (BOTTER et al., 1996). Por exemplo, para $I=3$ e $c=3$, tem-se a Tabela 2 .

\begin{tabular}{ccccc}
\hline & A1 & A2 & A3 & Total \\
\hline B1 & $\mathrm{n} 11$ & $\mathrm{n} 12$ & $\mathrm{n} 13$ & $\mathrm{n} 1$. \\
\hline B2 & $\mathrm{n} 21$ & $\mathrm{n} 22$ & $\mathrm{n} 23$ & $\mathrm{n} 2$. \\
\hline B3 & $\mathrm{n} 31$ & $\mathrm{n} 32$ & $\mathrm{n} 33$ & $\mathrm{n} 3$. \\
\hline Total & $\mathrm{n} .1$ & $\mathrm{n} .2$ & $\mathrm{n} .3$ & $\mathrm{n}$ \\
\hline
\end{tabular}

Tabela 2 - Exemplo de tabela de contingência

Fonte: Botter et al. (1996)

Segundo Siegel e Castellan Jr (2006), o grau de liberdade é obtido multiplicando-se $(I-1) \times(c-1)$.

Em se tratando do teste de independência, o que se quer testar é a hipótese de que as variáveis $A$ e $B$ são independentes. Neste caso, a hipótese nula $(H)$ pode ser escrita como:

$$
H: P\left(A_{i} e B_{j}\right)=P\left(A_{i}\right) \times P\left(B_{j}\right),
$$

para $i=1, \ldots, l ; j=1, \ldots, c$.

A estatística usada para o teste de $\mathrm{H}$ é dada por:

$$
\chi^{2}=\sum_{i=1}^{l} \sum_{j=1}^{c} \frac{\left(O_{i j}-E_{i j}\right)^{2}}{E_{i j}},
$$

onde $\chi^{2}$ é o valor de qui-quadrado resultante do teste e $O_{i j}$ e $E_{i j}$ são, respectivamente, as freqüências observada e esperada para as categorias das variáveis A e B (BOTTER et al., 1996).

O Apêndice A apresenta o detalhamento do teste qui-quadrado, através de um exemplo de sua utilização.

Ressalva-se ainda que, em tabelas com grau de liberdade maior que do 1, para a aplicação do teste qui-quadrado, duas condições devem ser satisfeitas (SIEGEL e CASTELLAN JR, 2006):

- menos de $20 \%$ das células devem possuir freqüência esperada inferior a 5 ;

- nenhuma célula deve possuir freqüência esperada menor do que 1.

Caso a organização dos dados originais não atenda estas condições, o pesquisador pode reagrupar as células adjacentes das categorias originais, visando aumentar os 
valores de freqüência esperada das células resultantes (SIEGEL e CASTELLAN JR, 2006).

Para o presente trabalho, o software SPSS 14.0 for Windows, da SPSS Inc. (SPSS, 2005) foi utilizado para gerar as análises estatísticas apresentadas no capítulo 5. 


\section{ELABORAÇÃO E APLICAÇÃO DO SURVEY}

No capítulo anterior justificou-se a escolha do survey enquanto método para a presente pesquisa. Cabem ainda algumas considerações sobre as condições de contorno utilizadas para a pesquisa, apresentadas a seguir.

Uma vez que o objetivo da pesquisa envolve o conceito de maturidade organizacional em gerenciamento de projetos, a população de interesse para o estudo são as organizações estabelecidas no Brasil que se utilizam do gerenciamento de projetos. Assim, a unidade de análise da pesquisa é a organização.

Por sua vez, conforme será detalhado no item 4.2.4, a amostra da pesquisa corresponde a uma parcela desta população e foi constituída através de seus sujeitos, profissionais da área de gerenciamento de projetos da rede de contatos do pesquisador. Portanto, a unidade de observação da pesquisa é o profissional da organização.

Assim, o presente capítulo é composto de duas partes: a primeira descreve o modelo teórico elaborado com o intuito de atender aos objetivos da pesquisa, enquanto a segunda apresenta o projeto utilizado para a condução da pesquisa, detalhando as etapas de elaboração e aplicação do survey.

\subsection{O modelo teórico}

De modo a representar graficamente o objetivo da pesquisa, foi elaborado o modelo teórico abaixo apresentado na Figura 3.

O modelo teórico apresenta em seus quatro eixos alguns dos diversos critérios comumente utilizados para a seleção de projetos: o relacionamento com a estratégia organizacional, o desejo da Diretoria Executiva, critérios econômico-financeiros e a vantagem comercial. Assim, o critério de seleção de projetos é a primeira variável considerada para o estudo em questão. Uma vez que no foco da pesquisa está a garantia de que os projetos sejam selecionados de acordo com a estratégia 
organizacional, para o estudo em questão esta variável é dependente, uma vez que expressa o resultado ou saída da pesquisa.

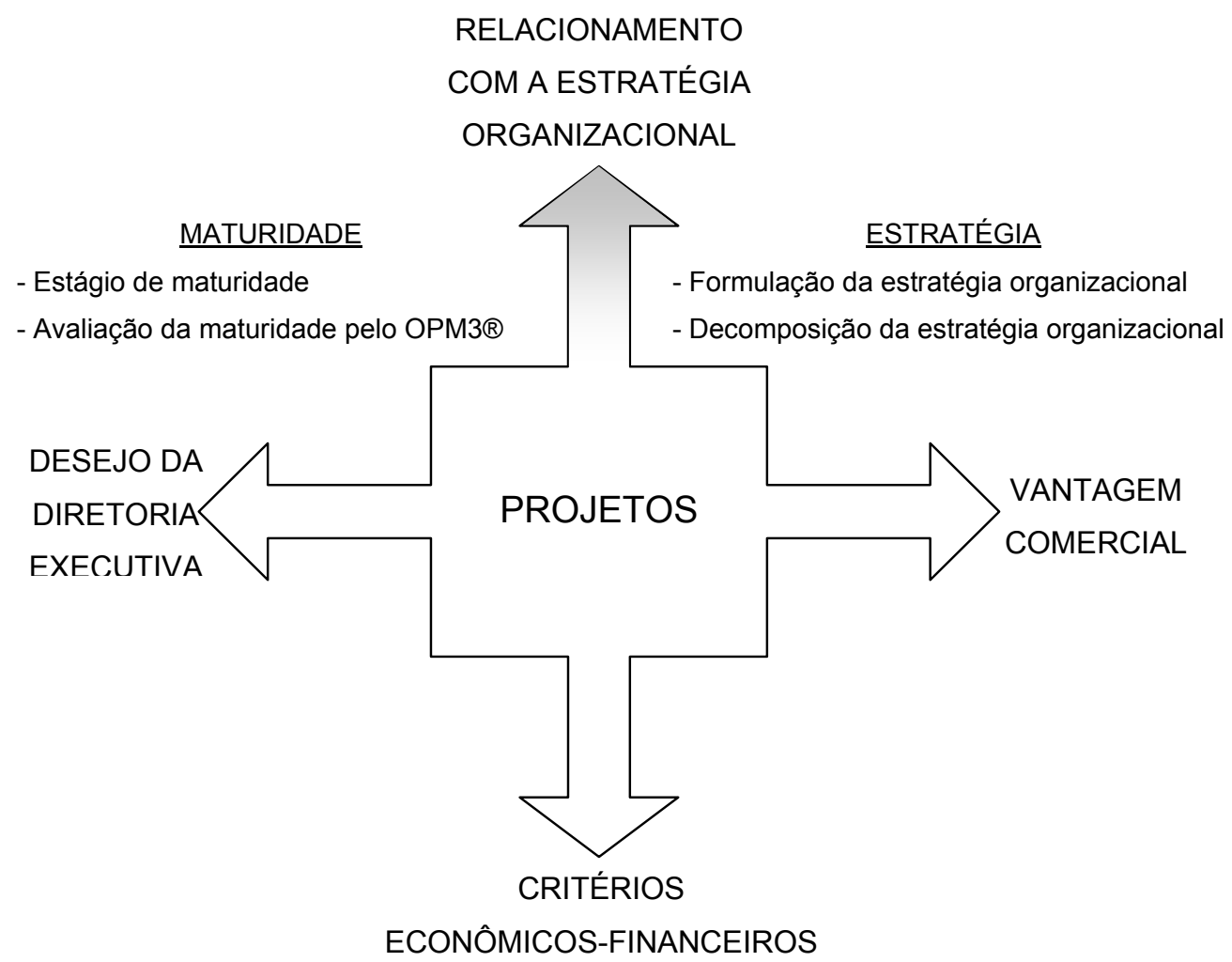

Figura 3 - Modelo teórico da pesquisa

O mesmo modelo teórico também pretende representar o objetivo do estudo de avaliar se a maturidade em gerenciamento de projetos e o processo de formulação da estratégia contribuem para a seleção de projetos de acordo com a estratégia organizacional. Por isso o desmembramento do problema de pesquisa nas duas Questões de Pesquisa (QP1 e QP2) apresentadas anteriormente e transcritas abaixo:

QP1: O nível de maturidade da organização contribui para a prática da seleção de projetos relacionados à estratégia organizacional?

QP2: A existência, na organização, de processo de formulação da estratégia contribui para a prática da seleção de projetos relacionados à estratégia organizacional?

Por sua vez, estas duas Questões de Pesquisa foram desmembradas nas hipóteses de pesquisa apresentadas no capítulo 1 visando restringir a amplitude dos temas 
estratégia e maturidade. Assim, no que tange à estratégia, a pesquisa avalia se o critério de seleção de projetos é influenciado pela existência de processo sistemático de formulação da estratégia empresarial e pela decomposição da estratégia empresarial nos níveis tático e operacional. Já em relação à maturidade, será avaliada a influência do estágio de maturidade predominante na organização para cada domínio definido pelo OPM3® (projeto, programa e portfólio) e da utilização do questionário de Auto-Avaliação proposto pelo $O P M 3 \circledR$ para verificação do nível de maturidade.

Assim, as demais variáveis de pesquisa são:

- Estágio de maturidade: estágio predominante na organização para cada domínio definido pelo OPM3® (projeto, programa e portfólio).

- Avaliação da maturidade pelo OPM3®: utilização, pela organização, do questionário de Auto-Avaliação proposto pelo $O P M 3 \AA$ para verificação do nível de maturidade.

- Formulação da estratégia organizacional: existência, na organização, de processo sistemático de formulação da estratégia.

- Decomposição da estratégia organizacional: existência, na organização, de ação para decomposição da estratégia nos níveis tático e operacional.

Uma vez que estas variáveis serão utilizadas para justificar que a seleção de projetos ocorra de acordo com seu relacionamento com a estratégia organizacional, no estudo em questão estas variáveis de pesquisa são classificadas como independentes.

A Figura 4 apresenta as Questões (QPs) e hipóteses $(H)$ da pesquisa inseridas no modelo teórico.

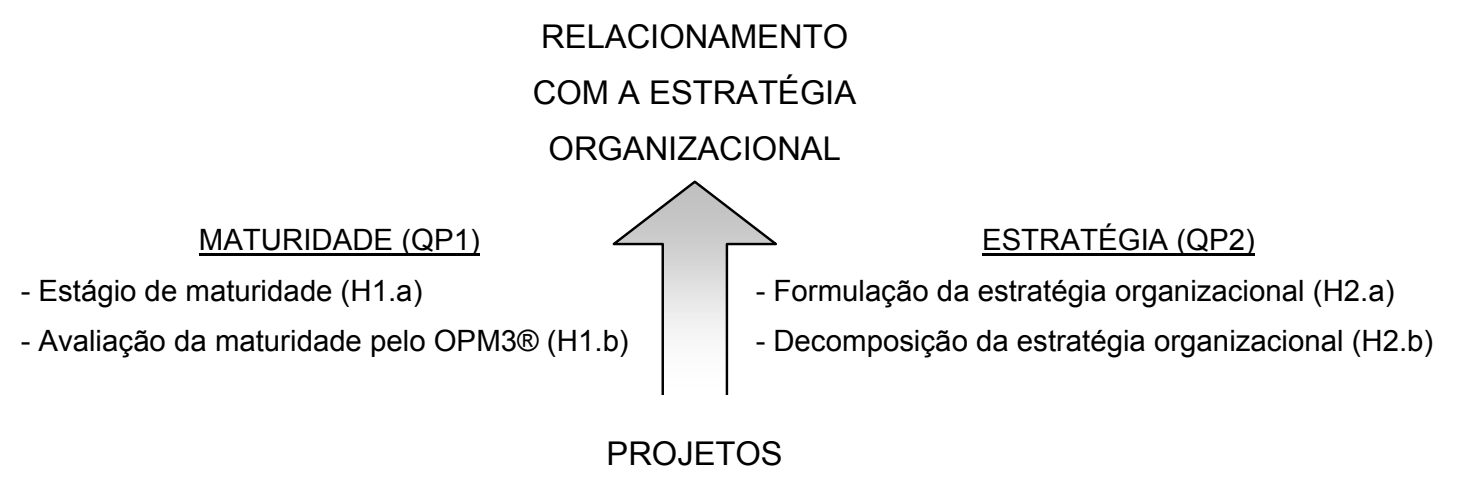

Figura 4 - Questões e hipóteses da pesquisa inseridas no modelo teórico da pesquisa 
A Tabela 3 apresenta de forma resumida as variáveis de pesquisa e suas respectivas classificações, bem como as Questões de Pesquisa às quais estão associadas.

\begin{tabular}{lcc}
\hline \multicolumn{1}{c}{ Variável } & Tipo & $\begin{array}{c}\text { Questão de } \\
\text { Pesquisa }\end{array}$ \\
\hline Critério de seleção de projetos & Dependente & QP1/ QP2 \\
\hline Estágio de maturidade - domínio projeto & Independente & QP1 \\
\hline Estágio de maturidade - domínio programa & Independente & QP1 \\
\hline Estágio de maturidade - domínio portfólio & Independente & QP1 \\
\hline Avaliação da maturidade pelo OPM3® & Independente & QP1 \\
\hline Formulação da estratégia organizacional & Independente & QP2 \\
\hline Decomposição da estratégia organizacional & Independente & QP2 \\
\hline \multicolumn{2}{c}{ Tabela 3 - Variáveis da pesquisa e associação com as Questões de Pesquisa }
\end{tabular}

\subsection{Projeto de pesquisa}

A condução da pesquisa em questão ocorreu de acordo com o projeto de pesquisa representado graficamente pela Figura 5.

A etapa da revisão da literatura está descrita no capítulo 2 e procurou identificar o material publicado até o momento do presente estudo sobre o modelo de maturidade em gerenciamento de projetos OPM3 $®$ e sobre estratégia organizacional. Também foram abordados no capítulo citado assuntos relacionados à construção da teoria sobre o modelo OPM $3 \circledast$, quais sejam, a implementação da metodologia de gerenciamento de projetos e a maturidade em gerenciamento de projetos.

Os demais processos relacionados à pesquisa, apresentados na Figura 5, serão descritos nos itens a seguir. 


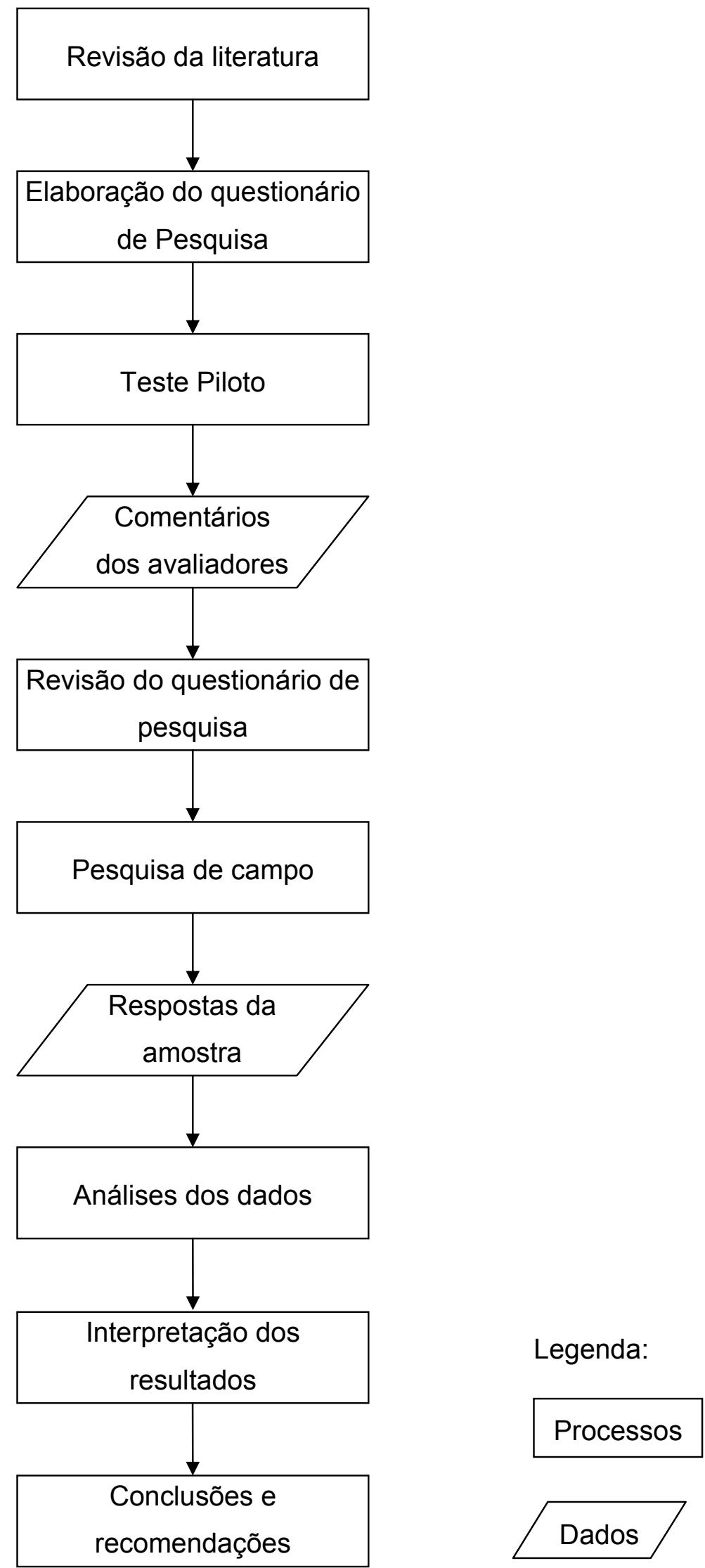

Figura 5 - Projeto de pesquisa 


\subsubsection{Elaboração do questionário de pesquisa}

Após a revisão da literatura descrita no capítulo 2, foi elaborado o questionário de pesquisa, onde se procurou atender às recomendações da literatura citada no capítulo anterior, quais sejam:

- Número de questões adequado ao escasso tempo disponível dos respondentes;

- Padronização das questões e dos dados coletados, viabilizada pelo uso do questionário web-based, possibilitando a análise estatística;

- Utilização de linguagem usual para os profissionais da área de gerenciamento de projetos.

Enquanto instrumento de pesquisa, o questionário procurou obter informações sobre as variáveis de pesquisa. Outras questões foram elaboradas visando possibilitar a caracterização da amostra e familiarização do pesquisador aos dados coletados, consistindo na análise descritiva citada no item 3.3.

Assim, foram elaboradas perguntas referentes a cada variável descrita no item 4.1. As questões elaboradas e as respectivas alternativas encontram-se abaixo:

- Variável: critério de seleção de projetos

Questão elaborada: Você considera que em sua empresa a seleção de projetos é feita de acordo com:

a) o desejo da Diretoria Executiva

b) o relacionamento com a estratégia organizacional

c) a vantagem comercial

d) critérios econômico-financeiros (ex: período de payback, taxa interna de retorno, valor atual líquido, etc.)

e) outro:

- Variáveis: estágio de maturidade para os domínios projeto, programa e portfólio

Questão elaborada: Para cada domínio definido pelo OPM3, qual é o estágio predominante na sua organização? Assinale um estágio para cada domínio: 
PROJETO

a) Padronização

b) Medição

c) Controle

d) Melhoria Contínua
PROGRAMA

a) Padronização

b) Medição

c) Controle

d) Melhoria Contínua
PORTFÓLIO

a) Padronização

b) Medição

c) Controle

d) Melhoria Contínua

- Variável: Avaliação da maturidade pelo OPM3

Questão elaborada: Sua empresa já utilizou o questionário de Auto-Avaliação proposto pelo OPM3 para verificação do nível de maturidade?
a) sim, uma vez
b) sim, duas vezes
c) sim, mais de duas vezes
d) não, nunca foi aplicado
e) não é de meu conhecimento

- Variável: formulação da estratégia organizacional

Questão elaborada: Em sua empresa existe um processo sistemático de formulação da estratégia empresarial?
a) $\operatorname{sim}$
b) não
c) não é de meu conhecimento

- Variável: decomposição da estratégia organizacional

Questão elaborada: Em sua empresa há uma decomposição da estratégia empresarial para os níveis tático e operacional?
a) $\operatorname{sim}$
b) não
c) não é de meu conhecimento

Destaca-se que, para as variáveis estágio de maturidade para os domínios projeto, programa e portfólio, o questionário apresentava, antecedendo à pergunta, a descrição sucinta dos estágios de melhorias de processos e dos domínios.

Cabe ainda ressalvar que todas as variáveis desta pesquisa, e por conseqüência todas as questões elaboradas, utilizam escala de medida nominal, resultando em dados do mesmo tipo. 
Assim, o instrumento de pesquisa submetido ao teste piloto encontra-se disponível no Apêndice B deste documento. Convém lembrar que, visando ampliar o tamanho da amostra a ser atingida, o questionário atendeu aos objetivos de uma pesquisa mais ampla. No citado apêndice estão sendo apresentadas apenas as questões que possuem relação direta com o objeto deste trabalho.

\subsubsection{Teste Piloto}

Em conformidade com a literatura apresentada no capítulo anterior, foi realizado o teste piloto do instrumento de pesquisa para o qual foram selecionadas 6 pessoas da rede de contatos do pesquisador, sendo 2 representantes dos colegas (pesquisadores), 2 profissionais especialistas em gerenciamento de projetos e 2 pessoas representando os respondentes. O convite aos profissionais foi feito através de e-mail específico, no qual se destacou em um parágrafo inicial que se tratava de um teste piloto. Também foi enviado, anexo ao e-mail, um texto sobre o objetivo da pesquisa, de modo a possibilitar a avaliação do questionário enquanto meio para se atingir os objetivos da pesquisa.

Visando agilizar e facilitar o envio e o recebimento dos dados, a solicitação de preenchimento do questionário foi enviada por e-mail aos avaliadores e o instrumento de pesquisa foi disponibilizado eletronicamente no endereço www.kuaitema.com.br/pesquisa/pesquisa.htm.

O questionário de pesquisa analisado pelos profissionais envolvidos no teste piloto, bem como o modelo do e-mail enviado aos avaliadores, encontram-se respectivamente nos Apêndices $\mathrm{B}$ e $\mathrm{C}$ deste documento.

Como resultado do teste piloto, três profissionais retornaram suas avaliações acerca do instrumento de pesquisa. Uma vez que cada um representava uma das categorias (pesquisador, especialista e respondente), as avaliações recebidas foram consideradas suficientes para a continuidade do trabalho.

Como resultado deste processo, foram obtidos como dados os "Comentários dos avaliadores", mencionados na Figura 5. Abaixo encontram-se alguns trechos dos comentários considerados relevantes para o trabalho: 
- "Entendo o conteúdo como muito acadêmico; não sei se você obterá resultados bons no mercado corporativo com esta linguagem. Acho que poderia ser mais direto e simples com as questões."

- 'O público para uma pesquisa como esta deve ser bem seleto: PMO's, Gerentes de Projetos Seniores, Gerentes de Programas; caso contrário, nem entenderão sobre o que esta sendo pesquisado."

- "Encontrei um problema: na pergunta sobre a utilização do OPM3, se a resposta for negativa vocês pedem para nos dirigirmos para a questão 9 , mas na verdade é a questão 10."

- "OPM3 é um conceito novo e muito pouco utilizado do Brasil."

- "Sua análise será pautada somente neste modelo (OPM3) e, sendo assim, penso que existem poucas empresas no Brasil que adotaram tal modelo."

- "O objetivo da pesquisa fala em eficácia. Como se sabe, eficácia está associada a resultados. E, por isso vai minha questão: você irá conseguir medir o resultado nas empresas que implementaram OPM3?"

A partir dos comentários recebidos, o questionário de pesquisa foi revisado, conforme é apresentado no item a seguir.

\subsubsection{Revisão do questionário de pesquisa}

Nesta etapa, os comentários foram agrupados e analisados conforme sua contribuição; em seguida, foram implementadas as alterações consideradas pertinentes no questionário de pesquisa. Abaixo seguem as contribuições e as respectivas alterações implementadas no questionário, quando consideradas aplicáveis:

Contribuição: existência de poucas organizações no Brasil que utilizaram o modelo OPM3® para verificação do nível de maturidade, limitando a amostra da pesquisa.

- Alteração no questionário: agrupamento das questões referentes à maturidade em gerenciamento de projetos no Bloco III, de modo a facilitar o preenchimento pelos respondentes pertencentes a organizações que não utilizaram o modelo OPM3 ${ }^{\circledR}$. 
Contribuição: utilização de linguagem acadêmica.

- Não foi implementada alteração, uma vez que o questionário serviria de instrumento de pesquisa com caráter acadêmico.

Contribuição: problema de direcionamento entre as questões.

- Alteração no questionário: alterado o texto para que o respondente que optasse pela resposta negativa se dirigisse à questão 10 .

Quanto à sugestão sobre o público da pesquisa constituir-se de PMO's (neste caso, remetendo aos Project Manager Officers, ou profissionais que atuam no EGP), Gerentes de Projetos Seniores e Gerentes de Programas, coincidiu com a unidade de observação da pesquisa, identificada anteriormente como sendo o profissional da área de gerenciamento de projetos.

Cabe ainda ressaltar que atenção particular foi dada ao comentário sobre a eficácia (resultado) nas empresas que implementaram o OPM $3 \circledR$ versus o objetivo da pesquisa. De fato, a utilização da palavra "eficácia" remeteria à medição dos resultados obtido pelas empresas que implementaram o modelo, o que, além de abranger um estudo complexo, não representava o real propósito deste pesquisador. Por estas razões, o objetivo do estudo foi reescrito e encontra-se no item 1.2.

O questionário revisado foi constituído conforme Tabela 4 abaixo e encontra-se, em sua versão final, no Apêndice $D$ do presente documento.

\begin{tabular}{|c|c|l|}
\hline Bloco & $\begin{array}{c}\text { Número de } \\
\text { Questões }\end{array}$ & \multicolumn{1}{|c|}{ Informações coletadas } \\
\hline I & 7 & $\begin{array}{l}\text { Caracterização do entrevistado (cargo e relação com a área } \\
\text { de gerenciamento de projetos) e da organização (origem do } \\
\text { capital, setor de atuação, número de funcionários e estrutura } \\
\text { organizacional predominante). }\end{array}$ \\
\hline II & 3 & $\begin{array}{l}\text { Caracterização do ambiente de gerência de projetos da } \\
\text { organização (importância, metodologia e seleção de } \\
\text { projetos. }\end{array}$ \\
\hline III & 8 & $\begin{array}{l}\text { Caracterização do processo de formulação e decomposição } \\
\text { da estratégia e avaliação da maturidade em gerenciamento } \\
\text { de projetos (estágio, avaliação pelo OPM®, prazo da última } \\
\text { avaliação e implementação das melhorias). }\end{array}$ \\
\hline
\end{tabular}


Após a revisão, o questionário de pesquisa foi disponibilizado no mesmo endereço eletrônico www.kuaitema.com.br/pesquisa/pesquisa.htm.

\subsubsection{Pesquisa de campo}

Após a revisão do questionário, iniciou-se a etapa de pesquisa de campo propriamente dita.

Para a seleção da amostra, Fink (1995c) cita entre os tipos de amostragens nãoprobabilísticas a amostragem por conveniência, na qual são selecionados os respondentes que estão prontos e disponíveis, e a amostragem snowball (bola de neve), na qual os membros da população indicam outros respondentes.

Para a pesquisa em questão, ambas as amostragens foram utilizadas. Na amostragem por conveniência, o e-mail solicitando o preenchimento do questionário foi enviado para 169 profissionais da área de gerenciamento de projetos da rede de contatos do pesquisador (o modelo de e-mail enviado aos respondentes encontra-se disponível no Apêndice E). Já na amostragem snowball, foram recebidas 64 respostas de e-mails redirecionados pelos respondentes da amostragem por conveniência, uma vez que esta solicitação estava contida no texto do e-mail enviado. Assim, a solicitação do preenchimento do questionário foi feita a 233 pessoas.

Entre os dias 30 de junho de 2006 e 02 de janeiro de 2007, foram recebidos 79 questionários, que constituíram a base "Respostas da amostra". Para limpeza da base, foram considerados como critérios de aceitação:

- Resposta única por respondente: para os respondentes que se identificaram, este item foi verificado através do nome e endereço de e-mail; para os demais respondentes, através do endereço IP. Assim, 1 questionário recebido não atendeu a este critério.

- Índice de questões respondidas superior a 75\%: para esta avaliação foram consideradas apenas as questões principais, ou seja, aquelas cujo preenchimento era obrigatório e que não estavam vinculadas a outra questão. Segundo este critério, todas as respostas recebidas foram consideradas válidas, conforme mostra a Figura 6. 


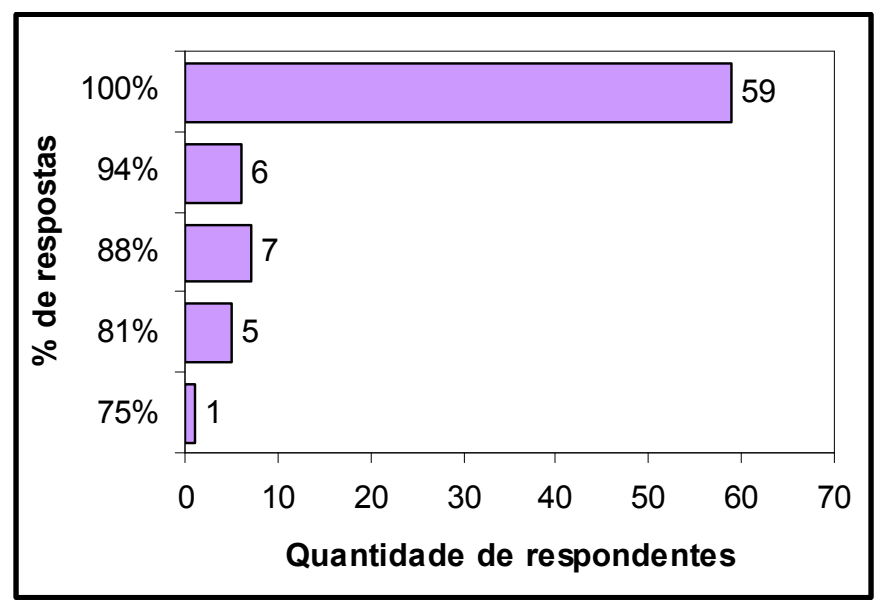

Figura 6 - Índice de questões principais respondidas

Portanto, após a limpeza a base "Respostas da amostra" contou com 78 respostas válidas. Assim, a taxa de retorno, ou seja, o percentual de respostas obtidas em relação ao número de solicitações de preenchimento do questionário feitas, foi de $33,5 \%$. Este índice foi considerado satisfatório, dado que a literatura considera razoável $30 \%$ de retorno para os questionários auto-administrados (SAUNDERS et al., 1997 apud ILIEVA; BARON; HEALEY, 2002).

O presente capítulo apresentou o modelo teórico da pesquisa e o projeto através do qual ela foi conduzida, detalhando as etapas de Elaboração do questionário de Pesquisa, Teste Piloto, Revisão do questionário de pesquisa e Pesquisa de campo. Os próximos capítulos apresentam as etapas seguintes do projeto de pesquisa: Análises dos dados, Interpretação dos resultados e Conclusões e recomendações. 


\section{ANÁLISES DOS DADOS}

No capítulo anterior, foram apresentados o modelo teórico da pesquisa e as etapas conduzidas até a obtenção da base "Respostas da amostra", com 78 respostas.

Neste capítulo, os dados coletados com a pesquisa de campo serão analisados estatisticamente. Em um primeiro item, será utilizada a análise descritiva para caracterizar o responde e a organização ao qual pertence no que tange a: tipo, origem do capital, setor de atuação, número de funcionários, estrutura organizacional, utilização de metodologia de gerenciamento de projetos e utilização do modelo OPM3® para avaliação do nível de maturidade. No item seguinte, serão apresentados os testes de hipóteses da pesquisa.

\subsection{Caracterização da amostra}

\subsubsection{Caracterização do respondente}

a) Quanto ao cargo ocupado na organização: 63\% dos respondentes ocupam cargo de Gerente, Supervisor ou Coordenador, conforme Figura 7.

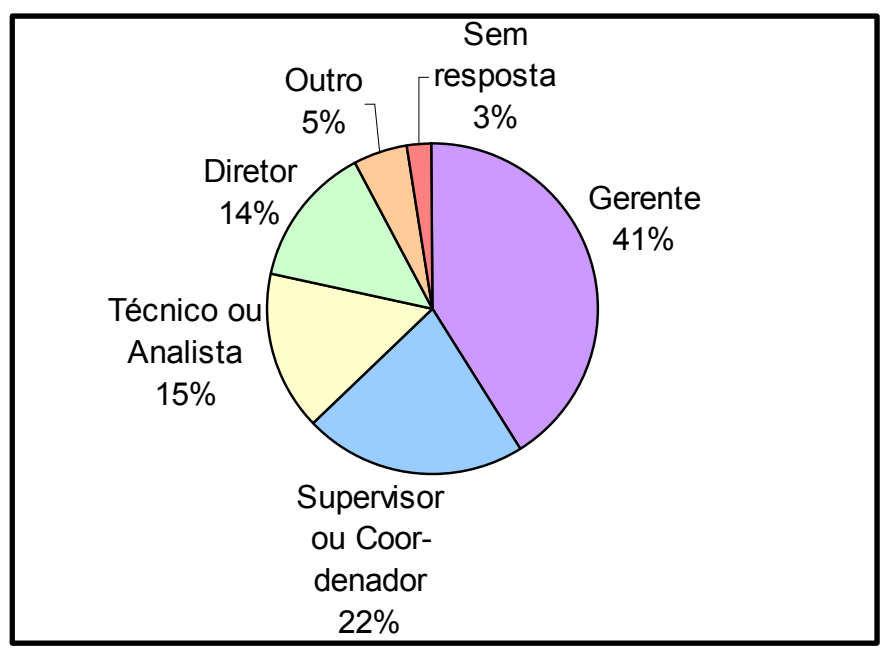

Figura 7 - Caracterização do respondente quanto ao cargo ocupado na organização 
b) Quanto ao grau de relação de suas atividades profissionais com a área de gerenciamento de projetos: $83 \%$ dos respondentes consideram que suas atividades profissionais estão relacionadas com a área de gerenciamento de projetos em grau muito alto ou alto. A distribuição percentual para as demais faixas é apresentada na Figura 8.

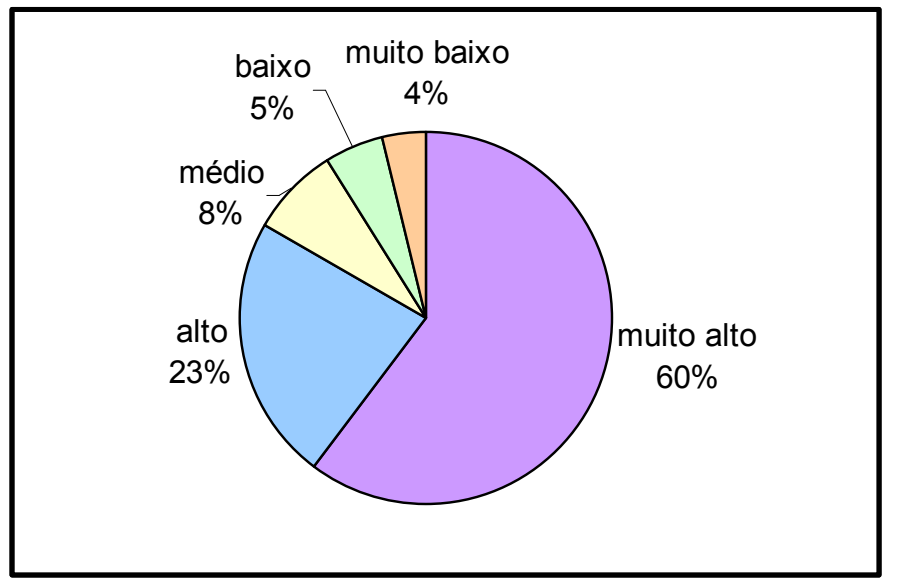

Figura 8 - Caracterização do respondente quanto ao grau de relação de suas atividades profissionais com a área de gerenciamento de projetos

\subsubsection{Caracterização da organização}

a) Quanto ao tipo: observou-se que $45 \%$ das organizações dos respondentes são parte de um grupo de empresas enquanto a maioria (55\% da amostra) refere-se a organizações independentes, conforme Figura 9.

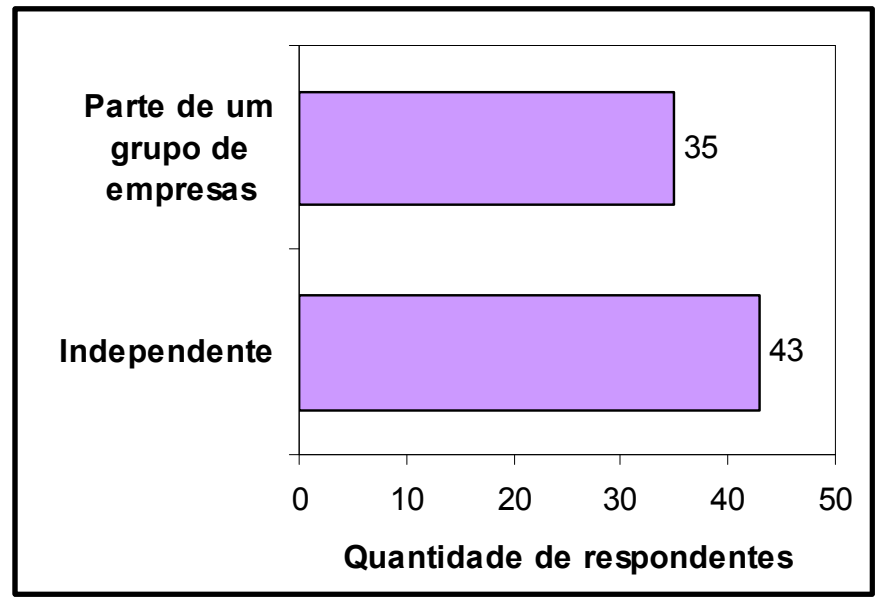

Figura 9 - Caracterização da organização quanto ao tipo 
b) Quanto à origem do capital: $85 \%$ das organizações dos respondentes são privadas, sendo $58 \%$ nacionais e $27 \%$ estrangeiras, conforme Figura 10.

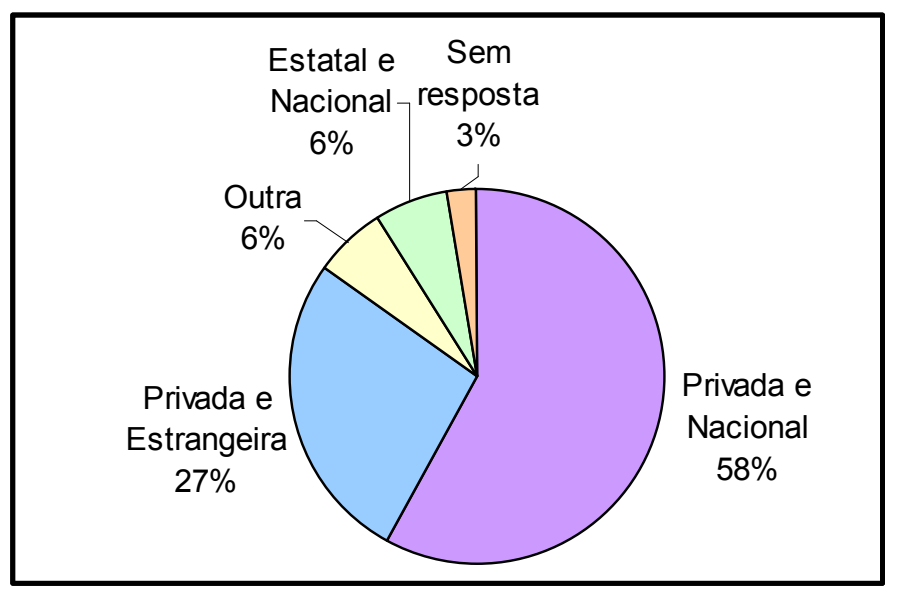

Figura 10 - Caracterização da organização quanto à origem do capital

c) Quanto ao setor de atuação: 62 (80\% da amostra) organizações dos respondentes atuam no setor de Serviços enquanto 15 (19\% da amostra) atuam na Indústria (Figura 11).

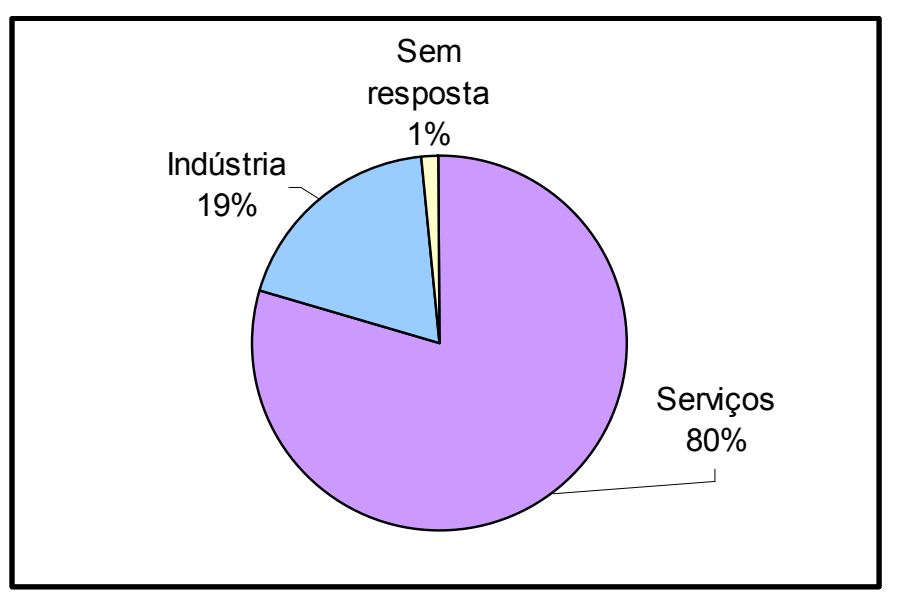

Figura 11 - Caracterização da organização quanto ao setor de atuação

d) Quanto ao número de funcionários: a maioria (49\% da amostra) das organizações dos respondentes possui mais de 500 funcionários. Também tiveram destaque as organizações com até 50 funcionários, representando $21 \%$ da amostra. A Figura 12 apresenta a distribuição percentual por faixas de quantidade de funcionários. 


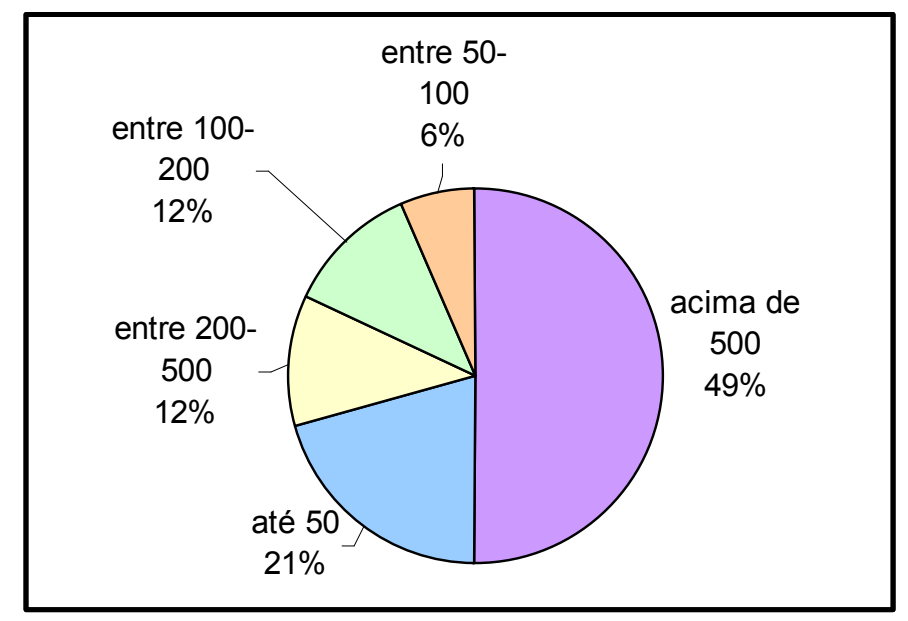

Figura 12 - Caracterização da organização quanto ao número de funcionários

e) Quanto à estrutura organizacional predominante: a maioria (36) dos respondentes, ou $47 \%$ da amostra, afirmou que a estrutura organizacional predominante em sua empresa é Funcional (hierárquica), enquanto 23 (29\% da amostra) afirmaram tratar-se de Projetizada.(orientada a projetos), conforme Figura 13.

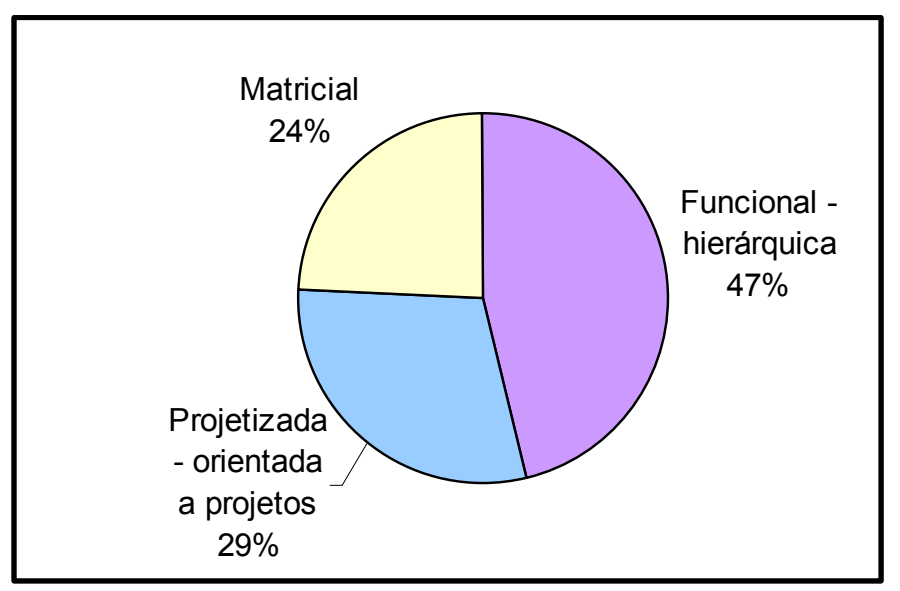

Figura 13 - Caracterização da organização quanto à estrutura organizacional predominante

\subsubsection{Caracterização da organização quanto ao gerenciamento de projetos}

a) Quanto ao grau de importância dado às técnicas modernas de gerenciamento de projetos: $63 \%$ dos respondentes consideram que a organização dá importância alta ou muito alta às técnicas modernas de gerenciamento de projetos, enquanto apenas 
$1 \%$ considera que seja muito baixa. A Figura 14 apresenta a distribuição percentual por faixas de importância dada às técnicas modernas de gerenciamento de projetos.

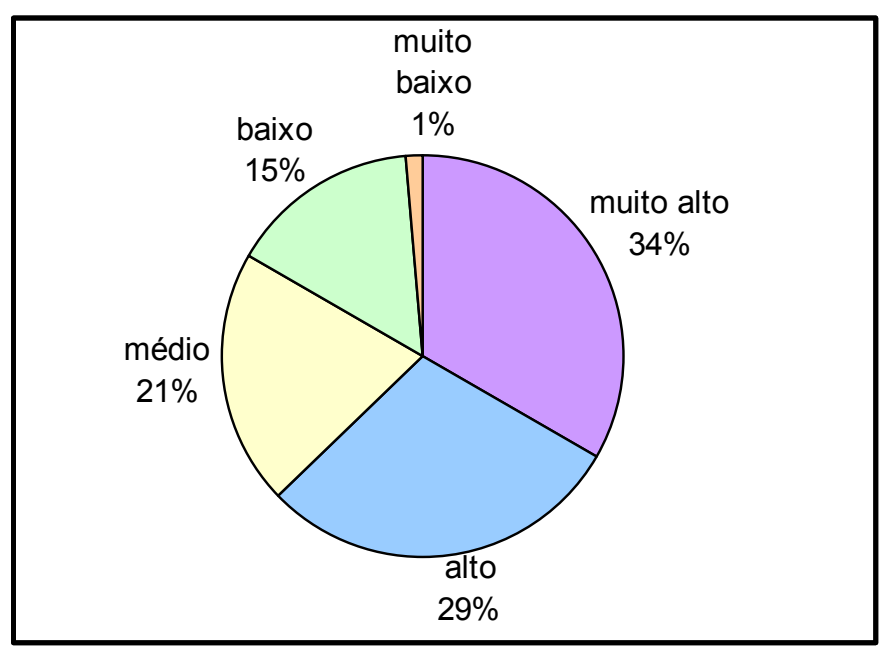

Figura 14 - Caracterização da organização quanto ao grau de importância dado às técnicas modernas de gerenciamento de projetos.

b) Quanto ao desenvolvimento e utilização de metodologia de gerenciamento de projetos aderente ao PMBoK®: a maioria dos respondentes $(79 \%)$ considera que sua organização desenvolveu e utiliza alguma metodologia de gerenciamento de projetos (Figura 15).

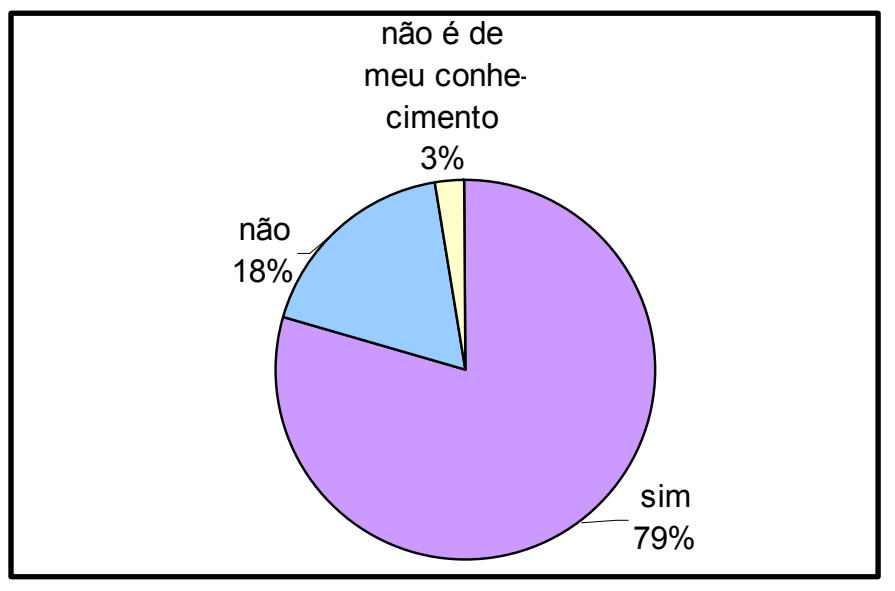

Figura 15 - Caracterização da organização quanto ao desenvolvimento e utilização de metodologia de gerenciamento de projetos

A maioria (56\%) dos respondentes considera que o grau de aderência dessa metodologia ao PMBoK® é alto ou muito alto, conforme Figura 16. 


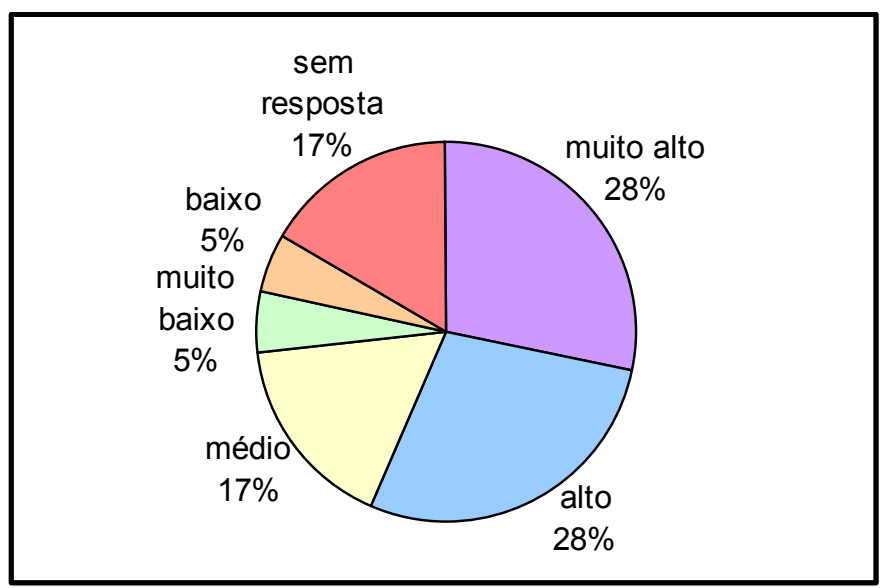

Figura 16 - Caracterização da organização quanto à aderência da metodologia de gerenciamento de projetos ao PMBoK

5.1.4 Caracterização da organização quanto à utilização do modelo OPM3® para avaliação do nível de maturidade

a) Quanto à utilização do questionário de Auto-Avaliação proposto pelo OPM3® para verificação do nível de maturidade: a maioria (49\%) dos respondentes afirmou que o questionário de Auto-Avaliação nunca foi aplicado, enquanto apenas $17 \%$ afirmaram que ele foi utilizado pelo menos uma vez (Figura 17).

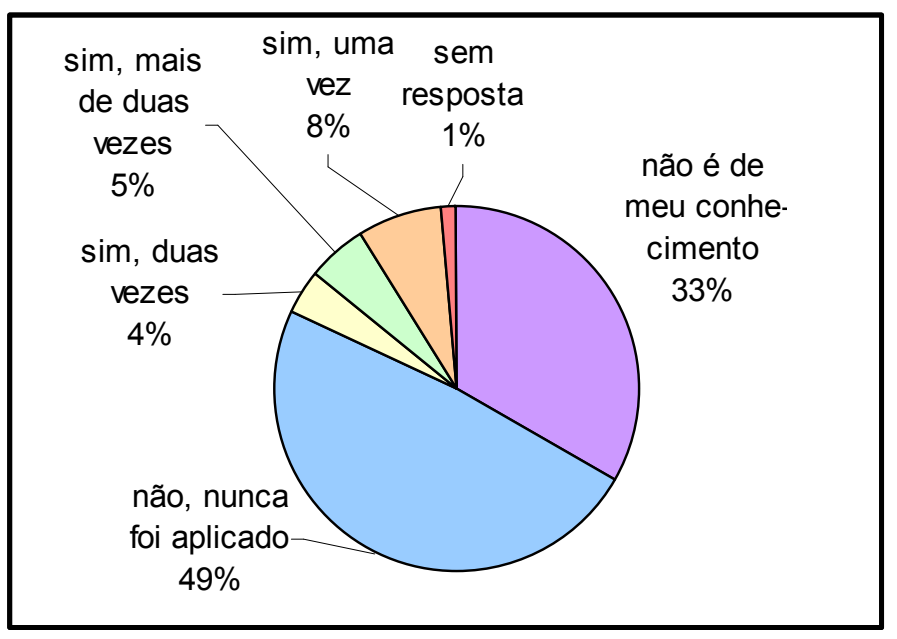

Figura 17 - Caracterização da organização quanto à utilização do questionário de Auto-Avaliação proposto pelo OPM3® para verificação do nível de maturidade 
b) Quanto ao tempo decorrido da última avaliação do nível de maturidade da organização pelo OPM3®: inicialmente observa-se que para esta análise foram obtidas apenas 19 respostas. Deste universo, na maioria (58\%) das organizações a avaliação ocorreu há menos de 1 ano, conforme apresenta a Figura 18.

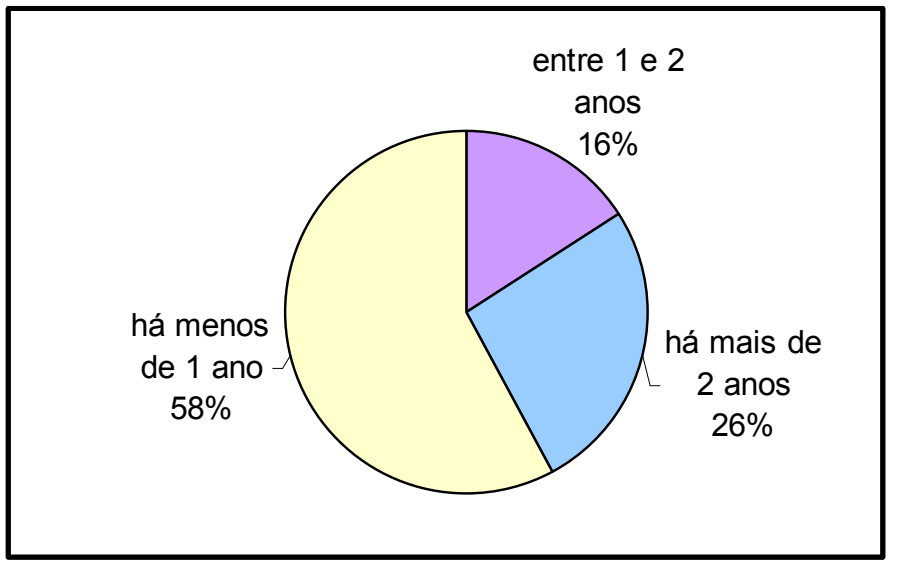

Figura 18 - Caracterização da organização quanto ao tempo decorrido da última avaliação do nível de maturidade da organização pelo OPM3®

c) Quanto à elaboração do Plano de Melhorias como parte da avaliação da empresa pelo modelo de maturidade OPM3ß: $51 \%$ da amostra, ou seja, 40 respondentes, não responderam a esta questão, sendo desconsiderados da análise. Dos respondentes, 18 (ou 48\% deste novo universo) afirmaram não ter conhecimento sobre o assunto, conforme detalha a Figura 19. Apenas 13 respondentes $(34 \%)$ afirmaram que o Plano de Melhorias foi elaborado.

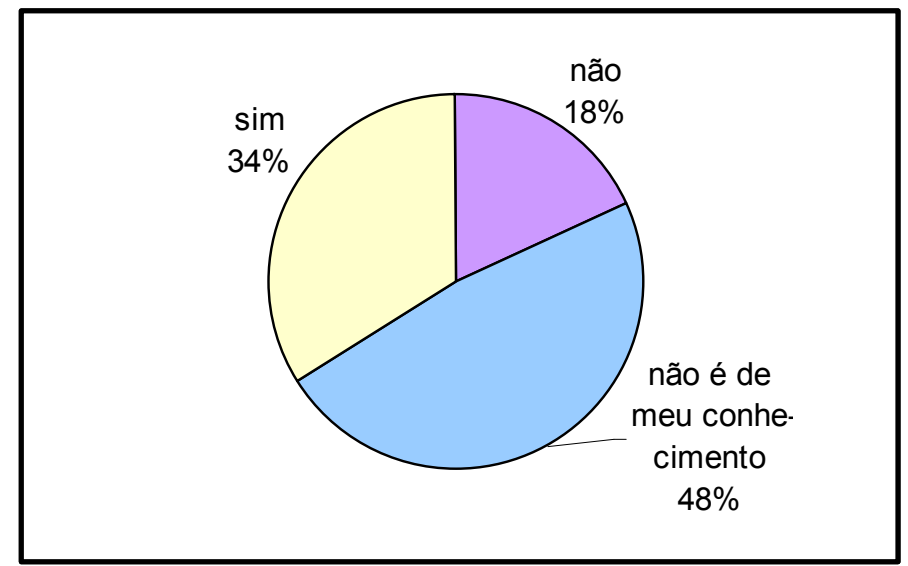

Figura 19 - Caracterização da organização quanto à elaboração do Plano de Melhorias como parte da avaliação da empresa pelo modelo de maturidade OPM3® 
d) Quanto à existência, no Plano de Melhorias elaborado após a Auto-Avaliação pelo modelo OPM3, de ação relacionada à identificação e seleção de projetos através do seu relacionamento com a estratégia empresarial (Melhor Prática 6180 - Seleção de Projetos de acordo com a Estratégia): 41 profissionais não responderam a esta questão. Dos 37 restantes, 54\% afirmaram não possuir conhecimento sobre o assunto, enquanto 24\% (9 respondentes) negaram a existência desta Melhor Prática no Plano de Melhorias, conforme Figura 20.

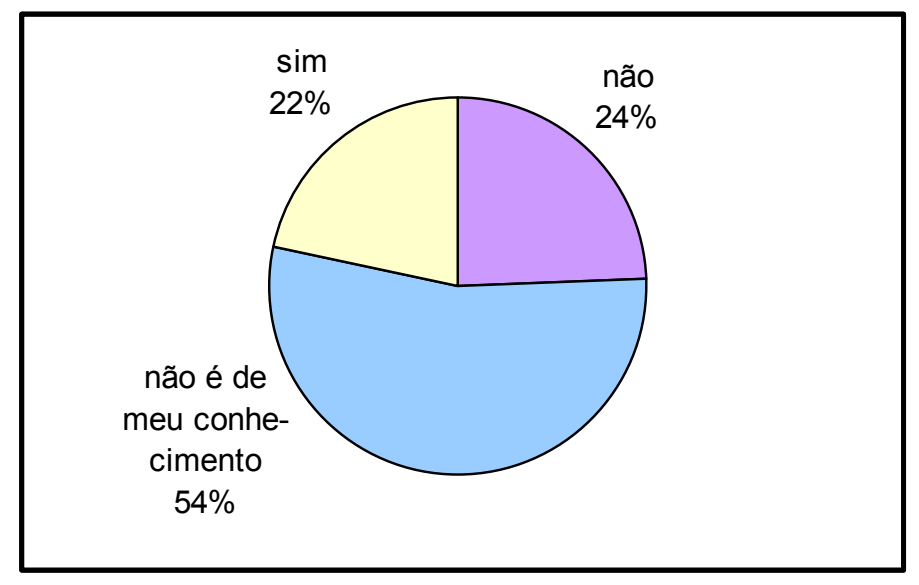

Figura 20 - Caracterização da organização quanto à existência de ação relacionada à identificação e seleção de projetos através do seu relacionamento com a estratégia empresarial

As principais dificuldades apontadas pelos respondentes para a implementação das melhorias foram, nesta ordem: as mudanças organizacionais necessárias, a resistência das pessoas e a alocação dos profissionais designados para as atividades do plano de melhorias em projetos.

e) Quanto ao aumento na quantidade de projetos selecionados de acordo com a estratégia após a aplicação do OPM $3 \circledR$ : dos 34 profissionais que responderam a esta questão, apenas $6(18 \%)$ afirmaram que houve aumento na quantidade de projetos selecionados de acordo com a estratégia (Figura 21). 


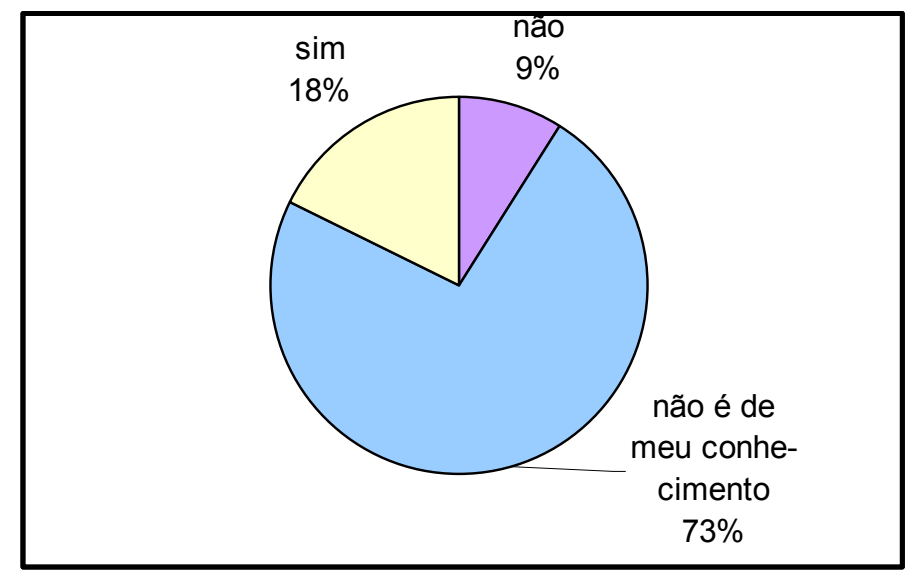

Figura 21 - Caracterização da organização quanto ao aumento na quantidade de projetos selecionados de acordo com a estratégia após a aplicação do OPM3®

Da análise apresentada neste capítulo, conclui-se que a maioria dos respondentes (unidades de observação) possui atividades profissionais relacionadas com a área de gerenciamento de projetos em grau muito alto ou alto e ocupa cargo de Gerente, Supervisor ou Coordenador.

Já para organização (unidade de análise), as descrições apresentadas encontram-se agrupadas abaixo:

- $55 \%$ são independentes;

- $85 \%$ são privadas;

- $80 \%$ atuam no setor de Serviços;

- 49\% possuem mais de 500 funcionários;

- $47 \%$ possuem estrutura organizacional predominante Funcional (hierárquica);

- $63 \%$ dão importância alta ou muito alta às técnicas modernas de gerenciamento de projetos;

- $79 \%$ desenvolveram e utilizam alguma metodologia de gerenciamento de projetos;

- $56 \%$ apresentam grau de aderência dessa metodologia ao PMBoK® alto ou muito alto;

- 49\% nunca aplicaram o questionário de Auto-Avaliação proposto pelo OPM3® para verificação do nível de maturidade. 


\subsection{Testes estatísticos das Hipóteses}

Este item apresenta os testes das hipóteses da pesquisa apresentadas no capítulo 1, quais sejam:

QP1: O nível de maturidade da organização contribui para a prática da seleção de projetos relacionados à estratégia organizacional?

H1.a: O critério de seleção de projetos é influenciado pelo estágio de maturidade predominante na organização para cada domínio definido pelo OPM3® (projeto, programa e portfólio).

H1.b: O critério de seleção de projetos é influenciado pela utilização do questionário de Auto-Avaliação proposto pelo $\mathrm{OPM}{ }^{\circledR}$ para verificação do nível de maturidade.

QP2: A existência, na organização, de processo de formulação da estratégia contribui para a prática da seleção de projetos relacionados à estratégia organizacional?

H2.a: O critério de seleção de projetos é influenciado pela existência de processo sistemático de formulação da estratégia empresarial.

H2.b: O critério de seleção de projetos é influenciado pela decomposição da estratégia empresarial nos níveis tático e operacional.

Uma vez que todas as variáveis da pesquisa originaram dados nominais, será utilizado o método qui-quadrado para análise estatística dos dados, dado que exista quantidade de observações suficiente, ou seja, sejam verificadas as condições apresentadas no capítulo 3: menos de $20 \%$ das células com freqüência esperada inferior a 5 e nenhuma célula com freqüência esperada menor do que 1. Cabe ainda lembrar que o teste qui-quadrado será utilizado como teste de independência, ou seja, em cada um dos itens 5.2.1 a 5.2.4 será testada a hipótese nula de que as duas variáveis da pesquisa em análise são independentes.

Como ferramenta de apoio para a análise estatística, será utilizado o software SPSS 14.0 for Windows (SPSS, 2005). 
5.2.1 Relação entre o estágio de maturidade predominante na organização para os domínios projeto, programa e portfólio e a prática da seleção de projetos de acordo com a estratégia organizacional

Teste relacionado à Hipótese H1.a: O critério de seleção de projetos é influenciado pelo estágio de maturidade predominante na organização para cada domínio definido pelo OPM3® (projeto, programa e portfólio).

Neste teste serão consideradas as seguintes variáveis e respectivas questões extraídas do instrumento de pesquisa:

- Variável dependente: critério de seleção de projetos

Questão elaborada: Você considera que em sua empresa a seleção de projetos é feita de acordo com:

a) o desejo da Diretoria Executiva

b) o relacionamento com a estratégia organizacional

c) a vantagem comercial

d) critérios econômico-financeiros (ex: período de payback, taxa interna de retorno, valor atual líquido, etc.)

e) outro:

- Variáveis independentes: estágio de maturidade para os domínios projeto, programa e portfólio

Questão elaborada: Para cada domínio definido pelo OPM3®, qual é o estágio predominante na sua organização? Assinale um estágio para cada domínio:

PROJETO

a) Padronização

b) Medição

c) Controle

d) Melhoria Contínua
PROGRAMA

a) Padronização

b) Medição

c) Controle

d) Melhoria Contínua
PORTFÓLIO

a) Padronização

b) Medição

c) Controle

d) Melhoria Contínua

A seguir serão realizadas análises estatísticas similares para os domínios projeto, programa e portfólio. 


\section{DOMÍNIO PROJETO}

Para estas questões foram obtidas 72 respostas, correspondendo a $92,3 \%$ do total de respostas válidas. A Tabela 5 apresenta a distribuição das respostas obtidas.

\begin{tabular}{|c|c|c|c|c|c|c|}
\hline & & \multicolumn{4}{|c|}{$\begin{array}{l}\text { Estágio de maturidade predominante na } \\
\text { organização para o domínio projeto }\end{array}$} & \multirow{2}{*}{ Total } \\
\hline & & $\begin{array}{l}\text { a) Padro- } \\
\text { nização }\end{array}$ & $\begin{array}{c}\text { b) } \\
\text { Medição }\end{array}$ & c) Controle & $\begin{array}{l}\text { d) Melhoria } \\
\text { Contínua }\end{array}$ & \\
\hline \multirow{4}{*}{$\begin{array}{l}\text { Critério de } \\
\text { seleção de } \\
\text { projetos }\end{array}$} & Relacionamento & 7 & 1 & 7 & 10 & 25 \\
\hline & organizacional & $10 \%$ & $1 \%$ & $10 \%$ & $14 \%$ & $35 \%$ \\
\hline & Outros critérios & 19 & 5 & 11 & 12 & 47 \\
\hline & & $26 \%$ & $7 \%$ & $15 \%$ & $17 \%$ & $65 \%$ \\
\hline \multirow{2}{*}{ Total } & & 26 & 6 & 18 & 22 & 72 \\
\hline & & $36 \%$ & $8 \%$ & $25 \%$ & $31 \%$ & $100 \%$ \\
\hline
\end{tabular}

A Tabela 6 apresenta os dados obtidos a partir da análise estatística.

\begin{tabular}{l|r|}
\hline Qui-quadrado de Pearson* & 2,817 \\
\hline Graus de liberdade & 3 \\
\hline$p$-value & 0,421 \\
\hline Número de casos válidos & 72 \\
\hline `2 células (25\%) possuem valor \\
esperado inferior a 5. \\
O valor mínimo esperado é 2,08.
\end{tabular}

Tabela 6 - Teste qui-quadrado para o Critério de seleção de projetos x Estágio de maturidade predominante na organização para o domínio projeto

Fonte: Autor / SPSS

Verifica-se, a partir análise dos dados da Tabela 6, que as condições necessárias para a aplicação do teste qui-quadrado não foram satisfeitas, uma vez que mais de $20 \%$ das células tiveram freqüência esperada inferior a 5.

Visando contornar esta limitação, foi proposto o agrupamento dos dados referentes à variável "Estágio de maturidade predominante na organização para o domínio projeto” em dois grupos: “a) Padronização ou b) Medição” e “c) Controle ou 
d) Melhoria Contínua", conforme apresentado na Tabela 7.

\begin{tabular}{|c|c|c|c|c|}
\hline & & \multicolumn{2}{|c|}{$\begin{array}{l}\text { Estágio de maturidade } \\
\text { predominante na organização } \\
\text { para o domínio projeto }\end{array}$} & \multirow{2}{*}{ Total } \\
\hline & & $\begin{array}{l}\text { a) Padro- } \\
\text { nização ou b) } \\
\text { Medição }\end{array}$ & $\begin{array}{l}\text { c) Controle ou } \\
\text { d) Melhoria } \\
\text { Contínua }\end{array}$ & \\
\hline \multirow{4}{*}{$\begin{array}{l}\text { Critério de } \\
\text { seleção de } \\
\text { projetos }\end{array}$} & Relacionamento & 8 & 17 & 25 \\
\hline & organizacional & $11 \%$ & $24 \%$ & $35 \%$ \\
\hline & & 24 & 23 & 47 \\
\hline & Gutios cinemins & $33 \%$ & $32 \%$ & $65 \%$ \\
\hline \multirow{2}{*}{ Total } & & 32 & 40 & 72 \\
\hline & & $44 \%$ & $56 \%$ & $100 \%$ \\
\hline
\end{tabular}

Tabela 7 - Tabela de contingência para Critério de seleção de projetos $x$ Estágio de maturidade predominante na organização para o domínio projeto (agrupamento A)

Fonte: Autor / SPSS

A Tabela 8 apresenta os dados obtidos a partir da análise estatística.

\begin{tabular}{|c|c|}
\hline Qui-quadrado de Pearson* & 2,402 \\
\hline Graus de liberdade & 1 \\
\hline$p$-value & 0,121 \\
\hline Número de casos válidos & 72 \\
\hline
\end{tabular}

Tabela 8 - Teste qui-quadrado para o Critério de seleção de projetos x Estágio de maturidade predominante na organização para o domínio projeto (agrupamento A)

Fonte: Autor / SPSS

A partir dos dados agrupados, os critérios de aplicação do teste qui-quadrado foram atendidos, com menos de $20 \%$ das células apresentando valor esperado inferior a 5 e com o valor mínimo esperado superior a 1 . O p-value obtido $(0,121$ ou $12,1 \%)$ superou o valor de $\alpha$ adotado (5\%), sustentando-se a hipótese nula, ou seja, as variáveis Critério de seleção de projetos e Estágio de maturidade predominante na organização para o domínio projeto são independentes. Assim, a hipótese formulada para a pesquisa H1.a (o critério de seleção de projetos é influenciado pelo estágio de maturidade predominante na organização para o domínio projeto) deve ser rejeitada. 
DOMÍNIO PROGRAMA

Foram obtidas 65 respostas, correspondendo a 83,3\% das respostas da base "Respostas da amostra". A tabela de contingência para a análise em questão encontra-se na Tabela 9.

\begin{tabular}{|c|c|c|c|c|c|c|}
\hline & & \multicolumn{4}{|c|}{$\begin{array}{l}\text { Estágio de maturidade predominante na } \\
\text { organização para o domínio programa }\end{array}$} & \multirow{2}{*}{ Total } \\
\hline & & $\begin{array}{l}\text { a) Padro- } \\
\text { nização }\end{array}$ & b) Medição & c) Controle & $\begin{array}{l}\text { d) Melhoria } \\
\text { Contínua }\end{array}$ & \\
\hline \multirow{4}{*}{$\begin{array}{l}\text { Critério de } \\
\text { seleção de } \\
\text { projetos }\end{array}$} & Relacionamento & 5 & 3 & 8 & 6 & 22 \\
\hline & organizacional & $8 \%$ & $5 \%$ & $12 \%$ & $9 \%$ & $34 \%$ \\
\hline & & 21 & 8 & 7 & 7 & 43 \\
\hline & Uutros criterios & $32 \%$ & $12 \%$ & $11 \%$ & $11 \%$ & $66 \%$ \\
\hline \multirow{2}{*}{ Total } & & 26 & 11 & 15 & 13 & 65 \\
\hline & & $40 \%$ & $17 \%$ & $23 \%$ & $20 \%$ & $100 \%$ \\
\hline
\end{tabular}

Tabela 9 - Tabela de contingência para Critério de seleção de projetos $x$ Estágio de maturidade predominante na organização para o domínio programa Fonte: Autor / SPSS

A Tabela 10 apresenta o resultado do teste qui-quadrado aplicado.

\begin{tabular}{|l|r|}
\hline Qui-quadrado de Pearson* & 6,116 \\
\hline Graus de liberdade & 3 \\
\hline$p$-value & 0,106 \\
\hline Número de casos válidos & 65 \\
\hline *2 células (25\%) possuem valor \\
esperado inferior a 5. \\
O valor mínimo esperado é 3,72.
\end{tabular}

Tabela 10 - Teste qui-quadrado para o Critério de seleção de projetos x Estágio de maturidade predominante na organização para o domínio programa Fonte: Autor / SPSS

Da análise da Tabela 10, observa-se que as condições necessárias para a aplicação do teste qui-quadrado não foram satisfeitas, uma vez que mais de $20 \%$ das células possuem freqüência esperada inferior a 5 . Novamente o agrupamento de dados se fez necessário e está demonstrado na Tabela 11. 


\begin{tabular}{|c|c|c|c|c|}
\hline & & \multicolumn{2}{|c|}{$\begin{array}{l}\text { Estágio de maturidade } \\
\text { predominante na organização } \\
\text { para o domínio programa }\end{array}$} & \multirow{2}{*}{ Total } \\
\hline & & $\begin{array}{l}\text { a) Padro- } \\
\text { nização ou b) } \\
\text { Medição }\end{array}$ & $\begin{array}{l}\text { c) Controle ou } \\
\text { d) Melhoria } \\
\text { Contínua }\end{array}$ & \\
\hline \multirow{4}{*}{$\begin{array}{l}\text { Critério de } \\
\text { seleção de } \\
\text { projetos }\end{array}$} & $\begin{array}{l}\text { Relacionamento } \\
\text { com a estratégia }\end{array}$ & 8 & 14 & 22 \\
\hline & organizacional & $12 \%$ & $22 \%$ & $34 \%$ \\
\hline & & 29 & 14 & 43 \\
\hline & Uutros criterios & $45 \%$ & $22 \%$ & $66 \%$ \\
\hline \multirow{2}{*}{ Total } & & 37 & 28 & 65 \\
\hline & & $57 \%$ & $43 \%$ & $100 \%$ \\
\hline
\end{tabular}

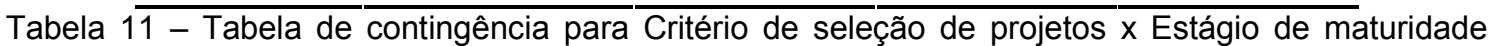
predominante na organização para o domínio programa (agrupamento A)

Fonte: Autor / SPSS

O resultado do teste qui-quadrado encontra-se na Tabela 12.

\begin{tabular}{l|r|}
\hline Qui-quadrado de Pearson* & 5,733 \\
\hline Graus de liberdade & 1 \\
\hline$p$-value & 0,017 \\
\hline Número de casos válidos & 65 \\
\hline $\begin{array}{l}\text { *0 células (0\%) possuem valor } \\
\text { esperado inferior a 5. } \\
\text { O valor mínimo esperado é 9,48. }\end{array}$
\end{tabular}

Tabela 12 - Teste qui-quadrado para o Critério de seleção de projetos x Estágio de maturidade predominante na organização para o domínio programa (agrupamento A)

Fonte: Autor / SPSS

Após o agrupamento dos dados, os critérios de aplicação do teste qui-quadrado foram atendidos. Como o p-value obtido $(0,017$ ou 1,7\%) é inferior ao valor de $\alpha$ adotado (5\%), a hipótese nula deve ser rejeitada, ou seja, as variáveis Critério de seleção de projetos e Estágio de maturidade predominante na organização para o domínio programa são dependentes. Assim, confirma-se a hipótese formulada para a pesquisa H1.a (o critério de seleção de projetos é influenciado pelo estágio de maturidade predominante na organização para o domínio programa). 


\section{DOMÍNIO PORTFÓLIO}

Foram obtidas 64 respostas, correspondendo a $82,1 \%$ das respostas válidas. A tabela de contingência para a análise em questão encontra-se na Tabela 13.

\begin{tabular}{|c|c|c|c|c|c|c|}
\hline & & \multicolumn{4}{|c|}{$\begin{array}{l}\text { Estágio de maturidade predominante na } \\
\text { organização para o domínio portfólio }\end{array}$} & \multirow{2}{*}{ Total } \\
\hline & & $\begin{array}{l}\text { a) Padro- } \\
\text { nização }\end{array}$ & b) Medição & c) Controle & $\begin{array}{l}\text { d) Melhoria } \\
\text { Contínua }\end{array}$ & \\
\hline \multirow{4}{*}{$\begin{array}{l}\text { Critério de } \\
\text { seleção de } \\
\text { projetos }\end{array}$} & $\begin{array}{l}\text { Relacionamento } \\
\text { com a estratégia }\end{array}$ & 10 & 4 & 4 & 4 & 22 \\
\hline & organizacional & $16 \%$ & $6 \%$ & $6 \%$ & $6 \%$ & $34 \%$ \\
\hline & \multirow{2}{*}{ Outros critérios } & 20 & 7 & 5 & 10 & 42 \\
\hline & & $31 \%$ & $11 \%$ & $8 \%$ & $16 \%$ & $66 \%$ \\
\hline \multirow{2}{*}{ Total } & & 30 & 11 & 9 & 14 & 64 \\
\hline & & $47 \%$ & $17 \%$ & $14 \%$ & $22 \%$ & $100 \%$ \\
\hline
\end{tabular}

Tabela 13 - Tabela de contingência para Critério de seleção de projetos $x$ Estágio de maturidade predominante na organização para o domínio portfólio

Fonte: Autor / SPSS

Na Tabela 14 podem ser observados os resultados do teste qui-quadrado.

\begin{tabular}{l|r|}
\hline Qui-quadrado de Pearson* & 0,647 \\
\hline Graus de liberdade & 3 \\
\hline$p$-value & 0,886 \\
\hline Número de casos válidos & 64 \\
\hline *3 células (37,5\%) possuem valor \\
esperado inferior a 5. \\
O valor mínimo esperado é 3,09.
\end{tabular}

Tabela 14 - Teste qui-quadrado para o Critério de seleção de projetos x Estágio de maturidade predominante na organização para o domínio portfólio

Fonte: Autor / SPSS

Verifica-se, a partir da análise da Tabela 14, que as condições necessárias para a aplicação do teste qui-quadrado não foram satisfeitas, uma vez que mais de $20 \%$ das células possuem freqüência esperada inferior a 5 . O agrupamento de dados foi utilizado visando contornar esta restrição, e encontra-se na Tabela 15. 


\begin{tabular}{|c|c|c|c|c|}
\hline & & \multicolumn{2}{|c|}{$\begin{array}{l}\text { Estágio de maturidade } \\
\text { predominante na organização } \\
\text { para o domínio portfólio }\end{array}$} & \multirow{2}{*}{ Total } \\
\hline & & $\begin{array}{l}\text { a) Padro- } \\
\text { nização ou b) } \\
\text { Medição }\end{array}$ & $\begin{array}{l}\text { c) Controle ou } \\
\text { d) Melhoria } \\
\text { Contínua }\end{array}$ & \\
\hline \multirow{4}{*}{$\begin{array}{l}\text { Critério de } \\
\text { seleção de } \\
\text { projetos }\end{array}$} & $\begin{array}{l}\text { Relacionamento } \\
\text { com a estratégia }\end{array}$ & 14 & 8 & 22 \\
\hline & organizacional & $22 \%$ & $13 \%$ & $34 \%$ \\
\hline & O & 27 & 15 & 42 \\
\hline & vutios ctiterios & $42 \%$ & $23 \%$ & $66 \%$ \\
\hline \multirow{2}{*}{ Total } & & 41 & 23 & 64 \\
\hline & & $64 \%$ & $36 \%$ & $100 \%$ \\
\hline
\end{tabular}

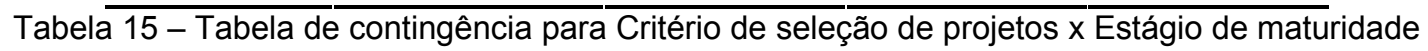
predominante na organização para o domínio portfólio (agrupamento A) Fonte: Autor / SPSS

A Tabela 16 apresenta os resultados do teste após o agrupamento dos dados.

\begin{tabular}{|l|r|}
\hline Qui-quadrado de Pearson* & 0,003 \\
\hline Graus de liberdade & 1 \\
\hline$p$-value & 0,959 \\
\hline Número de casos válidos & 64 \\
\hline${ }^{*} 0 \quad$ células (0\%) possuem valor \\
esperado inferior a 5. \\
O valor mínimo esperado é 7,91.
\end{tabular}

Tabela 16 - Teste qui-quadrado para o Critério de seleção de projetos x Estágio de maturidade predominante na organização para o domínio portfólio (agrupamento A)

Fonte: Autor / SPSS

Da Tabela 16, observa-se que os critérios de aplicação do teste qui-quadrado foram atendidos. O p-value obtido (0,959 ou $95,9 \%)$ superou o valor de $\alpha$ adotado (5\%), sustentando-se a hipótese nula, ou seja, as variáveis Critério de seleção de projetos e Estágio de maturidade predominante na organização para o domínio portfólio são independentes. Assim, a hipótese formulada para a pesquisa H1.a (o critério de seleção de projetos é influenciado pelo estágio de maturidade predominante na organização para o domínio portfólio) deve ser rejeitada. 
5.2.2 Relação entre utilização do modelo $O P M 3 ®$ para avaliação do nível de maturidade da organização e a prática da seleção de projetos de acordo com a estratégia organizacional

Teste relacionado à Hipótese H1.b: O critério de seleção de projetos é influenciado pela utilização do questionário de Auto-Avaliação proposto pelo OPM3® para verificação do nível de maturidade.

Para esta análise serão utilizadas duas variáveis de pesquisa e respectivas perguntas do instrumento de pesquisa transcritas abaixo:

- Variável dependente: critério de seleção de projetos

Questão elaborada: Você considera que em sua empresa a seleção de projetos é feita de acordo com:

a) o desejo da Diretoria Executiva

b) o relacionamento com a estratégia organizacional

c) a vantagem comercial

d) critérios econômico-financeiros (ex: período de payback, taxa interna de retorno, valor atual líquido, etc.)

e) outro:

- Variável independente: Avaliação da maturidade pelo OPM3

Questão elaborada: Sua empresa já utilizou o questionário de Auto-Avaliação proposto pelo OPM3 para verificação do nível de maturidade?
a) sim, uma vez
b) sim, duas vezes
c) sim, mais de duas vezes
d) não, nunca foi aplicado
e) não é de meu conhecimento

A Tabela 17 abaixo apresenta a tabulação dos dados obtidos analisando-se conjuntamente as variáveis. Para esta análise, foram obtidas 77 respostas, correspondendo a $98,7 \%$ da base "Respostas da amostra". 


\begin{tabular}{|c|c|c|c|c|c|c|c|}
\hline & & \multicolumn{5}{|c|}{ Avaliação da maturidade pelo OPM $3 \AA$} & \multirow{2}{*}{ Total } \\
\hline & & $\begin{array}{l}\text { a) sim, } \\
\text { uma vez }\end{array}$ & $\begin{array}{l}\text { b) sim, } \\
\text { duas } \\
\text { vezes }\end{array}$ & $\begin{array}{l}\text { c) sim, } \\
\text { mais de } \\
\text { duas } \\
\text { vezes }\end{array}$ & $\begin{array}{l}\text { d) não, } \\
\text { nunca foi } \\
\text { aplicado }\end{array}$ & $\begin{array}{l}\text { e) não é de } \\
\text { meu conhe- } \\
\text { cimento }\end{array}$ & \\
\hline \multirow{4}{*}{$\begin{array}{l}\text { Critério de } \\
\text { seleção de } \\
\text { projetos }\end{array}$} & Relacionamento & 3 & 3 & 2 & 13 & 5 & 26 \\
\hline & organizacional & $4 \%$ & $4 \%$ & $3 \%$ & $17 \%$ & $6 \%$ & $34 \%$ \\
\hline & \multirow{2}{*}{ Outros critérios } & 3 & 0 & 2 & 25 & 21 & 51 \\
\hline & & $4 \%$ & $0 \%$ & $3 \%$ & $32 \%$ & $27 \%$ & $66 \%$ \\
\hline \multirow{2}{*}{ Total } & & 6 & 3 & 4 & 38 & 26 & 77 \\
\hline & & $8 \%$ & $4 \%$ & $5 \%$ & $49 \%$ & $34 \%$ & $100 \%$ \\
\hline
\end{tabular}

Tabela 17 - Tabela de contingência para Critério de seleção de projetos x Avaliação da maturidade pelo OPM3®

Fonte: Autor / SPSS

A Tabela 18 apresenta a análise estatística realizada.

\begin{tabular}{|c|c|}
\hline Qui-quadrado de Pearson* & 9,523 \\
\hline Graus de liberdade & 4 \\
\hline$p$-value & 0,049 \\
\hline Número de casos válidos & 77 \\
\hline
\end{tabular}

Tabela 18 - Teste qui-quadrado para o Critério de seleção de projetos x Avaliação da maturidade pelo OPM3®

Fonte: Autor / SPSS

Da análise dos dados da Tabela 18, inicialmente observa-se que as condições necessárias para a aplicação do teste qui-quadrado não foram satisfeitas, uma vez que mais de $20 \%$ das células apresentam freqüência esperada inferior a 5 , apontando a necessidade do agrupamento dos dados.

Assim, foi considerado o agrupamento das respostas relacionadas à variável Avaliação da maturidade pelo OPM3®. Conforme apresentado na Tabela 19, as respostas "a) sim, uma vez", "b) sim, duas vezes" e "c) sim, mais de duas vezes" foram consideradas como uma única categoria, intitulada "sim". 


\begin{tabular}{|c|c|c|c|c|c|}
\hline & & \multicolumn{3}{|c|}{$\begin{array}{c}\text { Avaliação da maturidade pelo } \\
\text { OPM3 } \AA\end{array}$} & \multirow{2}{*}{ Total } \\
\hline & & Sim & Não & $\begin{array}{l}\text { Não é de } \\
\text { meu conhe- } \\
\text { cimento }\end{array}$ & \\
\hline \multirow{4}{*}{$\begin{array}{l}\text { Critério de } \\
\text { seleção de } \\
\text { projetos }\end{array}$} & $\begin{array}{l}\text { Relacionamento } \\
\text { com a estratégia }\end{array}$ & 8 & 13 & 5 & 26 \\
\hline & organizacional & $10 \%$ & $17 \%$ & $6 \%$ & $34 \%$ \\
\hline & utros oritórios & 5 & 25 & 21 & 51 \\
\hline & & $6 \%$ & $32 \%$ & $27 \%$ & $66 \%$ \\
\hline \multirow{2}{*}{ Total } & & 13 & 38 & 26 & 77 \\
\hline & & $17 \%$ & $49 \%$ & $34 \%$ & $100 \%$ \\
\hline
\end{tabular}

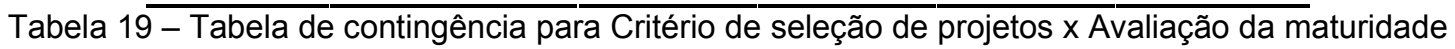
pelo OPM3® (agrupamento A)

Fonte: Autor / SPSS

A Tabela 20 apresenta o resultado do teste estatístico.

\begin{tabular}{l|r|}
\hline Qui-quadrado de Pearson* & 6,943 \\
\hline Graus de liberdade & 2 \\
\hline$p$-value & 0,031 \\
\hline Número de casos válidos & 77 \\
\hline *1 célula (16,7\%) possui valor \\
esperado inferior a 5. \\
O valor mínimo esperado é 4,39.
\end{tabular}

Tabela 20 - Teste qui-quadrado para o Critério de seleção de projetos x Avaliação da maturidade pelo OPM3® (agrupamento $A$ )

Fonte: Autor / SPSS

Da análise da Tabela 20, observa-se que foram cumpridos os pré-requisitos para a aplicação do teste qui-quadrado, a saber, valor mínimo esperado superior a 1 e menos de $20 \%$ das células com valor esperado inferior a 5.

A Tabela 20 apresenta ainda o valor de $p$-value $=0,031$. Ou seja, para $\alpha=5 \%$, obtevese $p$-value $<\alpha$, significando que a hipótese nula deve ser rejeitada, ou seja, não se sustenta a independência entre as variáveis Avaliação da maturidade pelo OPM3® e Critério de seleção de projetos. Assim, confirma-se a hipótese formulada para a pesquisa H1.b (o critério de seleção de projetos é influenciado pela utilização do questionário de Auto-Avaliação proposto pelo $O P M 3 \circledR$ para verificação do nível de maturidade). 
5.2.3 Relação entre a existência de processo de formulação da estratégia e a prática da seleção de projetos de acordo com a estratégia organizacional

Teste relacionado à Hipótese H2.a: O critério de seleção de projetos é influenciado pela existência de processo sistemático de formulação da estratégia empresarial.

Para estas questões serão utilizadas as variáveis de pesquisa critério de seleção de projetos e formulação da estratégia organizacional. As questões do instrumento de pesquisa relacionadas às mesmas foram transcritas a seguir:

- Variável dependente: critério de seleção de projetos

Questão elaborada: Você considera que em sua empresa a seleção de projetos é feita de acordo com:

a) o desejo da Diretoria Executiva

b) o relacionamento com a estratégia organizacional

c) a vantagem comercial

d) critérios econômico-financeiros (ex: período de payback, taxa interna de retorno, valor atual líquido, etc.)

e) outro:

- Variável independente: formulação da estratégia organizacional

Questão elaborada: Em sua empresa existe um processo sistemático de formulação da estratégia empresarial?
a) $\operatorname{sim}$
b) não
c) não é de meu conhecimento

Para estas questões, foram obtidas 78 respostas, ou seja, 100\% das respostas contidas na base "Respostas da amostra", distribuídas conforme a Tabela 21. 


\begin{tabular}{|c|c|c|c|c|c|}
\hline & & \multicolumn{3}{|c|}{$\begin{array}{c}\text { Existência de processo sistemático } \\
\text { de formulação da estratégia } \\
\text { empresarial }\end{array}$} & \multirow{2}{*}{ Total } \\
\hline & & a) $\operatorname{sim}$ & b) não & $\begin{array}{c}\text { c) não é de } \\
\text { meu } \\
\text { conhecimento }\end{array}$ & \\
\hline \multirow{4}{*}{$\begin{array}{l}\text { Critério de } \\
\text { seleção de } \\
\text { projetos }\end{array}$} & Relacionamento & 22 & 2 & 2 & 26 \\
\hline & $\begin{array}{l}\text { com a estrategla } \\
\text { organizacional }\end{array}$ & $28 \%$ & $3 \%$ & $3 \%$ & $33 \%$ \\
\hline & & 31 & 13 & 8 & 52 \\
\hline & Uutros criterios & $40 \%$ & $17 \%$ & $10 \%$ & $67 \%$ \\
\hline \multirow{2}{*}{ Total } & & 53 & 15 & 10 & 78 \\
\hline & & $68 \%$ & $19 \%$ & $13 \%$ & $100 \%$ \\
\hline
\end{tabular}

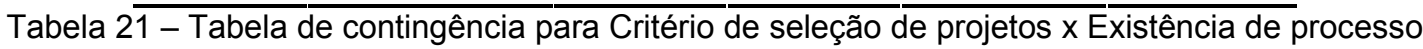
sistemático de formulação da estratégia empresarial

Fonte: Autor / SPSS

O teste de hipótese da Tabela 21 encontra-se na Tabela 22 abaixo:

\begin{tabular}{|l|r|}
\hline Qui-quadrado de Pearson* & 5,094 \\
\hline Graus de liberdade & 2 \\
\hline$p$-value & 0,078 \\
\hline Número de casos válidos & 78 \\
\hline $\begin{array}{l}\text { *1 célula (16,7\%) possui } \\
\text { esperado inferior a 5. } \\
\text { O valor mínimo esperado é 3,33. }\end{array}$
\end{tabular}

Tabela 22 - Teste qui-quadrado para Critério de seleção de projetos x Existência de processo sistemático de formulação da estratégia empresarial

Fonte: Autor / SPSS

Da Tabela 22, observa-se que os critérios de aplicação do teste qui-quadrado foram atendidos, já que menos de $20 \%$ das células apresentaram valor esperado inferior a 5 e o valor mínimo esperado é superior a 1 . Uma vez que o $p$-value obtido $(0,078$ ou $7,8 \%$ ) é superior ao valor de $\alpha$ adotado ( $5 \%$ ), é sustentada a hipótese nula, ou seja, as variáveis Critério de seleção de projetos e Formulação da estratégia organizacional são independentes. Portanto, a hipótese formulada para a pesquisa H2.a (o critério de seleção de projetos é influenciado pela existência de processo sistemático de formulação da estratégia empresarial) deve ser rejeitada. 
5.2.4 Relação entre a existência de processo de decomposição da estratégia nos níveis tático e operacional e a prática da seleção de projetos de acordo com a estratégia organizacional

Teste relacionado à Hipótese H2.b: O critério de seleção de projetos é influenciado pela decomposição da estratégia empresarial nos níveis tático e operacional.

Serão utilizadas as variáveis de pesquisa critério de seleção de projetos e decomposição da estratégia organizacional e suas respectivas questões do instrumento de pesquisa:

- Variável dependente: critério de seleção de projetos

Questão elaborada: Você considera que em sua empresa a seleção de projetos é feita de acordo com:

a) o desejo da Diretoria Executiva

b) o relacionamento com a estratégia organizacional

c) a vantagem comercial

d) critérios econômico-financeiros (ex: período de payback, taxa interna de retorno, valor atual líquido, etc.)

e) outro:

- Variável independente: decomposição da estratégia organizacional

Questão elaborada: Em sua empresa há uma decomposição da estratégia empresarial para os níveis tático e operacional?
a) $\operatorname{sim}$
b) não
c) não é de meu conhecimento

Para estas questões também foram obtidas 78 respostas, ou seja, $100 \%$ das respostas válidas recebidas. A Tabela 23 apresenta a distribuição das respostas. 


\begin{tabular}{|c|c|c|c|c|c|}
\hline & & \multicolumn{3}{|c|}{$\begin{array}{l}\text { Existência de decomposição da } \\
\text { estratégia empresarial para os níveis } \\
\text { tático e operacional }\end{array}$} & \multirow{2}{*}{ Total } \\
\hline & & a) $\operatorname{sim}$ & b) não & $\begin{array}{c}\text { c) não é de } \\
\text { meu } \\
\text { conhecimento }\end{array}$ & \\
\hline \multirow{4}{*}{$\begin{array}{l}\text { Critério de } \\
\text { seleção de } \\
\text { projetos }\end{array}$} & Relacionamento & 20 & 3 & 3 & 26 \\
\hline & organizacional & $26 \%$ & $4 \%$ & $4 \%$ & $33 \%$ \\
\hline & Outros gritórios & 30 & 13 & 9 & 52 \\
\hline & 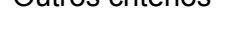 & $38 \%$ & $17 \%$ & $12 \%$ & $67 \%$ \\
\hline \multirow{2}{*}{ Total } & & 50 & 16 & 12 & 78 \\
\hline & & $64 \%$ & $21 \%$ & $15 \%$ & $100 \%$ \\
\hline
\end{tabular}

Tabela 23 - Tabela de contingência para Critério de seleção de projetos x Existência de decomposição da estratégia empresarial para os níveis tático e operacional Fonte: Autor / SPSS

A Tabela 24 apresenta o teste de hipótese das variáveis Critério de seleção de projetos e Existência de decomposição da estratégia empresarial para os níveis tático e operacional.

\begin{tabular}{l|r|}
\hline Qui-quadrado de Pearson* & 2,906 \\
\hline Graus de liberdade & 2 \\
\hline$p$-value & 0,234 \\
\hline Número de casos válidos & 78 \\
\hline *1 célula (16,7\%) possui valor \\
esperado inferior a 5. \\
O valor mínimo esperado é 4,00.
\end{tabular}

Tabela 24 - Teste qui-quadrado para Critério de seleção de projetos x Existência de decomposição da estratégia empresarial para os níveis tático e operacional Fonte: Autor / SPSS

Novamente, observa-se que os critérios de aplicação do teste qui-quadrado foram atendidos, já que menos de $20 \%$ das células apresentaram valor esperado inferior a 5 e o valor mínimo esperado é superior a 1 . O p-value obtido $(0,234$ ou 23,4\%) superou o valor de $\alpha$ adotado (5\%), sustentando-se a hipótese nula, ou seja, as variáveis Critério de seleção de projetos e Existência de decomposição da estratégia empresarial para os níveis tático e operacional são independentes. Assim, a hipótese formulada para a pesquisa H2.b (o critério de seleção de projetos é 
influenciado pela decomposição da estratégia empresarial nos níveis tático e operacional) deve ser rejeitada. 


\section{INTERPRETAÇÃO DOS RESULTADOS}

Este capítulo procura interpretar os resultados do trabalho à medida que confronta as análises apresentadas no capítulo 5 e a sua capacidade de responder às questões da pesquisa. O presente capítulo está dividido em dois itens, cada um relacionado a uma questão de pesquisa.

\subsection{O nível de maturidade e a prática da seleção de projetos de acordo com a estratégia organizacional}

Este item objetiva responder à Questão de Pesquisa abaixo:

QP1: O nível de maturidade da organização contribui para a prática da seleção de projetos relacionados à estratégia organizacional?

Para tanto, serão interpretados os resultados dos testes de independência relacionados às hipóteses H1.a e H1.b:

H1.a: O critério de seleção de projetos é influenciado pelo estágio de maturidade predominante na organização para cada domínio definido pelo OPM3® (projeto, programa e portfólio).

Variáveis: Critério de seleção de projetos e Estágio de maturidade para os domínios projeto, programa e portfólio.

H1.b: O critério de seleção de projetos é influenciado pela utilização do questionário de Auto-Avaliação proposto pelo $O P M 3 \AA$ para verificação do nível de maturidade.

Variáveis: Critério de seleção de projetos e Avaliação da maturidade pelo OPM3®.

Para verificação da hipótese H1.a, foram realizados três testes estatísticos apresentados no item 5.2.1 e relacionados a cada domínio (projeto, programa e portfólio). Cabe ressaltar que, para os três domínios, fez-se necessário o agrupamento dos dados, uma vez que não havia sido atendido o critério de menos de $20 \%$ das células com freqüência esperada inferior a 5 . 
Assim, comparando-se o nível de significância $\alpha$ (5\%) aos valores de $p$-value obtidos após o agrupamento de dados para os domínios projeto $(12,1 \%)$, programa $(1,7 \%)$ e portfólio $(95,9 \%)$, conclui-se pela rejeição da hipótese nula para os domínios projeto e portfólio e pela sustentação da hipótese nula para o domínio portfólio. Ou seja:

- as variáveis Critério de seleção de projetos e Estágio de maturidade para o domínio projeto são independentes;

- as variáveis Critério de seleção de projetos e Estágio de maturidade para o domínio programa são dependentes;

- as variáveis Critério de seleção de projetos e Estágio de maturidade para o domínio portfólio são independentes.

As grandes variações nos valores de p-value obtidos para cada domínio (de 1,7 a $95,9 \%)$ indicam que as diferenças de comportamento entre os domínios não ocorre de maneira ocasional. Ou seja, como não há consenso entre as análises estatísticas dos dados, não pode ser comprovada a influência do estágio de maturidade sobre o critério de seleção de projetos.

Visando ilustrar estas diferenças, foi feita a representação gráfica do relacionamento entre as variáveis Critério de seleção de projetos e Estágio de maturidade para cada domínio. Assim, as freqüências observadas na pesquisa e apresentadas anteriormente através das Tabelas 5, 9 e 13 estão representados nas Figuras 22, 23 e 24 , que se referem respectivamente aos domínios projeto, programa e portfólio.

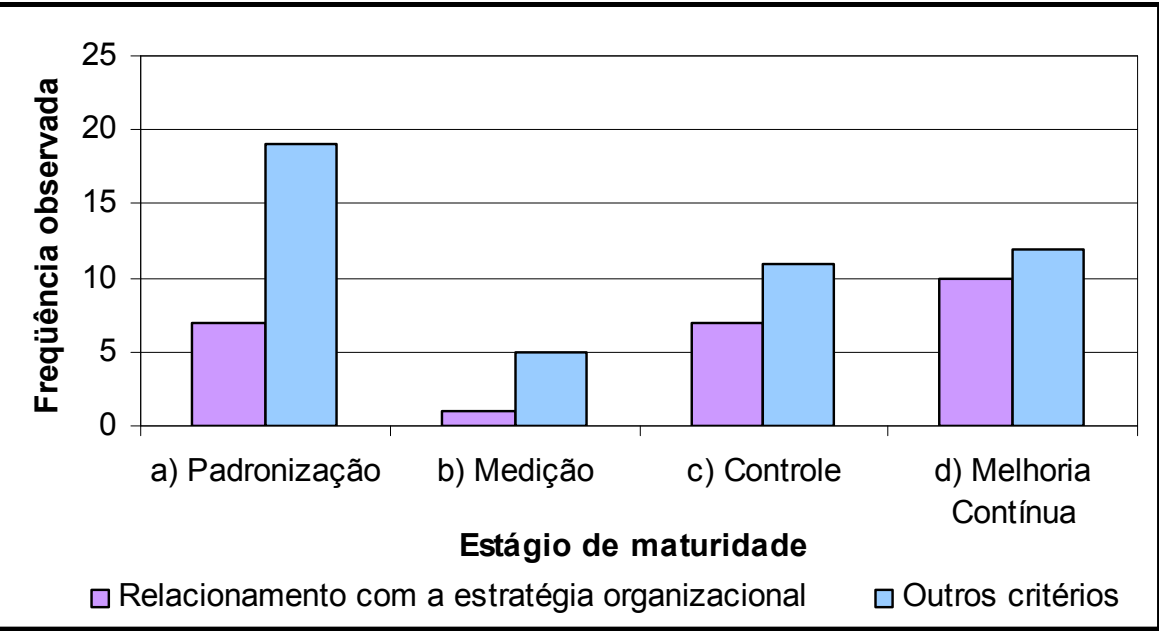

Figura 22 - Freqüência observada para Critério de seleção de projetos x Estágio de maturidade predominante na organização para o domínio projeto 


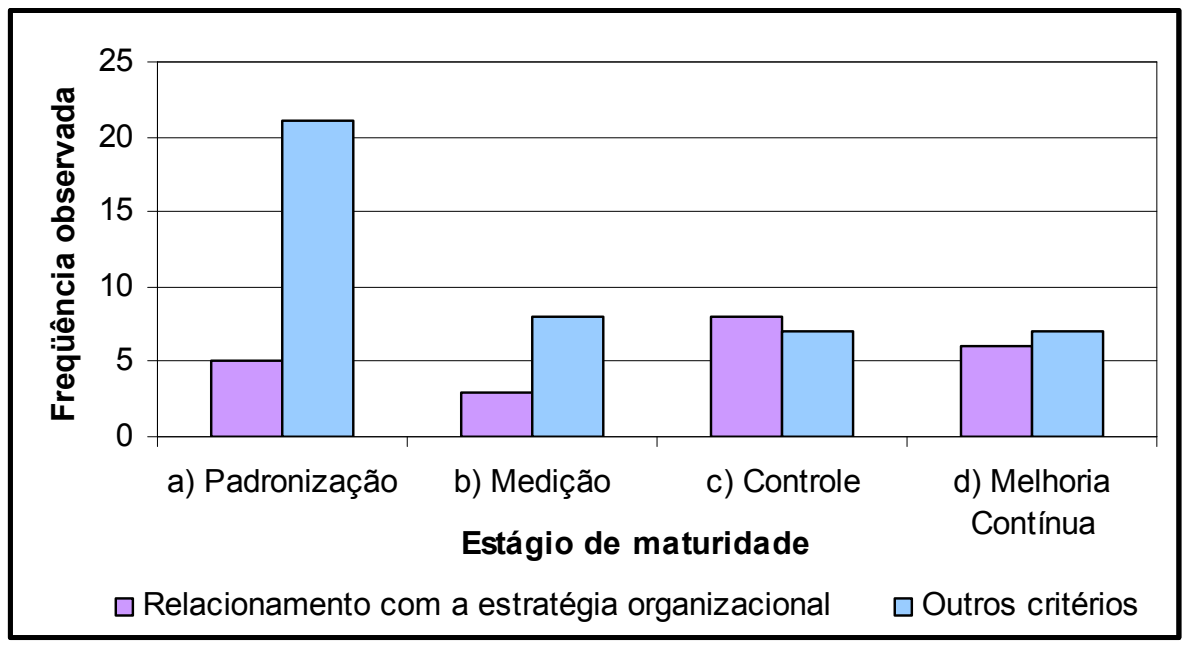

Figura 23 - Freqüência observada para Critério de seleção de projetos x Estágio de maturidade predominante na organização para o domínio programa

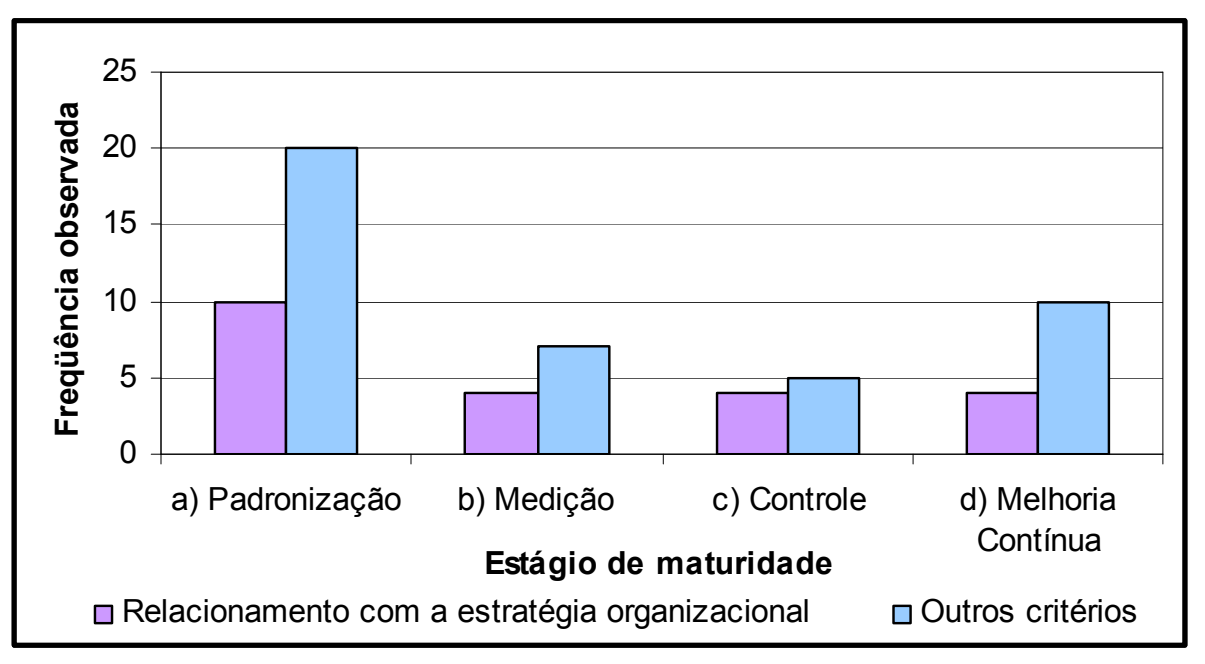

Figura 24 - Freqüência observada para Critério de seleção de projetos x Estágio de maturidade predominante na organização para o domínio portfólio

Analisando-se visualmente os três gráficos, observa-se que, conforme há a evolução do estágio de maturidade para a Melhoria Contínua, há uma tendência de diminuição da proporção entre o Critério de seleção de projetos de acordo com "Outros critérios" e de acordo com o "Relacionamento com a estratégia organizacional". Esta proporção será chamada "Coeficiente de critério de seleção" e está representada na Figura 25. 


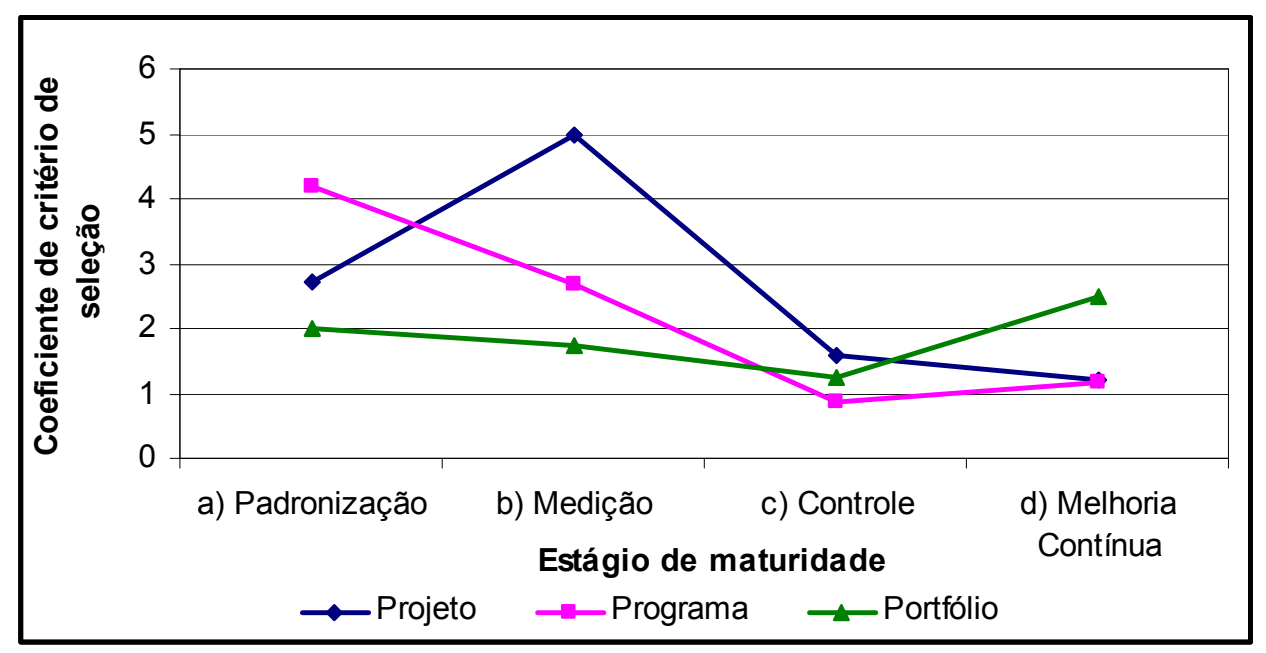

Figura 25 - Coeficiente de critério de seleção por estágio de maturidade e domínio.

A Figura 25 permite a comparação entre os três domínios. Cabe ressaltar que o domínio Programa é o que melhor representa a diminuição do Coeficiente de critério de seleção conforme há a evolução do estágio de maturidade até o Controle.

Voltando à tentativa de responder à QP1, no teste estatístico associado à hipótese H1.b, apresentado no item 5.2.2, o valor de $p$-value $(3,1 \%)$ inferior a $\alpha(5 \%)$ significa que a hipótese nula deve ser rejeitada. Assim, a independência entre as variáveis Avaliação da maturidade pelo OPM $3 \circledast$ e Critério de seleção de projetos não se sustenta, indicando que o critério de seleção de projetos é influenciado pela utilização do questionário de Auto-Avaliação proposto pelo OPM3® para verificação do nível de maturidade.

A partir da discussão apresentada neste item, a resposta à QP1 seria positiva, ou seja: a utilização do modelo OPM3® para avaliação do nível de maturidade da organização influencia a prática da seleção de projetos relacionados à estratégia organizacional. Cabe ressalvar que não foi possivel, com a presente pesquisa, afirmar que o estágio de maturidade predominante na organização para cada domínio também influencia a prática da seleção de projetos relacionados à estratégia organizacional. 


\section{2 $O$ processo de formulação da estratégia e a prática da seleção de projetos de acordo com a estratégia organizacional}

Este item procurará responder a Questão de Pesquisa 2, transcrita abaixo:

QP2: A existência, na organização, de processo de formulação da estratégia contribui para a prática da seleção de projetos relacionados à estratégia organizacional?

A esta questão estão associadas as hipóteses abaixo e as respectivas variáveis:

H2.a: O critério de seleção de projetos é influenciado pela existência de processo sistemático de formulação da estratégia empresarial.

Variáveis: Critério de seleção de projetos e Formulação da estratégia organizacional.

H2.b: O critério de seleção de projetos é influenciado pela decomposição da estratégia empresarial nos níveis tático e operacional.

Variáveis: Critério de seleção de projetos e Decomposição da estratégia organizacional.

Do teste estatístico relacionado à hipótese H2.a apresentado no item 5.2.3, foi obtido o $p$-value de 7,8\%. Como este valor é superior ao valor de $\alpha$ adotado para a pesquisa (5\%), é sustentada a hipótese nula, ou seja, as variáveis Critério de seleção de projetos e Formulação da estratégia organizacional são independentes. Ou seja, com os dados da pesquisa de campo, não pode ser comprovada a influência do processo sistemático de formulação da estratégia empresarial sobre o critério de seleção de projetos.

Por sua vez, o teste estatístico associado à hipótese H2.b, descrito no item 5.2.4, obteve $p$-value igual a $23,4 \%$, também superior ao nível de significância $\alpha$. Assim, as variáveis Critério de seleção de projetos e Existência de decomposição da estratégia empresarial para os níveis tático e operacional também são independentes, não podendo ser comprovada a influência da decomposição da estratégia empresarial nos níveis tático e operacional sobre o critério de seleção de projetos.

A partir dos dados obtidos com a pesquisa, a resposta à QP2 seria negativa, ou seja: a existência, na organização, de processo de formulação da estratégia não influencia a prática da seleção de projetos relacionados à estratégia organizacional. 


\section{CONCLUSÕES E RECOMENDAÇÕES}

A presente pesquisa surgiu do anseio do pesquisador em verificar, na prática, a relação entre a maturidade em gerenciamento de projetos e a capacidade de vinculação da estratégia organizacional aos projetos.

Resumidamente, o projeto de pesquisa foi conduzido em três grandes etapas: revisão bibliográfica, aplicação do survey e interpretação dos dados. A etapa de revisão bibliográfica permitiu ao pesquisador analisar, sob a óptica de referencial teórico, temas de seu convívio enquanto profissional da área de gerenciamento de projetos exercendo suas atividades em uma organização: modelo OPM ${ }^{\circledR}$ para avaliação da maturidade em gerenciamento de projetos e a estratégia organizacional. Também possibilitou ao pesquisador o embasamento teórico necessário para proceder à escolha do método de pesquisa, conduzir o projeto de pesquisa e proceder à análise dos dados. Já a aplicação do survey permitiu ao pesquisador coletar dados que, após receberem análises descritiva e inferencial, puderam ser interpretados.

Neste capítulo serão apresentadas as considerações finais a respeito deste estudo. Ressalta-se aqui que o encerramento deste projeto de pesquisa de modo algum representa o esgotamento do tema. Assim, o capítulo encontra-se dividido em dois itens: o primeiro resume as contribuições e limitações do estudo, e o segundo apresenta as recomendações do pesquisador para pesquisas futuras.

\subsection{Contribuições e limitações do estudo}

A principal contribuição obtida com a pesquisa refere-se à identificação de elementos facilitadores da seleção de projetos relacionados à estratégia organizacional. Também pode ser citada como contribuição secundária a ampliação da quantidade de pesquisas acadêmicas realizadas com apoio de tecnologia para o recebimento dos dados, neste caso, e-mail e hospedagem na Internet. Outras contribuições referem-se à proposição do modelo teórico para a pesquisa e à 
realização da pesquisa de campo em si, esta última permitindo a obtenção de dados sobre empresas nacionais no que tange ao gerenciamento de projetos e à utilização do modelo OPM3® para avaliação do nível de maturidade.

Em relação aos resultados obtidos, apenas foi possível comprovar que a utilização do modelo OPM $3 \circledR$ para avaliação do nível de maturidade da organização influencia a prática da seleção de projetos relacionados à estratégia organizacional. As demais expectativas do pesquisador foram negadas, ou seja, não foi possível provar que a prática da seleção de projetos relacionados à estratégia organizacional seja influenciada pela existência de processo de formulação da estratégia ou pelo estágio de maturidade predominante na organização para cada domínio.

Em se tratando das limitações do estudo, cita-se como principal a pequena quantidade de empresas brasileiras onde o questionário de Auto-Avaliação proposto pelo OPM3® foi utilizado. Não foi investigado neste trabalho se tal fato deve-se ao pouco tempo de existência do modelo OPM3® como é conhecido hoje ou se reflete, em última instância, a dificuldade de aplicação do modelo.

Também pode ser citada como limitação a obtenção da visão da organização através da percepção do respondente nos casos onde existia alguma subjetividade na questão proposta (por exemplo, grau de importância dado às técnicas de gerenciamento de projetos e o critério de seleção de projetos). Cabe ressalvar que, por se tratarem de variáveis que não são facilmente quantificáveis ou usualmente analisadas pela própria organização, a dificuldade em obtê-las por outro meios impossibilitaria a inclusão das mesmas no estudo, justificando a aceitação desta limitação.

Dentre os problemas que possam ter gerado falhas na pesquisa, destaca-se que diversos respondentes apresentaram os estágios de melhoria de processos predominantes na organização mesmo nos casos onde o questionário de AutoAvaliação proposto pelo OPM3 para verificação do nível de maturidade não foi utilizado. Este problema foi ocasionado por um equívoco na ordem de apresentação das questões no instrumento de pesquisa, tendo a questão "Para cada domínio definido pelo OPM3, qual é o estágio predominante na sua organização?" antecedido a questão "Sua empresa já utilizou o questionário de Auto-Avaliação proposto pelo OPM3 para verificação do nível de maturidade?".

Outro problema observado na pesquisa pode ter ocorrido em decorrência da pequena utilização do $O P M 3 \AA$ associada a um problema conceitual: os termos 
programa e portfólio são utilizados habitualmente pelos profissionais das organizações com significado diferente do conceito de domínio proposto pelo OPM3®. Embora a terminologia utilizada nesta pesquisa acadêmica tenha sido apresentada no texto do questionário auto-administrado, supõe-se que este problema conceitual possa ter ocasionado as diferenças de comportamento apontadas na análise estatística entre as variáveis Critério de seleção de projetos e Estágio de maturidade em cada domínio.

\subsection{Recomendações para pesquisas futuras}

Embora tenha sua contribuição acadêmica, o projeto de pesquisa não esgota o tema da pesquisa; tampouco as recomendações a seguir pretendem fazê-lo. Apenas estão relacionados alguns itens vislumbrados pelo pesquisador durante a condução de sua pesquisa como possíveis objetos de pesquisas futuras relacionadas ao tema:

- Aumento da amostra e conseqüente aumento na quantidade de empresas que se utilizaram do OPM3®;

- Inclusão de elemento temporal à pesquisa (longitudinal) através de reavaliação após período de tempo considerado suficiente para a propagação do OPM3®;

- Complementação desta pesquisa através da abordagem qualitativa em organizações que já tenham aplicado o OPM3® mais de uma vez;

- Identificação de outros fatores influenciadores da seleção de projetos relacionados à estratégia organizacional. Nesta pesquisa, não foi possível comprovar a influência da existência de processo de formulação da estratégia e do estágio de maturidade predominante na organização para cada domínio;

- Investigação sobre a causa da pequena quantidade de empresas brasileiras onde o questionário de Auto-Avaliação proposto pelo OPM3® foi utilizado;

- Verificação de alteração nos resultados para populações estratificadas, por setor de atuação (por exemplo, empresas de $\mathrm{TI}$ ) ou outra característica comum (por exemplo, empresas que tenham utilizado o $\mathrm{CMMI}$ ). 


\section{REFERÊNCIAS}

BOTTER, D. A. et al. Noções de Estatística - com apoio computacional. São Paulo: Instituto de Matemática e Estatística - USP, 1996. 231p. Versão preliminar do texto de apoio à disciplina de graduação do Departamento de Estatística, MAE-116 Noções de Estatística.

CHIAVENATO, I. Comportamento Organizacional: a dinâmica do sucesso das organizações. São Paulo: Pioneira Thomson Learning, 2004.

CRAWFORD, J. K. The Strategic Project Office: A Guide to Improving Organizational Performance. New York: Marcel Dekker Inc., 2002

CRESWELL, J.W. Research Design: qualitative \& quantitative approaches. London: Sage, 1994.

DINSMORE, P. C. Transformando estratégias empresariais através da gerência por projetos. Trad. de Bazán Tecnologia e Lingüística. Rio de Janeiro: Qualitymark Ed., 1999.

ECO, U. Como se faz uma tese. Trad. de Gilson Cesar Cardoso de Souza. São Paulo: Editora Perspectiva S.A., 1977.

ENGLUND, R. L.; GRAHAM, R. J.; DINSMORE, P. C. Creating the Project Office: A Manager's Guide to Leading Organizational Change. San Francisco: John Wiley \& Sons, Inc., 2003.

FILIPPINI, R. Operations management research: some reflections on evolution, models and empirical studies in OM. International Journal of Operations \& Product Management. v.17, n.7, p.655-670, 1997.

FINK, A. The survey handbook. Thousand Oaks: Sage Publications, Inc., 1995a. The survey kit, v.1.

FINK, A. How to ask survey questions. Thousand Oaks: Sage Publications, Inc., 1995b. The survey kit, v.2. 
FINK, A. How to sample in surveys. Thousand Oaks: Sage Publications, Inc., 1995c. The survey kit, v.6.

FINK, A. How to analyse survey data. Thousand Oaks: Sage Publications, Inc., 1995d. The survey kit, v.8.

FORZA, C. Survey research in operations management: a process-based perspective. International Journal of Operations \& Product Management. v.22, n.2, p.152-194, 2002.

FREITAS, $H$. et al. O método de pesquisa survey. Revista de Administração da USP. v.35, n.3, p.105-112, 2000.

HILLSON, D. Assessing organisational project management capability. Journal of Facilities Management. v.2, n.3, p.298-311, 2003.

ILIEVA, J.; BARON, S.; HEALEY, N. M. Online surveys in marketing research: Pros and cons. International Journal of Market Research. v.44, n.3, p.361-376, 2002.

JUDGEV, K.; THOMAS, J. Project management maturity models: The silver bullets of competitive advantage? Project Management Journal. v.33, n.4, p.4-14, 2002.

KERZNER, H. Strategic Planning for a Project Office. Project Management Journal. v.34, n. 2, p.13-25,2003.

KERZNER, H. Gestão de Projetos: as melhores práticas. Trad. Marco Antonio Viana Borges, Marcelo Klippel e Gustavo Severo de Borba. Porto Alegre: Bookman, 2002.

KERZNER, H. Strategic planning for project management using a project management maturity model. New York: John Wiley \& Sons, Inc., 2001.

MINTZBERG, H. Cinco Ps para estratégia. In: MINTZBERG, H. et al. O processo da estratégia: conceitos, contextos e casos selecionados. Trad. de Luciana de Oliveira da Rocha. 4.ed. Porto Alegre: Bookman, 2006. p. 24-29.

OLIVEIRA, D. P. R. Estratégia empresarial e vantagem competitiva: como estabelecer, implementar e avaliar. 4.ed. revisada e atualizada. São Paulo: Atlas, 2005. 
PARRA FILHO, D.; SANTOS, J.A. Metodologia Científica. São Paulo: Futura, 1998.

PITAGORSKY, G. A scientific approach to project management. Machine Design. v. 73, n. 14, p.78-82, 2001.

PROJECT MANAGEMENT INSTITUTE. Organizational Project Management Maturity Model (OPM3): Knowledge Foundation. Newtown Square, Pennsylvania: Project Management Institute Inc., 2003.

PROJECT MANAGEMENT INSTITUTE. A Guide to the Project Management Body of Knowledge (PMBOK Guide) - 3rd edition. Newtown Square, Pennsylvania: Project Management Institute Inc., 2004.

PROJECT MANAGEMENT INSTITUTE. Newtown Square, PA. Apresenta informações sobre os profissionais associados e certificados. Disponível em: <http://www.pmi.org/prod/groups/public/documents/info/gmc memberfactsheet.asp>. Acesso em: 27 de maio 2007.

RABECHINI JR, R. Competências e Maturidade em Gestão de Projetos: Uma Perspectiva Estruturada. 2003. 286p. Tese - Escola Politécnica, Universidade de São Paulo. São Paulo, 2003.

ROSE, K. Organizational Project Management Maturity Model by Project Management Institute. Project Management Journal. v. 35, n. 1, p.59, 2004.

SCHLICHTER, J.; FRIEDRICH, R.; HAECK, B. The Development of OPM3 ${ }^{\mathrm{TM}}$. In: PMI ${ }^{\circ}$ Global Congress Europe, The Hague, The Netherlands, 2003. Anais. 1 CDROM.

SIEGEL, S.; CASTELLAN JR., N.J. Estatística não-paramétrica para ciências do comportamento. Porto Alegre: Artmed, 2006.

SPSS 14.0 for Windows, release 14.0.0. SPSS Inc., 2005.

YIN, R. K. Case study research: design and methods. 2. ed. Thousands: Sage Publications, 1994. 


\section{GLOSSÁRIO}

Browser - software utilizado para acesso ao conteúdo disponível em páginas ou sites na Internet; navegador.

E-mail - correspondência eletrônica

Endereço IP - código numérico que identifica de forma única um dispositivo conectado a rede. Cada ponto de acesso à Internet possui um endereço IP que o identifica de forma única na rede, de forma que os demais dispositivos desta rede possam saber quem enviou ou solicitou determinado conteúdo e possam saber a quem enviar a resposta correspondente a esta solicitação.

HTML (Hyper Text Markup Language ou Linguagem de formatação de hipertexto) Trata-se de uma linguagem utilizada para produzir páginas na Internet. De modo geral, são documentos de texto escritos em códigos que podem ser interpretados pelos browsers para exibir as páginas da internet.

IP (Internet Protocol ou Protocolo de Internet) - É um protocolo de rede, ou seja, a forma padronizada como a informação trafega em uma rede de dados, como, por exemplo, a Internet.

Software - uma seqüência de instruções a serem seguidas por qualquer dispositivo capaz de interpretá-las, como o computador, por exemplo; programa de computador.

URL (Uniform Resourse Locator ou Localizador Uniforme de Recursos) - É o endereço de um recurso (um arquivo, uma impressora, etc.) disponível em uma rede; no caso da Internet, normalmente indica o endereço eletrônico de um conteúdo, como uma página ou site.

Web-based - expressão que se refere a um novo conceito de serviços ou sofwares construídos exclusivamente para utilização ou acesso pela Internet; hospedadas na Internet. 


\section{APÊNDICE A - TESTE DE INDEPENDÊNCIA QUI-QUADRADO}

O presente apêndice visa detalhar a aplicação do teste qui-quadrado através da aplicação do exemplo abaixo, adaptado de Fink (1995d).

\section{Exemplo:}

Suponha a realização de uma pesquisa com 208 estudantes do ensino médio para identificar suas preferências no que tange à carreira. Neste grupo, 103 estudantes passaram 1 ano em um programa especial de treinamento (trainne); os outros, não. A divisão entre os estudantes que preferem ir para a faculdade antes de procurar emprego e os que preferem entrar na força de trabalho imediatamente pode encontra-se na Tabela A:

\begin{tabular}{lccc}
\hline & $\begin{array}{c}\text { Participaram do } \\
\text { Programa }\end{array}$ & $\begin{array}{c}\text { Não participaram } \\
\text { do programa }\end{array}$ & Total \\
\hline $\begin{array}{l}\text { Preferem ir para } \\
\text { a faculdade }\end{array}$ & 80 & 30 & 110 \\
\hline $\begin{array}{l}\text { Não preferem ir } \\
\text { para a faculdade }\end{array}$ & 23 & 75 & 98 \\
\hline \multicolumn{1}{c}{ Total } & 103 & 105 & 208 \\
\hline & $\begin{array}{l}\text { Tabela A - Tabela de contingência } \\
\text { Fonte: traduzido de Fink (1995d) }\end{array}$
\end{tabular}

A questão de pesquisa é: existe diferença entre os participantes do programa e os outros estudantes na quantidade ou proporção de estudantes que prefere continuar seus estudos?

Inicialmente observa-se que a pesquisa apresenta duas variáveis que serão chamadas de "participação no programa" e "preferência pela faculdade". A Tabela B apresenta a porcentagem de cada célula em relação ao total da linha: 


\begin{tabular}{lrrr}
\hline & $\begin{array}{c}\text { Participaram do } \\
\text { Programa }\end{array}$ & $\begin{array}{c}\text { Não participaram } \\
\text { do programa }\end{array}$ & Total \\
\hline $\begin{array}{l}\text { Preferem ir para } \\
\text { a faculdade }\end{array}$ & 80 & 30 & 110 \\
\cline { 2 - 4 } $\begin{array}{l}\text { Não preferem ir } \\
\text { para a faculdade }\end{array}$ & $72,7 \%$ & $27,3 \%$ & $100,0 \%$ \\
\hline & 23 & 75 & 98 \\
\hline Total & 103 & $76,5 \%$ & $100,0 \%$ \\
\hline
\end{tabular}

Tabela B - Percentual de distribuição para as variáveis da pesquisa

Da tabela pode-se observar que, embora o percentual dos estudantes que participaram e não participaram do programa envolvidos na pesquisa seja praticamente o mesmo (50\% do total), a distribuição percentual analisando-se a variável "preferência pela faculdade" é bastante diferente, sugerindo a dependência entre as variáveis.

Para a situação de independência total entre as variáveis, os valores esperados para a combinação das variáveis, bem como o cálculo que originou cada valor, encontrase na Tabela $\mathrm{C}$.

\begin{tabular}{lrrr}
\hline & $\begin{array}{c}\text { Participaram do } \\
\text { Programa }\end{array}$ & $\begin{array}{c}\text { Não participaram do } \\
\text { programa }\end{array}$ & Total \\
\hline $\begin{array}{l}\text { Preferem ir para } \\
\text { a faculdade }\end{array}$ & $\begin{array}{rrrr}410 \times 4 \%= \\
54,47\end{array}$ & $\begin{array}{r}110 \times 50,5 \%= \\
55,53\end{array}$ & 110 \\
\hline $\begin{array}{l}\text { Não preferem ir } \\
\text { para a faculdade }\end{array}$ & $98 \times \begin{array}{r}49,5 \%= \\
48,53\end{array}$ & $98 \times 50,5 \%=$ & 98 \\
\hline \multicolumn{1}{c}{ Total } & 103 & 105 & 208 \\
\hline
\end{tabular}

$\overline{\text { Tabela } \mathrm{C} \text { - Valores esperados para a situação de independência entre as variáveis }}$

A fórmula apresentada no capítulo 3 para o teste $\mathrm{H}$ é:

$$
\chi^{2}=\sum_{i=1}^{l} \sum_{j=1}^{c} \frac{\left(O_{i j}-E_{i j}\right)^{2}}{E_{i j}},
$$

Aplicando-se a fórmula para os dados de freqüência observada e esperada apresentados nas Tabelas B e C, obtém-se o valor de $\chi^{2}$ (qui-quadrado) $=50,30$. 
O teste em si consiste na comparação entre o valor de $\chi^{2}$ obtido e o valor crítico obtido na tabela de Distribuição qui-quadrado. Assim, a hipótese nula é rejeitada, ou seja, não se sustenta a independência, se $\chi^{2}$ for maior que o valor crítico, para um dado valor de $\alpha$ e o grau de liberdade calculado da tabela de contingência.

No exemplo apresentado, para $\alpha=1 \%$ e 1 grau de liberdade, o valor crítico obtido na tabela de Distribuição qui-quadrado é 6,635, ou seja, 99\% da distribuição está abaixo de 6,635. Como o valor obtido pelo teste está acima do valor crítico, a hipótese nula é rejeitada e conclui-se que a e "preferência pela faculdade" está relacionada à "participação no programa" (BOTTER et al., 1996). 


\title{
APÊNDICE B - INSTRUMENTO DE PESQUISA PARA O TESTE PILOTO
}

\author{
ESCOLA POLITÉCNICA DA USP \\ ISP $\frac{\text { Departamento äelengelharia }}{\text { Naral e Oceântoa }}$
}

\author{
Programa de Pós-Graduação em Gestão de Projetos \\ Nível: Mestrado \\ Orientador: Prof. Dr. Marcelo Ramos Martins \\ Pesquisador: Marcia M. Martins Pereira \\ Questionário de Pesquisa
}

\section{Apresentação}

O presente questionário faz parte das atividades de pesquisa desenvolvidas em dissertação de mestrado do programa de Pós-graduação em Gestão de Projetos da Escola Politécnica - Departamento de Engenharia Naval e Oceânica. Apresenta como objetivos principais: avaliar a aplicação do modelo de maturidade OPM3 e a sua contribuição para a garantia do alinhamento à estratégia organizacional.

Os resultados desta pesquisa, além de contribuírem para o delineamento do tema pesquisado, serão, depois de consolidados, encaminhados aos respondentes. As informações levantadas pela pesquisa são de caráter estritamente confidencial, estando vedada a divulgação ou acesso aos dados individuais da fonte informante para qualquer empresa, órgão público ou pessoa física.

O questionário completo é constituído por 18 questões, em sua maioria de múltiplaescolha. As perguntas estão divididas em 2 (dois) blocos, conforme descrição a seguir:

BLOCO I - Características da Empresa e do Respondente:

Caracterização do entrevistado e da empresa.

BLOCO II - O Gerenciamento de Projetos na Empresa: 
Caracterização do ambiente de gerência de projetos da empresa, incluindo conceitos como a avaliação da maturidade em gerenciamento de projetos.

A unidade de investigação da pesquisa é a empresa, analisada sobre a ótica das informações fornecidas pelos respondentes. Portanto, solicitamos que nos informe 0 nome de sua empresa e seu email visando:

1. identificar o universo de empresas envolvidas na pesquisa;

2. possibilitar o envio dos resultados consolidados para os respondentes;

3. sanar eventuais dúvidas no entendimento das respostas fornecidas;

4. possibilitar futuros contatos para entrevistas qualitativas.

Importante: estes dados não serão mencionados nos relatórios consolidados, nem na dissertação, servindo apenas para orientar os pesquisadores, razão pela qual está fora dos blocos de questões.

Nome ou Identificação da Empresa:

Seu email:

DESDE JÁ AGRADECEMOS A SUA COLABORAÇÃO.

\section{BLOCO I - Características da Empresa e do Respondente}

Considere as seguintes definições para responder a este bloco de perguntas:

- A empresa industrial ou de serviços é a unidade jurídica caracterizada por uma firma ou razão social, que responde pelo capital investido e cuja principal atividade é industrial ou de serviços.

- A estrutura organizacional funcional apresenta uma hierarquia em que cada funcionário possui um superior bem definido. Os funcionários são agrupados por especialidade, como por exemplo produção, marketing, engenharia, etc.

- $\quad$ Na estrutura organizacional projetizada, as pessoas são agrupadas tendo como critério o projeto no qual estão envolvidos em determinado instante. Cada projeto é como um "departamento temporário" cujo chefe é o gerente de projeto, cuja equipe é a equipe do projet oe que existe enquanto o projeto não termina. Este tipo de estrutura apresenta muita flexibilidade e alta eficácia quanto a respostas a mudanças ambientais. 
- A estrutura organizacional matricial é caracterizada por uma combinação de características das organizações funcional e por projeto. As matrizes fracas mantêm muitas das características de uma organização funcional, enquanto as matrizes fortes possuem muitas das características da organização por projeto. Embora a organização matricial balanceada reconheça a necessidade de um gerente de projetos, ela não fornece ao gerente de projetos autoridade total sobre o projeto e os recursos financeiros do projeto

Esta primeira parte do questionário visa identificar algumas informações a seu respeito e a respeito de sua empresa.

1. A empresa é:

a) Independente

b) Parte de um grupo de empresas

Caso sua resposta anterior tenha sido "Parte de um grupo de empresas", qual é a relação com o grupo?
a) Matriz
b) Filial
c) Associada

2. Quanto à origem do capital, a empresa onde você trabalha é:
a) Privada e Estrangeira
b) Privada e Nacional
c) Estatal e Nacional
d) Outra:

3. Assinale o setor de atuação da empresa, conforme a Classificação de Atividade Econômica (CAE) do IBGE:

a) Agricultura, pecuária, silvicultura e exploração florestal

b) Pesca

c) Indústrias extrativas

d) Indústrias de transformação

e) Produção e distribuição de eletricidade, gás e água

f) Construção

g) Comércio; reparação de veículos automotores, objetos pessoais e domésticos 
h) Alojamento e alimentação

i) Transporte, armazenagem e comunicações

j) Intermediação financeira, seguros, previdência complementar e serviços relacionados

k) Atividades imobiliárias, aluguéis e serviços prestados às empresas

l) Administração pública, defesa e seguridade social

m) Educação

n) Saúde e serviços sociais

o) Outros serviços coletivos, sociais e pessoais

p) Serviços domésticos

q) Organismos internacionais e outras instituições extraterritoriais

r) Outro:

4. Qual é o número de funcionários da empresa?

a) até 50

b) entre $50-100$

c) entre $100-200$

d) entre $200-500$

e) acima de 500

5. A estrutura organizacional predominante em sua empresa é:
a) Funcional (hierárquica)
b) Matricial
c) Projetizada (orientada a projetos)
d) Outra:

6. Em sua empresa existe um processo sistemático de formulação da estratégia empresarial?
a) $\operatorname{sim}$
b) não
c) não é de meu conhecimento

7. Em sua empresa há uma decomposição da estratégia empresarial para os níveis tático e operacional?
a) $\operatorname{sim}$
b) não 
c) não é de meu conhecimento

8. Qual o cargo que você ocupa na empresa?
a) Diretor
b) Gerente
c) Supervisor ou Coordenador
d) Técnico ou Analista
e) Outro:

9. Qual é o grau de relação de suas atividades profissionais com a área de gerenciamento (planejamento e controle) de projetos?
a) muito baixo
b) baixo-
c) médio-
d) alto -
e) muito alto

\section{BLOCO II - O Gerenciamento de Projetos na Empresa}

Este bloco de perguntas objetiva colher informações a respeito das competências de sua empresa no que concerne à utilização de técnicas de gerenciamento de projetos. Considere as seguintes definições para responder a este bloco de perguntas:

- $\quad$ Projeto (project) - Um empreendimento temporário feito para criar um produto, serviço ou resultado único.

- Gerenciamento de Projetos (project management) - é o planejamento, organização, direção e controle de recursos da empresa por um relativo período de tempo, que tenha sido estabelecido para completar um conjunto específico de objetivos e metas.

- Referências de Conhecimentos de Gerenciamento de Projetos as práticas modernas de gerenciamento de projetos são influenciadas por diversas fontes de conhecimentos. Atualmente, a mais difundida no Brasil é o PMBoK (Project Management Body of Knowledge), publicado pelo PMI (Project Management Institute). 
- Maturidade Organizacional em Gerenciamento de Projetos Kerzner define a maturidade em gerenciamento de projetos como o desenvolvimento de sistemas e processos que são por natureza repetitivos e garantem uma alta probabilidade de que cada um deles seja um sucesso.

- Modelo de Maturidade Organizacional em Gerenciamento de Projetos: visando prover uma base para que as organizações possam incrementar a maturidade em gerenciamento de projetos, 0 PMI propôs um padrão para avaliação denominado OPM3 (Organizational Project Management Maturity Model). Este modelo de maturidade analisa a progressão das Melhores Práticas em gerenciamento de projetos associada aos progressivos estágios de melhorias de processos (padronização, medição, controle e melhoria contínua) e aos domínios (Gerenciamento de Projetos, Gerenciamento de Programas e Gerenciamento de Portfólio), conforme figura abaixo.

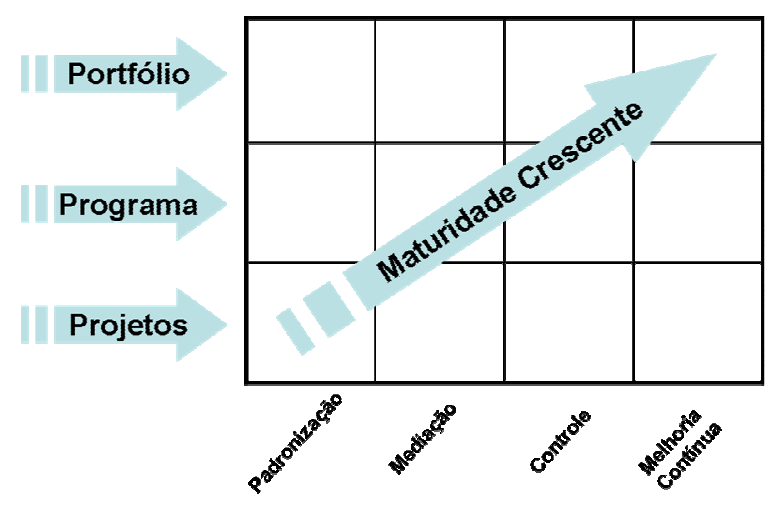

Fonte: adaptado de PROJECT MANAGEMENT INSTITUTE.

Organizational Project Management Maturity Model (OPM3)

Knowledge Foundation. Newtown Square, PA, 2003.

- As próximas questões estão numa ordem de lógica, que aumenta o detalhe das práticas de gerenciamento de projetos por sua empresa. Avalie cada questão, e se for o caso, favor pular para o final do questionário -

1. Qual é o grau de importância que sua empresa dá às técnicas modernas de gerenciamento de projetos?

a) muito baixo 

b) baixo
c) médio
d) alto
e) muito alto

2. Sua empresa desenvolveu e utiliza alguma metodologia de gerenciamento de projetos?
a) $\operatorname{sim}$
b) não
c) não é de meu conhecimento

Caso afirmativo, qual é o grau de aderência dessa metodologia ao PMBoK ?
a) muito baixo
b) baixo
c) médio
d) alto
e) muito alto

3. Você considera que em sua empresa a seleção de projetos é feita de acordo com:

a) o desejo da Diretoria Executiva

b) o relacionamento com a estratégia organizacional

c) a vantagem comercial

d) critérios econômico-financeiros (ex: período de payback, taxa interna de retorno, valor atual líquido, etc.)

e) outro:

4. Sua empresa já utilizou o questionário de Auto-Avaliação proposto pelo OPM3 para verificação do nível de maturidade?
a) sim, uma vez
b) sim, duas vezes
c) sim, mais de duas vezes
d) não, nunca foi aplicado
e) não é de meu conhecimento

Caso sua resposta tenha sido negativa, por favor dirija-se à questão 9.

5. Há quanto tempo ocorreu a última avaliação do nível de maturidade de sua empresa pelo OPM3? 

a) há menos de 1 ano
b) entre 1 e 2 anos
C) há mais de 2 anos

6. Para cada domínio definido pelo OPM3, qual é o estágio predominante na sua organização? Assinale um estágio para cada domínio:

PROJETO

a) Padronização

b) Medição

c) Controle

d) Melhoria Contínua
PROGRAMA

a) Padronização

b) Medição

c) Controle

d) Melhoria Contínua

\section{PORTFÓLIO}

a) Padronização

b) Medição

c) Controle

d) Melhoria Contínua

7. A avaliação da empresa pelo modelo de maturidade OPM3 incluiu a elaboração do Plano de Melhorias?
a) $\operatorname{sim}$
b) não
c) não é de meu conhecimento.

8. Após a Auto-Avaliação pelo modelo OPM3, constou do Plano de Melhorias alguma ação relacionada à identificação e seleção de projetos através do seu relacionamento com a estratégia empresarial (Melhor Prática 6180 - Seleção de Projetos de acordo com a Estratégia)?
a) $\operatorname{sim}$
b) não
c) não é de meu conhecimento.

Caso sua resposta tenha sido afirmativa, quais as principais dificuldades encontradas pela empresa na implementação das melhorias? (Se necessário, selecione mais de uma alternativa)

a) falta de apoio da direção executiva

b) mudanças organizacionais necessárias

c) resistência das pessoas

d) alocação dos profissionais designados para as atividades do plano de melhorias em projetos, gerando sobrealocação

e) outras: 
9. Após a aplicação do OPM3, houve aumento na quantidade de projetos selecionados de acordo com a estratégia?
a) $\operatorname{sim}$
b) não
c) não é de meu conhecimento.

- Final do Questionário -

Mesmo que não tenha respondido todas as questões, favor enviar as respostas. 


\section{APÊNDICE C - E-MAIL PARA AVALIADORES DO TESTE PILOTO}

uss Deparamento acengenharia

Escola Politécnica da USP

Departamento de Engenharia Naval e Oceânica

Programa de Pós-Graduação em Gestão de Projetos

Nível: Mestrado

Prezado Sr(a). <avaliador>

-----Teste Piloto do Questionário de Pesquisa -------

Você foi selecionado para avaliar o nosso instrumento de pesquisa antes da apresentação para uma população maior. Pedimos a gentileza que nos retornasse seus comentários e críticas, respondendo a este e-mail. Ficaríamos agradecidos se nos respondesse até o dia 25/05/06.

-------E-mail a ser enviado para a População

O presente questionário faz parte das atividades de pesquisa desenvolvidas em dissertação de mestrado do programa de Pós-Graduação em Gestão de Projetos da Faculdade de Engenharia Naval e Oceânica. O trabalho tem como objetivos: avaliar a aplicação do modelo de maturidade OPM3 e a sua contribuição para a garantia do alinhamento à estratégia organizacional.

Uma parte imprescindível desse trabalho é o questionário on-line que disponibilizamos num website.

Solicitamos a gentileza de respondê-lo até o dia xx/xx/2006. Temos ciência de que seu tempo é escasso, porém o questionário irá lhe tomar pouco tempo para responder.

Assumimos o compromisso de lhe enviar cópia do resultado final do nosso trabalho.

Para acessar e responder a pesquisa, o endereço eletrônico é:

http://www.kuaitema.com.br/pesquisa/pesq.htm

Caso necessitem, favor entrar em contato.

Agradecemos muito pela colaboração e pelo tempo dispensado.

Marcia M. Martins Pereira (marcia.martins@poli.usp.br) 


\title{
APÊNDICE D - INSTRUMENTO DE PESQUISA
}

\author{
ESCOLA POLITÉCNICA DA USP \\ ISP \\ Deparamento ackingenliaria \\ 2 Nayal coceânica \\ Programa de Pós-Graduação em Gestão de Projetos \\ Nível: Mestrado \\ Orientador: Prof. Dr. Marcelo Ramos Martins \\ Pesquisador: Marcia M. Martins Pereira
}

\section{Questionário de Pesquisa}

\section{Apresentação}

O presente questionário faz parte das atividades de pesquisa desenvolvidas em dissertação de mestrado do programa de Pós-graduação em Gestão de Projetos da Escola Politécnica - Departamento de Engenharia Naval e Oceânica. Apresenta como objetivos principais avaliar: a aplicação do modelo de maturidade OPM3 e a sua contribuição para a garantia do alinhamento à estratégia organizacional.

Os resultados desta pesquisa, além de contribuírem para o delineamento do tema pesquisado, serão, depois de consolidados, encaminhados aos respondentes. As informações levantadas pela pesquisa são de caráter estritamente confidencial, estando vedada a divulgação ou acesso aos dados individuais da fonte informante para qualquer empresa, órgão público ou pessoa física.

O questionário completo é constituído por 18 questões, em sua maioria de múltiplaescolha. As perguntas estão divididas em 3 (três) blocos, conforme descrição a seguir:

BLOCO I - Características da Empresa e do Respondente: Caracterização do entrevistado e da empresa.

BLOCO II - O Gerenciamento de Projetos na Empresa: Caracterização do ambiente de gerência de projetos da empresa.

BLOCO III - Maturidade em Gerenciamento de Projetos na Empresa: Avaliação da maturidade em gerenciamento de projetos da empresa. 
A unidade de investigação da pesquisa é a empresa, analisada sobre a ótica das informações fornecidas pelos respondentes. Portanto, solicitamos que nos informe o nome de sua empresa e seu e-mail visando:

1. identificar o universo de organizações envolvidas na pesquisa;

2. possibilitar o envio dos resultados consolidados para os respondentes;

3. sanar eventuais dúvidas no entendimento das respostas fornecidas;

4. possibilitar futuros contatos para entrevistas qualitativas.

Importante: estes dados não serão mencionados nos relatórios consolidados, nem na dissertação, servindo apenas para orientar os pesquisadores, razão pela qual está fora dos blocos de questões.

Nome ou Identificação da Empresa:

Seu e-mail:

DESDE JÁ AGRADECEMOS A SUA COLABORAÇÃO!

\section{BLOCO I - Características da Empresa e do Respondente}

Considere as seguintes definições para responder a este bloco de perguntas:

- A empresa industrial ou de serviços é a unidade jurídica caracterizada por uma firma ou razão social, que responde pelo capital investido e cuja principal atividade é industrial ou de serviços.

- A estrutura organizacional funcional apresenta uma hierarquia em que cada funcionário possui um superior bem definido. Os funcionários são agrupados por especialidade, como por exemplo produção, marketing, engenharia, etc.

- Na estrutura organizacional projetizada, as pessoas são agrupadas tendo como critério o projeto no qual estão envolvidos em determinado instante. Cada projeto é como um "departamento temporário" cujo chefe é o gerente de projeto, cuja equipe é a equipe do projet oe que existe enquanto o projeto não termina. Este tipo de estrutura apresenta muita flexibilidade e alta eficácia quanto a respostas a mudanças ambientais.

- A estrutura organizacional matricial é caracterizada por uma combinação de características das organizações funcional e por projeto. As matrizes fracas mantêm muitas das características de uma organização funcional, enquanto as matrizes fortes possuem muitas das características da organização por projeto. Embora a organização matricial balanceada reconheça a necessidade 
de um gerente de projetos, ela não fornece ao gerente de projetos autoridade total sobre o projeto e os recursos financeiros do projeto.

Esta primeira parte do questionário visa identificar algumas informações a seu respeito e a respeito de sua empresa.

1. A empresa é:

a) Independente

b) Parte de um grupo de empresas

Caso sua resposta anterior tenha sido "Parte de um grupo de empresas", qual é a relação com o grupo?
a) Matriz
b) Filial
c) Associada

2. Quanto à origem do capital, a empresa onde você trabalha é:
a) Privada e Estrangeira
b) Privada e Nacional
c) Estatal e Nacional
d) Outra:

3. Assinale o setor de atuação da empresa, conforme:
a) Indústria
b) Comércio
c) Serviços

Caso seja possível, favor identificar a setor conforme a Classificação Nacional de Atividade Econômica (CNAE) do IBGE:

a) Agricultura, pecuária, silvicultura e exploração florestal

b) Pesca

c) Indústrias extrativas

d) Indústrias de transformação

e) Produção e distribuição de eletricidade, gás e água

f) Construção

g) Comércio; reparação de veículos automotores, objetos pessoais e domésticos

h) Alojamento e alimentação

i) Transporte, armazenagem e comunicações

j) Intermediação financeira, seguros, previdência complementar e serviços relacionados 
k) Atividades imobiliárias, aluguéis e serviços prestados às empresas

I) Administração pública, defesa e seguridade social

m) Educação

n) Saúde e serviços sociais

o) Outros serviços coletivos, sociais e pessoais

p) Serviços domésticos

q) Organismos internacionais e outras instituições extraterritoriais

4. Qual é o número de funcionários da empresa?
a) até 50
b) entre $50-100$
C) entre $100-200$
d) entre 200-500
e) acima de 500

5. A estrutura organizacional predominante em sua empresa é:
a) Funcional (hierárquica)
b) Matricial
c) Projetizada (orientada a projetos)
d) Outra:

6. Qual o cargo que você ocupa na empresa?
a) Diretor
b) Gerente
C) Supervisor ou Coordenador
d) Técnico ou Analista
e) Outro:

7. Qual é o grau de relação de suas atividades profissionais com a área de gerenciamento (planejamento e controle) de projetos?
a) muito baixo
b) baixo
c) médio
d) alto
e) muito alto 


\section{BLOCO II - O Gerenciamento de Projetos na Empresa}

Este bloco de perguntas objetiva colher informações a respeito das competências de sua empresa no que concerne à utilização de técnicas de gerenciamento de projetos. Considere as seguintes definições para responder a este bloco de perguntas:

- Projeto (project) - Um empreendimento temporário feito para criar um produto, serviço ou resultado único.

- Gerenciamento de Projetos (project management) - é o planejamento, organização, direção e controle de recursos da empresa por um relativo período de tempo, que tenha sido estabelecido para completar um conjunto específico de objetivos e metas.

- Referências de Conhecimentos de Gerenciamento de Projetos - as práticas modernas de gerenciamento de projetos são influenciadas por diversas fontes de conhecimentos. Atualmente, a mais difundida no Brasil é o PMBoK (Project Management Body of Knowledge), publicado pelo PMI (Project Management Institute).

1. Qual é o grau de importância que sua empresa dá às técnicas modernas de gerenciamento de projetos?
a) muito baixo
b) baixo
c) médio
d) alto
e) muito alto

2. Sua empresa desenvolveu e utiliza alguma metodologia de gerenciamento de projetos?
a) $\operatorname{sim}$
b) não
c) não é de meu conhecimento

Caso afirmativo, qual é o grau de aderência dessa metodologia ao PMBoK ?
a) muito baixo
b) baixo
c) médio
d) alto
e) muito alto 
3. Você considera que em sua empresa a seleção de projetos é feita de acordo com:

a) o desejo da Diretoria Executiva

b) o relacionamento com a estratégia organizacional

c) a vantagem comercial

d) critérios econômico-financeiros (ex: período de payback, taxa interna de retorno, valor atual líquido, etc.)

e) outro:

\section{BLOCO III - Maturidade em Gerenciamento de Projetos na Empresa}

Este bloco de perguntas objetiva colher informações a respeito de sua empresa no que concerne à análise e o grau de maturidade em gerenciamento de projetos. Considere as seguintes definições para responder a este bloco de perguntas:

- Maturidade Organizacional em Gerenciamento de Projetos - Kerzner define a maturidade em gerenciamento de projetos como o desenvolvimento de sistemas e processos que são por natureza repetitivos e garantem uma alta probabilidade de que cada um deles seja um sucesso.

- Modelo de Maturidade Organizacional em Gerenciamento de Projetos visando prover uma base para que as organizações possam incrementar a maturidade em gerenciamento de projetos, o PMI propôs um padrão para avaliação denominado OPM3 (Organizational Project Management Maturity Model). Este modelo de maturidade analisa a progressão das Melhores Práticas em gerenciamento de projetos associada aos progressivos estágios de melhorias de processos (padronização, medição, controle e melhoria contínua) e aos domínios (Gerenciamento de Projetos, Gerenciamento de Programas e Gerenciamento de Portfólio), conforme figura abaixo. 


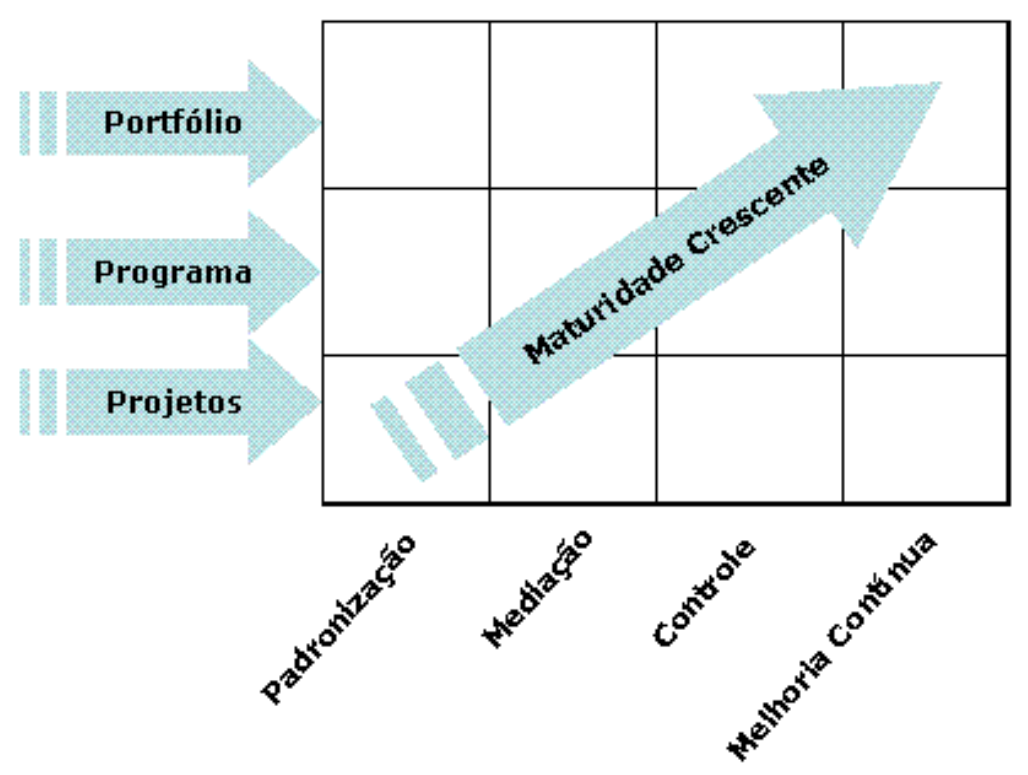

Fonte: adaptado de PROJECT MANAGEMENT INSTITUTE. Organizational Project Management Maturity Model (OPM3) Knowledge Foundation. Newtown Square, PA, 2003.

1. Em sua empresa existe um processo sistemático de formulação da estratégia empresarial?
a) $\operatorname{sim}$
b) não
c) não é de meu conhecimento

2. Em sua empresa há uma decomposição da estratégia empresarial para os níveis tático e operacional?
a) $\operatorname{sim}$
b) não
c) não é de meu conhecimento

3. Para cada domínio definido pelo OPM3, qual é o estágio predominante na sua organização? Assinale um estágio para cada domínio:

\section{PROJETO}
a) Padronização
a) Padronização
b) Medição
b) Medição
c) Controle
c) Controle
d) Melhoria Contínua
d) Melhoria Contínua
a) Padronização
b) Medição
c) Controle
d) Melhoria Contínua

\section{PORTFÓLIO}

4. Sua empresa já utilizou o questionário de Auto-Avaliação proposto pelo OPM3 para verificação do nível de maturidade? 

a) sim, uma vez
b) sim, duas vezes
c) sim, mais de duas vezes
d) não, nunca foi aplicado
e) não é de meu conhecimento

Caso sua resposta tenha sido negativa, por favor dirija-se ao final do questionário.

5. Há quanto tempo ocorreu a última avaliação do nível de maturidade de sua empresa pelo OPM3?
a) há menos de 1 ano
b) entre 1 e 2 anos
c) há mais de 2 anos

6. A avaliação da empresa pelo modelo de maturidade OPM3 incluiu a elaboração do Plano de Melhorias?
a) $\operatorname{sim}$
b) não
c) não é de meu conhecimento.

7. Após a Auto-Avaliação pelo modelo OPM3, constou do Plano de Melhorias alguma ação relacionada à identificação e seleção de projetos através do seu relacionamento com a estratégia empresarial (Melhor Prática 6180 - Seleção de Projetos de acordo com a Estratégia)?
a) $\operatorname{sim}$
b) não
c) não é de meu conhecimento.

Caso sua resposta tenha sido afirmativa, quais as principais dificuldades encontradas pela empresa na implementação das melhorias? (Se necessário, selecione mais de uma alternativa)

a) falta de apoio da direção executiva

b) mudanças organizacionais necessárias

c) resistência das pessoas

d) alocação dos profissionais designados para as atividades do plano de melhorias em projetos, gerando sobrealocação

e) outras:

8. Após a aplicação do OPM3, houve aumento na quantidade de projetos selecionados de acordo com a estratégia? 

a) $\operatorname{sim}$
b) não
c) não é de meu conhecimento.

- Final do Questionário -

Mesmo que não tenha respondido todas as questões, favor enviar as respostas. 


\section{APÊNDICE E - E-MAIL PARA RESPONDENTES}

\section{usp Deparamentóactengenharia \\ 2. Nayte Oceánica sa}

Escola Politécnica da USP

Departamento de Engenharia Naval e Oceânica

Programa de Pós-Graduação em Gestão de Projetos

Nível: Mestrado

Prezado Sr(a).,

O presente questionário faz parte das atividades de pesquisa desenvolvidas em dissertação de mestrado do programa de Pós-Graduação em Gestão de Projetos da Faculdade de Engenharia Naval e Oceânica. O trabalho tem como objetivos: avaliar a aplicação do modelo de maturidade OPM3 e a sua contribuição para a garantia do alinhamento à estratégia organizacional.

Uma parte imprescindível desse trabalho é o questionário on-line que disponibilizamos num website.

Temos ciência de que seu tempo é escasso, porém o questionário irá lhe tomar pouco tempo para responder.

Assumimos o compromisso de lhe enviar cópia do resultado final do nosso trabalho.

Para acessar e responder a pesquisa, o endereço eletrônico é:

http://www.kuaitema.com.br/pesquisa/pesq.htm

PEDIMOS A GENTILEZA DE ENCAMINHAR PARA OUTRAS PESSOAS QUE POSSAM COLABORAR.

Caso necessitem, favor entrar em contato.

Agradecemos muito pela colaboração e pelo tempo dispensado.

\section{Marcia M. Martins Pereira}

marcia.martins@poli.usp.br 